NBER WORKING PAPER SERIES

\title{
LABOR MARKET RETURNS AND THE EVOLUTION OF COGNITIVE SKILLS: THEORY AND EVIDENCE
}

\author{
Santiago Hermo \\ Miika M. Päällysaho \\ David G. Seim \\ Jesse M. Shapiro \\ Working Paper 29135 \\ http://www.nber.org/papers/w29135 \\ NATIONAL BUREAU OF ECONOMIC RESEARCH \\ 1050 Massachusetts Avenue \\ Cambridge, MA 02138 \\ August 2021, Revised January 2022
}

We thank Dan Benjamin, Ernesto Dal Bó, Peter Fredriksson, Larry Katz, Pete Klenow, Erik Lindqvist, Neil Mehrotra, Kevin M. Murphy, Björn Öckert, Jakob Pietschnig, Eka Roivainen, Andrei Shleifer, David Strömberg, Jonas Vlachos, and seminar participants at UC Berkeley Haas School of Business, BI Norwegian Business School, CIDE, Stockholm University, University of Mannheim, Vanderbilt University, VATT Institute for Economic Research, Bocconi University, Collegio Carlo Alberto, ESE Rotterdam, and Tel Aviv University for helpful comments and exchanges. We thank our dedicated research assistants for their contributions to this project. We acknowledge support from the Jan Wallander and Tom Hedelius Foundation (Grant P2015-0095:1), and from the James M. and Cathleen D. Stone Wealth and Income Inequality Project, the Eastman Professorship, and the Population Studies and Training Center at Brown University. The study is in part based on data from the research infrastructure UGU at the University of Gothenburg. UGU is funded by Swedish Research Council (dnr. 2017-00628) and University of Gothenburg. Any opinions, findings, and conclusions or recommendations expressed in this material are those of the authors and do not necessarily reflect the views of the funding or data sources. Translations from Swedish to English are our own, with assistance from Google Translate. The views expressed herein are those of the authors and do not necessarily reflect the views of the National Bureau of Economic Research.

At least one co-author has disclosed additional relationships of potential relevance for this research. Further information is available online at http://www.nber.org/papers/w29135.ack

NBER working papers are circulated for discussion and comment purposes. They have not been peer-reviewed or been subject to the review by the NBER Board of Directors that accompanies official NBER publications.

(C) 2021 by Santiago Hermo, Miika M. Päällysaho, David G. Seim, and Jesse M. Shapiro. All rights reserved. Short sections of text, not to exceed two paragraphs, may be quoted without explicit permission provided that full credit, including () notice, is given to the source. 
Labor Market Returns and the Evolution of Cognitive Skills: Theory and Evidence Santiago Hermo, Miika M. Päällysaho, David G. Seim, and Jesse M. Shapiro

NBER Working Paper No. 29135

August 2021, Revised January 2022

JEL No. J24,J31,O52

\begin{abstract}
$\underline{\text { ABSTRACT }}$
A large literature in cognitive science studies the puzzling "Flynn effect" of rising fluid intelligence (reasoning skill) in rich countries. We develop an economic model in which a cohort's mix of skills is determined by different skills' relative returns in the labor market and by the technology for producing skills. We estimate the model using administrative data from Sweden. Combining data from exams taken at military enlistment with earnings records from the tax register, we document an increase in the relative labor market return to logical reasoning skill as compared to vocabulary knowledge. The estimated model implies that changes in labor market returns explain 37 percent of the measured increase in reasoning skill, and can also explain the decline in knowledge. An original survey of parents, an analysis of trends in school curricula, and an analysis of occupational characteristics show evidence of increasing emphasis on reasoning as compared to knowledge.

Santiago Hermo

Brown University

Providence, RI 02912

United States

santiago_hermo@brown.edu

Miika M. Päällysaho

Universitetsvägen $10 \mathrm{~A}$,

10691 Stockholm

Stockholm University

miika.paallysaho@ne.su.se

David G. Seim

Universitetsvägen 10 A, 10691 Stockholm

Stockholm University

david.g.seim@gmail.com

Jesse M. Shapiro

Department of Economics

Harvard University

Littauer Center

Cambridge, MA 02138

and NBER

jesse.m.shapiro@gmail.com
\end{abstract}




\section{Introduction}

A large and important literature in cognitive science documents substantial gains in intelligence (IQ) scores across successive cohorts in developed countries, sometimes called the "Flynn effect" (see, for example, Schaie et al. 2005; Flynn 2007, 2012; Trahan et al. 2014; Pietschnig and Voracek 2015; Flynn and Shayer 2018). ${ }^{1}$ These gains are especially pronounced for fluid intelligence, a notion of general reasoning ability often measured with abstract reasoning tasks (Pietschnig and Voracek 2015). There are less pronounced gains, or even declines, in crystallized intelligence, a notion of domain knowledge often measured with knowledge assessments such as vocabulary tests (Schaie et al. 2005; Pietschnig and Voracek 2015). ${ }^{2}$ Understanding the causes of these trends is important in part because of evidence that a population's level of cognitive skills influences its economic productivity, economic growth, and distribution of income (e.g., Bishop 1989; Hanushek and Woessmann 2008, Section 5). ${ }^{3}$

There is no consensus on the precise causes of cohort trends in cognitive performance, which some consider to be an important puzzle. ${ }^{4}$ Research in cognitive science emphasizes factors, such as improvements in health and nutrition, that expand the supply of skill (e.g., Pietschnig and Voracek 2015; Rindermann et al. 2017). But the incentive to invest in particular dimensions of skill may also evolve over time in response to the demands of the economy.

In this paper, we study the role of labor market returns in determining cohort trends in skill levels and skill composition. We focus on Sweden, where an administrative data join between standardized test scores (collected for military conscription typically at age 18 or 19) and earnings (collected by the tax agency over the lifecycle) allows us to measure the level of and return to skill in a consistent way across cohorts for the near-population of men.

We develop a model of an economy whose aggregate output is determined by the aggregate skills of workers. Skills, which can be multidimensional, are determined both by an exogenous endowment (e.g., health) and an investment decision made early in life (by parents, children, and schools). The investment decision is in turn influenced by the lifetime labor market returns to

\footnotetext{
${ }^{1}$ Rindermann et al. (2017) write, "Among the most discussed topics in intelligence research is the rise of average IQ test results across generations in the 20th century" (p. 242).

${ }^{2}$ Cattell (1943) writes, "Fluid ability has the character of a purely general ability to discriminate and perceive relations between any fundaments, new or old... Crystallized ability consists of discriminatory habits long established in a particular field." (p. 178).

${ }^{3}$ There is also evidence that a population's level of cognitive skills is related to its levels of patience and risk aversion (Falk et al. 2018; Potrafke 2019).

${ }^{4}$ Deary (2020) writes, "If there were a prize in the field of human intelligence research, it might be for the person who can explain the 'Flynn effect'..." (also quoted in Wai and Putallaz 2011).
} 
different skills. We identify the relative returns to different skills by assuming that unobserved determinants of an individual's earnings are correlated with the individual's skill endowment only through its market value. Under this assumption, the relative returns to different skills can be recovered from a Mincerian regression of the log of earnings on skills in a cross-section of individuals.

We parameterize the model so that a single unknown parameter governs the degree to which individuals can substitute investment across skill dimensions. We identify this parameter by assuming that long-run average shocks to the technology for producing skills are proportional across fluid and crystallized intelligence.

We take the model to the data. Across the birth cohorts 1962-1975, we find that performance on a logical reasoning task_our proxy for fluid intelligence-improved by 4.4 percentile points, measured in terms of the distribution in the 1967 cohort. The estimated lifetime earnings premium to an additional percentile point of logical reasoning performance fell by 0.08 log points, from a base of $0.48 \log$ points. Turning to performance on a vocabulary knowledge test—our proxy for crystallized intelligence-we find that performance declined by 2.9 percentile points. The estimated lifetime premium to an additional percentile point of vocabulary knowledge fell by 0.07 $\log$ points, but from a much lower base of $0.16 \log$ points.

Because logical reasoning performance rose while its market return fell, a model in which logical reasoning is the only skill dimension would imply that there must have been an increase in the supply of skill, consistent with the hypothesis of a growth in the endowment of fluid intelligence of the sort emphasized in the cognitive science literature. A richer picture emerges when incorporating the second skill dimension. Vocabulary knowledge performance fell along with its market return, suggesting a decline in the demand for this skill dimension. Moreover, the premium to vocabulary knowledge relative to logical reasoning fell by $38 \log$ points. Seen through the lens of our model, the declining relative premium to crystallized intelligence drove a reallocation of effort towards developing abstract reasoning and away from acquiring knowledge.

We use the model to decompose the observed trends in skills into a portion driven by changing labor market returns and a portion driven by other factors. According to the estimated model, if the market returns to different skills had remained constant at their 1962 level, logical reasoning and vocabulary knowledge performance would have increased by 2.8 and 3.0 percentile points, respectively. The estimated model thus implies that trends in labor market returns explain 37 percent of the growth in logical reasoning performance (roughly, $100 \times \frac{4.4-2.8}{4.4}$ ) and more than 
fully explain the decline in vocabulary knowledge.

We extend our baseline analysis in a few directions. First, we use a nationally representative survey linked to earnings records to expand our analysis to a broader set of birth cohorts, from 1948 to 1977 , and to skills measured at a younger age, around age 13. We find that the relative level of and return to logical reasoning performance rose across these cohorts, though our estimates are less precise than those from the (much larger) enlistment sample. Second, we adjust the estimated trends in skill levels and skill returns to account for the role of covariates such as height and secondary school completion. Although adjusting for covariates is conceptually delicate, as some covariates may themselves respond to labor market returns, we find broadly similar conclusions across a variety of sensitivity analyses. Third, we extend our model to incorporate non-cognitive skills. We continue to estimate an important role for changes in labor market returns in explaining the evolution of cognitive skills, but we also highlight limitations of this analysis that arise because the measure of non-cognitive skills in our data is not directly comparable across cohorts.

We also explore whether the main actors in skill investment-parents and schools-place increasing emphasis on reasoning relative to knowledge. In an original survey, we find that parents of more recent cohorts tend to regard reasoning ability as more important for their children than knowledge of facts. In a review of pedagogical scholarship, and an original quantitative text analysis, we find evidence of a trend towards increasing emphasis on reasoning relative to knowledge in primary school curricula in Sweden. Turning to the demand for skills, we show evidence of relative growth in occupations that place more emphasis on reasoning as opposed to knowledge. We view this evidence as consistent with the mechanism underlying our estimated model.

Our analysis has some important limitations. A first limitation is that we treat the skill demand portion of the model fairly abstractly and do not offer a precise account of why some skills have become relatively more valuable in the labor market over time, though we show some suggestive evidence based on occupational characteristics. A second limitation is that our conclusions require assumptions on unmeasured determinants of earnings and skills. We specify and discuss these assumptions, their plausibility, and their importance in more detail in the body of the paper, where we also discuss evidence on sensitivity to departures from key assumptions. A third limitation is that we focus on the labor market returns to skills and do not measure their nonmarket returns, though we show that our conclusions are preserved if market and non-market returns to skill move in proportion across cohorts. A final limitation is that, due to the nature of the military enlistment data that we use, our main analyses are limited to men only, though in an appendix we show results 
for women in the survey sample.

The main contribution of this paper is to develop and apply an economic model to quantify the role of labor market returns in determining cohort trends in multidimensional cognitive skills. We are not aware of prior work that does this. A large literature in economics studies the determinants and market value of (possibly multidimensional) cognitive and non-cognitive skills (see, for example, the review by Sanders and Taber 2012 and recent papers by Roys and Taber 2020 and Agostinelli and Wiswall 2020). Our analysis of the market for skills is closely related to the work of Katz and Murphy (1992) and the large literature that follows (see, e.g., Deming 2017 and the review by Acemoglu and Autor 2011), but differs in focusing on explaining trends across cohorts (rather than time periods) and in offering an explicit quantitative model of the supply of (rather than demand for) skills. As we do, Heckman et al. (1998) develop a general-equilibrium model of the supply and demand for skill. Their model is richer than ours in its treatment of labor demand but does not incorporate multiple dimensions of skill. ${ }^{5}$

A large literature in cognitive science (reviewed, for example, in Pietschnig and Voracek 2015) studies causes of trends in various measures of ability or intelligence. Although some work in this literature considers the possibility that social demands affect the development of skills, we are not aware of work in this literature that quantifies trends in the economic returns to different types of skills, or that uses an estimated model to link trends in skills to trends in their returns. ${ }^{6}$ We are also not aware of prior work that quantifies long-term trends in parents' and schools' emphasis on reasoning vs. knowledge. ${ }^{7}$

An additional contribution of this paper is to document trends in the relative labor market returns to different dimensions of cognitive skill. Much prior work in economics and other fields studies trends in the level of and returns to skills, ${ }^{8}$ including some work using linked administrative

\footnotetext{
${ }^{5}$ Our model of the supply of skill, which focuses on cohort-level trends, is more stylized than in work that focuses on the skill formation process itself (see, e.g., Cunha et al. 2006, 2010; Doepke et al. 2019). In particular, unlike much of the work reviewed in, e.g., Heckman and Mosso (2014), we treat the skill investment decision as static and do not model the dynamics of skill formation during childhood.

${ }^{6}$ Dickens and Flynn (2001) specify and simulate a quantitative model in which genetic endowments and environmental factors interact to produce measured intelligence. They discuss the role of occupational demands in driving cohort differences in skills, but do not incorporate labor market returns into their quantitative model, and do not estimate the model's parameters. Flynn (2018, p. 79) notes that "When society asks us to increase our use of any skill over time, the brain responds," and cites research by Maguire et al. (2006) on the effect of occupational demands on brain structure in the context of London taxi and bus drivers.

${ }^{7}$ Okagaki and Sternberg (1993) study group differences in parents' conceptions of intelligence. Bietenbeck (2014) studies the effects on reasoning and knowledge skills of traditional and modern teaching practices. Cunha et al. (forthcoming), among others, study the relationship between parents' beliefs about the technology of skill formation and parents' investments in children's skills.

${ }^{8}$ For example, Castex and Dechter (2014) use survey data to document falling returns to cognitive skills as measured
} 
data from elsewhere in Europe, ${ }^{9}$ as well as some work using the same data from Sweden that we use. $^{10}$ Rönnlund et al. (2013) report trends in test scores in Sweden from 1970-1993. Lindqvist and Vestman (2011) study the labor market return to cognitive and non-cognitive skills in Sweden. Especially related, Edin et al. (forthcoming) estimate trends in the returns to cognitive and noncognitive skills in Sweden. None of these papers documents trends in the relative lifetime labor market returns to different dimensions of cognitive skill, or quantifies the role of labor market returns in driving cohort trends in skill levels in a model with multidimensional skills. ${ }^{11}$

The remainder of the paper is organized as follows. Section 2 presents our model and approach to identification. Section 3 describes the data we use. Section 4 presents our main findings. Section 5 discusses additional evidence related to the mechanisms in the model. Section 6 extends our analysis to incorporate non-cognitive skills. Section 7 concludes.

\section{Model}

\subsection{Production and Earnings}

There is a finite population of workers $i \in \mathscr{N}$, each of which is associated with a cohort $c(i) \in$ $\{\underline{c}, \ldots, \bar{c}\}$. Each worker is characterized by a skill level $\mathbf{x}_{i} \in \mathbb{R}_{\geq 0}^{J}$ for $J \geq 2$.

In each time period $t$, each worker $i$ has an experience level $a(i, t)=t-c(i)$ and supplies efficiency units $z_{i t} \in \mathbb{R}_{\geq 0}$, where $z_{i t}>0$ if $a(i, t) \in\{1, \ldots, A\}$ and $z_{i t}=0$ otherwise. Thus, members of cohort $c$ enter the labor force in period $c+1$ and exit the labor force after period $c+A$, and we identify the cohort $c$ with the period immediately before workers in the cohort enter the labor force.

Let $\mathbf{X}_{t}$ be the $J \times A$ matrix whose $a^{\text {th }}$ column is given by the sum of $z_{i t} \mathbf{x}_{i}$ over all workers $i$ with experience level $a(i, t)=a$. This matrix collects the total supply of skill in period $t$ for each

\footnotetext{
by Armed Forces Qualification Test scores in the US between the 1980s and 2000s.

${ }^{9}$ For example, Jokela et al. (2017) document cohort trends in personality traits using scores from military conscripts in Finland, and argue based on estimated labor market returns that the economic significance of cohort trends in personality traits is similar to that of cohort trends in cognitive abilities. Markussen and Røed (2020, Section 4.2) document declining labor market returns to men's cognitive skills using test scores from enrollment in military service in Norway.

${ }^{10}$ These data have also been used to study, among other topics, the effect of schooling on measured skills (Carlsson et al. 2015) and the effect of officer training on occupational outcomes later in life (Grönqvist and Lindqvist 2016).

${ }^{11}$ Jokela et al. (2017) document trends in the within-cohort rank correlation between three different dimensions of cognitive skill and earnings at age 30 (Figure 2, panel B) or ages 30-34 (Figure S1, panel B), but do not report trends in lifetime labor market returns from a model of earnings that accounts for multiple skill dimensions simultaneously. Lindquist (2005) models trends in the demand for skill in Sweden arising from capital-skill complementarity.
} 
dimension $j$ and experience level $a$. Let $\mathbf{X}_{t}^{-i}$ be the analogue of $\mathbf{X}_{t}$ excluding worker $i .^{12}$

Total output $Y_{t}$ at time $t$ is given by

$$
Y_{t}=F_{t}\left(\mathbf{X}_{t}\right)
$$

where $F_{t}(\cdot)$ is a scalar-valued differentiable function that may vary over time, for example due to changes in production technology.

In each period $t$, a worker $i$ earns his marginal product $w_{i t}$, which is given by

$$
\begin{aligned}
w_{i t} & =F_{t}\left(\mathbf{X}_{t}\right)-F_{t}\left(\mathbf{X}_{t}^{-i}\right) \\
& \approx z_{i t} \nabla F_{t, a(i, t)}^{\prime} \mathbf{x}_{i}
\end{aligned}
$$

where $\nabla F_{t, a}$ is the gradient of $F_{t}\left(\mathbf{X}_{t}\right)$ at $\mathbf{X}_{t}$ with respect to the $a^{t h}$ column of $\mathbf{X}_{t}$. We will assume that $\nabla F_{t, a(i, t)}^{\prime} \mathbf{x}_{i}>0$ for all workers $i$ in all periods $t$ of working life. Motivated by a large-population setting, we will treat $\mathbf{X}_{t}$ as fixed from the perspective of any individual worker $i$.

Pick a period $t$ of worker $i$ 's working life, so that $z_{i t}>0$, and rewrite the earnings equation as

$$
\ln \left(w_{i t}\right) \approx \ln \left(z_{i t}\right)+\ln \left(\nabla F_{t, a(i, t)}^{\prime} \mathbf{x}_{i}\right)
$$

Now take a first-order approximation around the mean skill level $\mathbf{x}_{t, a(i, t)}$ of individuals who share worker $i$ 's experience level at time $t$ to get

$$
\ln \left(w_{i t}\right) \approx \ln \left(z_{i t}\right)+\ln \left(\nabla F_{t, a(i, t)}^{\prime} \mathbf{x}_{t, a(i, t)}\right)+\frac{\nabla F_{t, a(i, t)}^{\prime}}{\nabla F_{t, a(i, t)}^{\prime} \mathbf{x}_{t, a(i, t)}}\left(\mathbf{x}_{i}-\mathbf{x}_{t, a(i, t)}\right)
$$

where we will again treat $\mathbf{x}_{t, a(i, t)}$ as fixed from the perspective of any individual worker $i$. We can write the preceding as

$$
\ln \left(w_{i t}\right) \approx B_{t, a(i, t)}+\mathbf{p}_{t, a(i, t)}^{\prime} \mathbf{x}_{i}+\ln \left(z_{i t}\right)
$$

${ }^{12}$ That is, the $a^{t h}$ column of $\mathbf{X}_{t}$ is

$$
\sum_{\{l \in \mathscr{N}: a(l, t)=a\}} z_{l t} \mathbf{x}_{l}
$$

and that of $\mathbf{X}_{t}^{-i}$ is

$$
\sum_{\{l \in \mathscr{N} \backslash\{i\}: a(l, t)=a\}} z_{l t} \mathbf{x}_{l} .
$$


where $B_{t, a}$ is a scalar, $\mathbf{p}_{t, a}$ is a vector of skill premia, and both of these are specific to a time period and experience level. ${ }^{13}$

We will proceed taking equation (1) to be exact. Although we have derived (1) from a particular model of the labor market, any model in which earnings take the form in (1) will be equivalent for the purposes of our subsequent analysis. Moreover, although for concreteness we refer to $z_{i t}$ as efficiency units, (1) makes clear that $z_{i t}$ captures any individual-and-period-specific determinants of earnings that are not included in $\mathbf{x}_{i}$.

\subsection{Skill Investment}

At the beginning of life, each worker $i$ chooses his skills $\mathbf{x}_{i}$ subject to the constraints

$$
\begin{aligned}
\mathbf{x}_{i} & \geq \mu_{i} \\
S_{c(i)}\left(\mathbf{x}_{i}-\mu_{i}\right) & \leq \bar{S}_{c(i)}
\end{aligned}
$$

where $\mu_{i} \in \mathbb{R}^{J}$ is an individual skill endowment, $\bar{S}_{c} \in \mathbb{R}_{>0}$ is a cohort-specific skill budget, and $S_{c}(\cdot)$ is a cohort-specific transformation function.

We can think of $\mathbf{x}_{i}-\mu_{i} \in \mathbb{R}_{\geq 0}^{J}$ as the skill investment of individual $i$, i.e., the increment in skills over and above the individual's endowment $\mu_{i}$. The endowment $\mu_{i}$ represents cross-sectional differences within a cohort, say in ability or access to schooling. The budget $\bar{S}_{c}$ can be seen as representing the total time and effort available for skill investment. The transformation function $S_{c}(\cdot)$ may be thought of as governing the ease of skill investment and of substituting investment across skill dimensions. The budget $\bar{S}_{c}$ and the function $S_{c}(\cdot)$ may differ across cohorts because of trends in the technology of skill formation, say because of improvements in health or nutrition. Although for simplicity we refer to the decision-maker as the worker, we may alternatively think of the skill investment decision as being made by the worker's parents, or by a collective decisionmaking process involving the worker, his parents, and the schooling system. ${ }^{14}$ Because we take the timing of entry into the labor market as given, we do not account for any foregone earnings due to time spent acquiring skills.

\footnotetext{
${ }^{13}$ Specifically,
}

$$
B_{t, a}=\ln \left(\nabla F_{t, a}^{\prime} \mathbf{x}_{t, a}\right)-1, \quad \mathbf{p}_{t, a}=\frac{\nabla F_{t, a}}{\nabla F_{t, a}^{\prime} \mathbf{x}_{t, a}} .
$$

${ }^{14}$ For example, we may think of the skill budget $\bar{S}_{c}$ as reflecting the sum of the effective time and effort available from the worker, his parents, and his teachers. 
Each worker consumes his earnings in each period and has time-separable preferences with a felicity function given by the log of consumption. Each worker discounts future felicity by a discount factor $\delta \in(0,1]$. At the time of choosing the skill investment, worker $i$ has full knowledge of the path of skill premia over his lifecycle, $\left\{\mathbf{p}_{c(i)+a, a}\right\}_{a=1}^{A}$. We further assume that worker $i$ 's skill investment does not influence the path of $z_{i t}$.

It follows that the worker's problem is equivalent to maximizing $\mathbf{P}_{c(i)}^{\prime} \mathbf{x}_{i}$ subject to (2), where

$$
\mathbf{P}_{c(i)}=\frac{\sum_{a=1}^{A} \delta^{a} \mathbf{p}_{c(i)+a, a}}{\sum_{a=1}^{A} \boldsymbol{\delta}^{a}}
$$

is the net present value of the skill premia $\mathbf{p}_{c(i)+a, a}$ at different experience levels $a$, normalized by the constant $\sum_{a=1}^{A} \delta^{a}$ to have a convenient interpretation as a weighted average. We refer to $\mathbf{P}_{c}$ as the lifetime skill premia faced by cohort $c$. Although we have assumed for concreteness that workers have full knowledge of the path of skill premia, the linearity of equation (1) in $\mathbf{x}_{i}$ means that we can alternatively allow for uncertainty in skill premia by replacing $\mathbf{p}_{c(i)+a, a}$ in (3) with its expectation. ${ }^{15}$ Likewise, although we have assumed that skills $\mathbf{x}_{i}$ are fixed throughout working life, it is possible to accommodate a linear, deterministic evolution of skills over the lifetime under a suitable reinterpretation of $\mathbf{p}_{c(i)+a, a}$ in (3). ${ }^{16}$

The worker's problem is also equivalent to maximizing $\mathbf{P}_{c(i)}^{\prime} \tilde{\mathbf{x}}_{i}$ subject to $\tilde{\mathbf{x}}_{i} \geq 0$ and $S_{c(i)}\left(\tilde{\mathbf{x}}_{i}\right) \leq$ $\bar{S}_{c(i)}$, where $\tilde{\mathbf{x}}_{i}=\mathbf{x}_{i}-\mu_{i}$. The solutions to this problem depend only on the cohort $c(i)$ of the worker and not on the worker's identity. In this sense, within-cohort variation in skill levels arises only due to variation in the individual skill endowment $\mu_{i}$. We assume that $\mu_{i}$ has mean zero within each cohort. This assumption is without loss of generality since we can always define $\mathbf{x}_{i}$ and $\mu_{i}$ relative to a cohort-specific mean endowment. ${ }^{17}$

${ }^{15}$ That is, taking $\mathrm{E}_{c}[\cdot]$ to be an expectation with respect to the information set of workers in cohort $c$ at the time that skill investments are made, we can take the worker's expected discounted utility to be

$$
\frac{\sum_{a=1}^{A} \delta^{a} \mathrm{E}_{c(i)}\left[\mathbf{p}_{c(i)+a, a}^{\prime}\right]}{\sum_{a=1}^{A} \delta^{a}} \mathbf{x}_{i} .
$$

${ }^{16}$ Specifically, suppose that each worker enters working life with chosen skills $\mathbf{x}_{i, 0}=\mathbf{x}_{i}$, which then evolve with experience according to $\mathbf{x}_{i, a}-\mathbf{x}_{i, a-1}=\Lambda_{c(i), a} \mathbf{x}_{i, a-1}$ for $a \in\{1, \ldots, A\}$, with $\Lambda_{c, a}>-I_{J}$ elementwise for all $c, a$. Then we can take $\mathbf{p}_{c(i)+a, a}^{\prime}=\tilde{\mathbf{p}}_{c(i)+a, a}^{\prime} \prod_{a^{\prime}=1}^{a}\left(\Lambda_{c(i), a^{\prime}}+I_{J}\right)$ where $\tilde{\mathbf{p}}_{c(i)+a, a}$ are the (contemporaneous) premia to the worker's skills $\mathbf{x}_{i, a}$ at experience level $a$.

${ }^{17}$ To see this, start with an endowment $\stackrel{\circ}{\mu}_{i}$ with mean $\stackrel{\circ}{\mu}_{c}=\frac{\sum_{\{i: c(i)=c\}} \stackrel{\circ}{i}_{i}}{|\{i: c(i)=c\}|}$ in cohort $c$, where $\stackrel{\circ}{\mu}_{c}$ need not be zero. The problem of maximizing $\mathbf{P}_{c(i)}^{\prime} \stackrel{\circ}{\mathbf{x}}_{i}$ subject to $\stackrel{\circ}{\mathbf{x}}_{i} \geq \stackrel{\circ}{i}_{i}$ and $S_{c(i)}\left(\stackrel{\circ}{\mathbf{x}}_{i}-\stackrel{\circ}{\mu}_{i}\right) \leq \bar{S}_{c(i)}$ is equivalent to the problem of maximiz- 


\subsection{Parameterization and Identification}

We will assume that the transformation function $S_{c}(\cdot)$ takes the constant elasticity form

$$
S_{c}(\tilde{\mathbf{x}})=\left(\sum_{j=1}^{J} K_{c j}^{\rho-1} \tilde{x}_{j}^{\rho}\right)^{\frac{1}{\rho}}
$$

where $\mathbf{K}_{c} \in \mathbb{R}_{>0}^{J}$ is a vector-valued parameter that we may think of as describing the cost of increasing skill along each of the $J$ dimensions for cohort $c$, and $\rho>1$ is a scalar parameter that determines the substitutability of effort across different skill dimensions.

Worker $i$ 's problem has a unique solution, with $\tilde{\mathbf{x}}_{i}=\tilde{\mathbf{x}}_{i^{\prime}}$ if $c(i)=c\left(i^{\prime}\right)$. Therefore write $\tilde{\mathbf{x}}_{c}=$ $\tilde{\mathbf{x}}_{c}\left(\mathbf{P}_{c}\right)$ as the optimal $\tilde{\mathbf{x}}_{i}$ for all workers $i$ in cohort $c$. Here $\tilde{\mathbf{x}}_{c}(\cdot)$ is a skill supply function that returns the optimal skill investment for members of cohort $c$ given the lifetime skill premia $\mathbf{P}_{c}{ }^{18}$ We assume that $\mathbf{P}_{c}>0$ for all $c$.

Imagine an econometrician who has data $\left\{\left(\mathbf{P}_{c}, \tilde{\mathbf{x}}_{c}\right)\right\}_{c=\underline{c}}^{\bar{c}}$ and wishes to learn the skill supply function $\tilde{\mathbf{x}}_{c}(\cdot)$. Focus on the first two dimensions, where we may think of fluid intelligence as dimension $j=1$ and crystallized intelligence as dimension $j=2$. Under the model, the relative supply of fluid intelligence obeys

$$
\ln \left(\frac{\tilde{x}_{c 1}}{\tilde{x}_{c 2}}\right)=\frac{1}{\rho-1} \ln \left(\frac{P_{c 1}}{P_{c 2}}\right)-\ln \left(\frac{K_{c 1}}{K_{c 2}}\right) .
$$

A standard difficulty in learning the elasticity of substitution $\frac{1}{\rho-1}$ is that the unobserved costs $\mathbf{K}_{c}$ may affect both skill investments (via the workers' incentives) and skill premia (via the labor market). We assume that, on average, there is no trend in the relative costs of the two skill dimensions.

Assumption 1. (Zero average relative supply shock.) We assume that

$$
\frac{1}{\bar{c}-\underline{c}} \sum_{c=\underline{c}}^{\bar{c}-1}\left[\ln \left(\frac{K_{c+1,1}}{K_{c+1,2}}\right)-\ln \left(\frac{K_{c 1}}{K_{c 2}}\right)\right]=0 .
$$

ing $\mathbf{P}_{c(i)}^{\prime} \mathbf{x}_{i}$ subject to [2] where $\mathbf{x}_{i}=\stackrel{\circ}{\mathbf{x}}_{i}-\stackrel{\circ}{\mu}_{c(i)}$ and $\mu_{i}=\stackrel{\circ}{\mu}_{i}-\stackrel{\circ}{\mu}_{c(i)}$. Here $\mu_{i}$ has mean zero within each cohort by construction.

${ }^{18}$ Specifically, for each skill $j \in\{1, \ldots, J\}$, we have

$$
\tilde{x}_{c j}\left(\mathbf{P}_{c}\right)=\frac{P_{c j}^{\frac{1}{\rho-1}} K_{c j}^{-1}}{\left(\sum_{j^{\prime}=1}^{J} P_{c j^{\prime}}^{\frac{\rho}{\rho-1}} K_{c j^{\prime}}^{-1}\right)^{\frac{1}{\rho}}} \bar{S}_{c} .
$$


Under Assumption 1, long-run improvements in the technology for producing skills are not systematically biased towards either fluid or crystallized intelligence.

Assumption 1 is sufficient for the identification of $\tilde{\mathbf{x}}_{c}(\cdot)$ under a regularity condition on $\mathbf{P}_{c}$.

Proposition 1. Under Assumption 1 if $\frac{P_{\bar{c} 1}}{P_{\bar{c} 2}} \neq \frac{P_{\underline{c} 1}}{P_{\underline{c} 2}}$, then the skill supply function $\tilde{\mathbf{x}}_{c}(\cdot)$ for each cohort $c$ is identified from data $\left\{\left(\mathbf{P}_{c}, \tilde{\mathbf{x}}_{c}\right)\right\}_{c=\underline{c}}^{\bar{c}}$.

All proofs are in Appendix A. The proof of Proposition 1 is constructive. Under Assumption 1 , an explicit expression for $\rho$ can be derived using equation (5). We can then learn the costs $\mathbf{K}_{c}$ and budget $\bar{S}_{c}$ up to suitable normalizations. The required regularity condition on $\mathbf{P}_{c}$ can in principle be checked in the data. Appendix $B$ presents conditions for the identification of $\tilde{\mathbf{x}}_{c}(\cdot)$ in the presence of a social multiplier in skill investment in the spirit of Dickens and Flynn (2001, equation 2").

Proposition 1 requires that the econometrician knows $\mathbf{P}_{c}$. This requirement can be relaxed to require only that $\mathbf{P}_{c}$ is known up to scale.

Corollary 1. Under the conditions of Proposition 1 the skill supply function $\tilde{\mathbf{x}}_{c}(\cdot)$ for each cohort $c$ is identified from data $\left\{\left(\alpha \mathbf{P}_{c}, \tilde{\mathbf{x}}_{c}\right)\right\}_{c=\underline{c}}^{\bar{c}}$, where the scalar $\alpha>0$ may be unknown.

Corollary 1 allows that the econometrician may understate or overstate the lifetime skill premia, provided the error is proportional across dimensions $j$ and the constant of proportionality does not differ across cohorts. An immediate implication is that if there are non-market returns to skill that evolve in proportion to market returns — say, because skills earn a premium on the marriage market only to the extent they improve a person's earning potential — then measurement of market returns is sufficient for identification of the skill supply function.

What remains is to establish conditions for the identification of $\tilde{\mathbf{x}}_{c}$ and $\mathbf{P}_{c}$. Recall that we assume that $\mu_{i}$ has mean zero within each cohort, implying that $\tilde{\mathbf{x}}_{c}=\overline{\mathbf{x}}_{c}$ for $\overline{\mathbf{x}}_{c}$ the mean skill of individuals in cohort $c$. Identification of $\tilde{\mathbf{x}}_{c}$ from the distribution of $\mathbf{x}_{i}$ is therefore trivial.

Recall also that $\mathbf{P}_{c}$ is the net present value of cohort-and-period-specific skill premia $\mathbf{p}_{t, a}=$ $\mathbf{p}_{t, t-c}$. We identify $\mathbf{p}_{t, t-c}$, up to scale, from a Mincerian regression of the log of earnings on measured skills. To do this, we restrict the relationship between the unobserved determinants of earnings $z_{i t}$ and skill endowments $\mu_{i}$, allowing that the econometrician may also observe a vector of covariates $\mathbf{d}_{i t}$.

Assumption 2. The values of $z_{i t}$ in each period t obey

$$
\mathrm{E}\left(\ln \left(z_{i t}\right) \mid \mu_{i}=\mu, \mathbf{d}_{i t}=\mathbf{d}, c(i)=c\right)=\zeta_{t, t-c}+\tilde{\alpha} \mathbf{p}_{t, t-c}^{\prime} \mu+\mathbf{d}^{\prime} \beta_{t, t-c}
$$


where $\zeta_{t, t-c}$ and $\beta_{t, t-c}$ are unknown parameters, and the scalar $\tilde{\alpha} \geq 0$ may also be unknown.

Assumption 2 allows that the unobserved determinants of earnings are linearly related both to the observed covariates $\mathbf{d}_{i t}$ and to the market value of the skill endowment $\mathbf{p}_{t, t-c}^{\prime} \mu_{i}$. Such a relationship can arise if the market supplies inputs complementary to the worker's endowment. ${ }^{19}$

Assumption 2 is sufficient to identify the cohort-and-period-specific skill premia $\mathbf{p}_{t, t-c}$, and hence the lifetime skill premia $\mathbf{P}_{c}$, up to scale, from the conditional expectation function of the $\log$ of earnings.

Proposition 2. Under Assumption 2 for some scalar $\alpha>0$, a multiple $\alpha \mathbf{P}_{c}$ of the lifetime skill premia for each cohort $c$ is identified from the conditional expectation function of the log of earnings,

$$
\mathrm{E}\left(\ln \left(w_{i t}\right) \mid \mathbf{x}_{i}=\mathbf{x}, \mathbf{d}_{i t}=\mathbf{d}, c(i)=c\right),
$$

for each time period $t \in\{c+1, \ldots, c+A\}$.

Importantly, Proposition 2 does not require that all determinants of earnings are observed, or that unobserved determinants of earnings are independent of skills. Instead, Proposition 2 requires that unobserved determinants of earnings are related to the skill endowment only through its market value, with a coefficient that does not vary across cohorts or periods. Appendix Cpresents alternative conditions for identification of $\mathbf{P}_{c}$ up to scale when skills are measured with error.

Although we identify $\mathbf{P}_{c}$ only up to an unknown multiple $\alpha>0$, going forward we will for simplicity write as if $\alpha=1$. Moreover, although for concreteness Assumption 2 requires that $\tilde{\alpha} \geq 0$, and hence that a regression of the log of earnings on skills will tend to overstate skill premia, the proofs of Corollary 1 and Proposition 2 make clear that $\tilde{\alpha} \neq-1$ is sufficient.

${ }^{19}$ Suppose, for example, that the efficiency units $z_{i t}$ of worker $i$ at time $t$ are given by $z_{i t}=\tilde{z}_{i t} \underline{z}_{t, a(i, t)}$ where $\tilde{z}_{i t} \geq 1$ is the amount of some input and $\underline{z}_{t, a}=\left(\nabla F_{t, a}^{\prime} \mathbf{x}_{t, a}\right)^{-1}$ is a scale factor that ensures that mean earnings in each period and experience level are unity if the minimum input is always supplied. Say that the input for worker $i$ at time $t$ is supplied competitively, with marginal product $\underline{z}_{t, a(i, t)} \nabla F_{t, a(i, t)}^{\prime} \mu_{i}$ given by the effect of an increase in $\tilde{z}_{i t}$ on total output from the worker's skill endowment, and marginal cost $\tilde{\alpha}^{-1}\left(\ln \left(\tilde{z}_{i t}\right)-\eta_{i t}\right)$ for $\eta_{i t}$ a shock. From equating marginal product and marginal cost, it follows that

$$
\ln \left(\tilde{z}_{i t}\right)=\tilde{\alpha} \mathbf{p}_{t, t-c}^{\prime} \mu_{i}+\eta_{i t}
$$

and therefore that Assumption 2 holds if

$$
\mathrm{E}\left(\eta_{i t} \mid \mu_{i}=\mu, \mathbf{d}_{i t}=\mathbf{d}, c(i)=c\right)=\tilde{\zeta}_{t, t-c}+\mathbf{d}^{\prime} \beta_{t, t-c}
$$

in each period $t$ for some $\tilde{\zeta}_{t, t-c}$. 


\subsection{Discussion}

Assumption 1 is violated if long-run improvements in skill production technology favor one skill dimension over the other. Testing this assumption is difficult because it imposes a restriction only on those changes in relative skill levels that would have occurred in the absence of changes in relative skill premia. ${ }^{20}$

However, it is possible to obtain some clues about the plausibility of this assumption from prior research in cognitive science and economics. Improvements in schooling are one potentially important cause of changes in skill production technology. Pietschnig and Voracek (2015, Table 2 ) argue that higher levels of education are linked especially to greater crystallized intelligence. ${ }^{21}$ Improvements in health and nutrition are another potentially important cause of changes in skill production technology. Pietschnig and Voracek (2015, Table 2) argue that some factors in this category (e.g., blood lead levels) do not affect fluid and crystallized intelligence differently, but that some (e.g., nutrition) have larger effects on fluid than crystallized intelligence. ${ }^{22}$ Other changes that may have improved skill production technology include increased availability of personal technology (e.g., video games) and a reduction in disease burden (Pietschnig and Voracek 2015, Table 2). ${ }^{23}$

Thus there are factors that favor crystallized intelligence, factors that favor fluid intelligence, and factors that do not favor one or the other. We may think of Assumption 1 as describing a situation where the opposing factors wash out. To the extent that they do not, and that changes in skill production technology favor crystallized intelligence, we expect to understate the role of labor market returns in explaining trends in skills. To the extent that changes instead favor fluid intelligence, we expect to overstate the role of labor market returns. ${ }^{24}$

${ }^{20}$ Following the proof of Proposition 1 , any data $\left\{\left(\mathbf{P}_{c}, \tilde{\mathbf{x}}_{c}\right)\right\}_{c=\underline{c}}^{\bar{c}}$ such that $\mathbf{P}_{c}, \tilde{\mathbf{x}}_{c}>0$ for all $c$, with $\operatorname{sgn}\left(\ln \left(\frac{\tilde{x}_{\bar{c} 1}}{\tilde{x}_{\bar{c} 2}} / \tilde{x}_{\tilde{x}_{c 1}}\right)\right)=$ $\operatorname{sgn}\left(\ln \left(\frac{P_{\bar{c} 1}}{P_{\bar{c} 2}} / \frac{P_{c 1}}{P_{c 2}}\right)\right) \neq 0$, are compatible with our model and with Assumption 1 .

${ }^{21}$ Cliffordson and Gustafsson (2008) and Carlsson et al. (2015) document stronger effects of schooling on crystallized than fluid intelligence using data from the same military enlistment battery that we study.

${ }^{22}$ In a review of the literature, Lam and Lawlis (2017) identify randomized trials showing evidence of effects of micronutrient interventions on both fluid and crystallized intelligence, though with larger effect sizes for fluid intelligence. See also Lynn (2009, pp. 253-254).

${ }^{23}$ Pietschnig and Voracek (2015, pp. 290-291) note that increased access to technology may have improved fluid more than crystallized intelligence, but also that gains in fluid intelligence have been observed in countries and time periods with lower levels of access to modern technology (see also Baker et al. 2015, p. 146). Simons et al. (2016) argue that there is limited evidence of effects of interventions such as video game playing on broader cognitive performance.

${ }^{24}$ Say that $\frac{P_{\overline{c 1}}}{P_{\bar{c} 2}}>\frac{P_{\underline{c} 1}}{P_{\underline{c} 2}}$. If $\frac{1}{\bar{c}-\underline{c}} \sum_{c=\underline{c}}^{\bar{c}-1}\left[\ln \left(\frac{K_{c+1,1}}{K_{c+1,2}}\right)-\ln \left(\frac{K_{c 1}}{K_{c 2}}\right)\right]>0$, then our construction will understate the elasticity of 
In our empirical analysis, we explore the sensitivity of our findings to departures from Assumption 1 and to accounting for measurable changes in schooling and health occurring at or before the ages at which we measure skills. We also study skills measured at various ages and therefore at different points in a person's schooling.

Assumption 2 is violated if there are unmeasured factors that directly affect earnings and whose correlation with a person's skill endowment is not proportional to the endowment's market value. In our empirical analysis, we explore the sensitivity of our findings to including proxies for candidate factors in the covariate set $\mathbf{d}_{i t}$.

\section{Data}

\subsection{Linked Data on Test Scores and Earnings}

Our main analysis uses data on scores from tests administered at military enlistment, typically at age 18 or 19, for the near-population of Swedish men born between 1962 and 1975 and who enlisted between 1980 and 1993 (War Archives 2016). Across all cohorts, these men took identical tests that were part of a group of tests called Enlistment Battery 80. Carlstedt (2000), Rönnlund et al. (2013), and Gyllenram et al. (2015) describe the tests in more detail. Appendix Table 2 shows how our results change when we vary the set of cohorts we include in the analysis.

To extend our analysis to a broader set of birth cohorts and earlier testing ages, we also use data on scores from tests administered, typically at age 13, as part of the Evaluation Through Follow-up, a large survey of Swedish families (Härnqvist 2000). These data cover around 10 percent of the birth cohorts 1948, 1953, 1967, 1972, and 1977. ${ }^{25}$ Härnqvist (1998) and Svensson (2011) describe the tests, which were unchanged across the cohorts, and the survey in more detail. We focus on males to parallel the military enlistment sample. The appendix presents supplementary findings for females.

Both data sources include tests for logical reasoning and vocabulary knowledge. In the enlistment data, the logical reasoning test consisted of drawing correct conclusions based on statements that are made complex by distracting negations or conditional clauses and numerical operations (Carlstedt and Mårdberg 1993; Gyllenram et al. 2015). The vocabulary knowledge test consisted

\footnotetext{
substitution $\frac{1}{\rho-1}$. If $\frac{1}{\bar{c}-\underline{c}} \sum_{c=\underline{c}}^{\bar{c}-1}\left[\ln \left(\frac{K_{c+1,1}}{K_{c+1,2}}\right)-\ln \left(\frac{K_{c 1}}{K_{c 2}}\right)\right]<0$, then our construction will overstate it.

${ }^{25}$ Extensions of our analysis in the appendix include data for birth cohorts 1982 and 1992, for which we can measure skill levels but have more limited information on earnings.
} 
of correctly identifying synonyms to a set of words (Gyllenram et al. 2015). In the survey data, the logical reasoning test consisted of guessing the next in a sequence of numbers, and the vocabulary knowledge test consisted of recognizing antonyms (Svensson 2011, Chapter 1). In both data sources, we observe the number of questions (out of a total of 40) that each person answered correctly on each test.

We treat performance on the logical reasoning test as our main measure of fluid intelligence $(j=1)$. We treat performance on the vocabulary knowledge test as our main measure of crystallized intelligence $(j=2)$. Pietschnig and Voracek (2015, Table 1) list guessing the next number in a sequence as an example of a task that measures fluid intelligence, and a vocabulary test as an example of a task that measures crystallized intelligence. ${ }^{26}$

Enlistees were assigned to military positions in part based on a composite cognitive score that depended on the logical reasoning test, the vocabulary knowledge test, and other tests (Grönqvist and Lindqvist 2016, pp. 873-874, 877). We are not aware of any incentives attached to the individual cognitive test components (e.g., logical reasoning, vocabulary knowledge) or any reason why incentives to perform well on the tests would have differed by birth cohort. The test questions are classified so could not be practiced in advance. We are not aware of any incentives attached to performance on the survey tests, which are not publicly available.

We include in our analysis only those individuals for whom we observe valid logical reasoning and vocabulary knowledge scores. For each data source and each dimension $j$, we let $x_{i j}$ denote the percentile rank of individual $i$ 's score within the distribution of scores of those born in $1967 .{ }^{27}$ The skill vector $\mathbf{x}_{i}=\left(x_{i 1}, x_{i 2}\right)$ then measures the performance of individual $i$ on each dimension $j$ relative to the set of individuals born in 1967. Appendix Table 2 shows how our results change when we instead measure an individual's skill by expressing the individual's score on each test as a percent of the maximum possible score. Appendix Table 1 shows the number of individuals in each birth cohort for each data source.

Both data sources also include a test of spatial reasoning. Appendix Table 2 shows how our results change when we combine logical and spatial reasoning skills into a single composite measure of fluid intelligence. For completeness, Appendix Figure 1 shows trends in the level of and pre-

\footnotetext{
${ }^{26}$ Carroll (1993) lists induction and sequential reasoning as two of the three factors most frequently associated with fluid intelligence, and verbal ability as the factor most frequently associated with crystallized intelligence, in a tabulation based on a hierarchical factor analysis (pp. 598-899; see also Flanagan and Dixon 2014).

${ }^{27}$ Specifically, $x_{i j}$ is equal to the average rank of sample individuals born in 1967 who have the same score as individual $i$ on dimension $j$, multiplied by 100 , divided by the number of sample individuals born in 1967, and centered by adding a constant so that $x_{i j}$ has an average value of 50 among those born in 1967.
} 
mium for technical skills, which are measured in the military enlistment data but not in the survey data. Appendix Figure 2 shows trends in the levels of and premia for skills in the military enlistment data for men born between 1954 and 1961, for which the format of the tests was different (War Archives 2016).

We join both sources of test scores to information on labor market earnings for the universe of Swedish residents from the Income and Tax Register for the years 1968-2018. ${ }^{28}$ For each individual $i$ in each year $t$, we let $w_{i t}$ be the total gross labor market earnings. Appendix Table 2 shows how our results change when we additionally include business income. ${ }^{29}$

Portions of our analysis use additional variables. From the enlistment data (War Archives 2016), we obtain the date on which an individual took the enlistment tests, the individual's height and weight as of enlistment, and a measure of non-cognitive skill that follows a standardized distribution. ${ }^{30}$ From other sources we obtain administrative data on each individual's employment history (Statistics Sweden 2020a, 2021), foreign-born status (Statistics Sweden 2014b), secondary schooling completion (Statistics Sweden 2014c), region of birth (Statistics Sweden 2021), family relations (Statistics Sweden 2014b), and parental labor market earnings (Statistics Sweden 2014a, 2021).

As we have highlighted above, Appendix Table 2 presents sensitivity analyses with respect to many of the choices we have made in constructing the variables for our analysis. We summarize and discuss the quantitative implications of these choices in Section 4.2 .

\subsection{Original Survey of Parents' Perceptions}

We conducted an original survey to assess the importance that parents place on different types of skills. We hosted the survey on a Stockholm University survey platform. We recruited participants via Facebook ads from October 17 through October 24, 2020. During this time, 1,199 respondents began the survey and 983 completed it. We asked each respondent their own year of birth as well as the range of birth years of their children, if any. We include in our analysis the 716 respondents who reported that their first child was born at least 16 years after their own birth year.

\footnotetext{
${ }^{28}$ Data on labor market earnings for 1990-2018 are from Statistics Sweden (2021), where we define gross labor market earnings using the concept described in Statistics Sweden (2016a, p. 137-138). Data for 1968-1989 are from Statistics Sweden (2014a), where we approximate the concept described in Statistics Sweden (2016a, p. 137-138) using the available data fields.

${ }^{29}$ We obtain data on business income for 1990-2018 from Statistics Sweden (2021). We define the resulting total income measure using the concept described in Statistics Sweden (2016a, pp. 141-142).

${ }^{30}$ Non-cognitive skill is evaluated based on an interview and scored on a Stanine (1-9) scale. Lindqvist and Vestman (2011, pp. 107-109 and Appendix F) and Edin et al. (forthcoming, p. 6) describe the measure in more detail.
} 
We asked these respondents the following question:

As a parent, how much do you encourage (or did you encourage) your children to develop the qualities below while growing up?

To be able to think critically and solve problems logically.

To be able to remember facts, such as the definitions of difficult words.

We intended the first quality to approximate the concept of fluid intelligence and the second to approximate the concept of crystallized intelligence. We also asked respondents about the importance of each quality in today's society, how much their own parents emphasized each quality, and how much their own primary school emphasized each quality. There were five possible answers ranging from "Not at all" to "Very much," and we classified each response according to whether the person rated the first quality as more important, the second quality as more important, or neither.

Appendix Figure 3 gives screenshots of the consent form and survey form. Appendix Figure 4 shows the distribution of year of birth, and year of birth of first child, among the respondents in our sample.

\section{Results}

\subsection{Trends in Skills and Skill Premia}

We let $c(i)$ be the year that worker $i$ turns 29 and we let $A=26$, so that the working life is from ages 30 through 55. Appendix Figure 5 shows that full-time work tends to be highest during these years. Appendix Table 2 shows how our findings change when we alter the beginning or ending year of working life, and when we restrict to workers who are employed year-round in a typical year.

We estimate the parameter $\mathbf{p}_{t, a}$ in equation (1) by ordinary least squares regression of the $\log$ of labor market earnings $\ln \left(w_{i t}\right)$ on the vector of percentile ranks $\mathbf{x}_{i}$, separately for each worker experience level (age) $a$ and for each year $t$ for which we measure earnings, excluding men with zero earnings. This yields an estimate of $\mathbf{p}_{c+a, a}$ for each $c, a$ such that $c+a \leq T$, for $T$ the most recent year of earnings data available. Appendix Figure 6illustrates the fit of the regression model for three example cohorts at three different ages.

To estimate $\mathbf{p}_{c+a, a}$ for $c, a$ such that $c+a>T$, we take the average estimate for the given cohort $c$ for all ages $a>10$ for which a regression estimate of $\mathbf{p}_{c+a, a}$ is available. Appendix Figure 
7illustrates this extrapolation for three example cohorts. Appendix Table 2 shows how our findings change when we average over a shorter or longer span of ages.

We plug the resulting estimates of $\mathbf{p}_{c+a, a}$ into equation (3), along with the value $\delta=0.96$, to get an estimate of the lifetime skill premia $\mathbf{P}_{c}$ for the cohorts $c \in\{\underline{c}, \ldots, \bar{c}\}$. Appendix Table 2 shows how our findings change when we vary the assumed value of $\delta$. We obtain standard errors for $\mathbf{P}_{c}$ via a nonparametric bootstrap in which we sample individuals $i$ with replacement.

Figure 1 depicts the average skill levels $\overline{\mathbf{x}}_{c}$ and the estimated lifetime skill premia $\mathbf{P}_{c}$ across cohorts in the enlistment data along with their 95 percent pointwise and uniform confidence intervals. For convenience we label cohorts with their birth year, i.e., $c-29$. Figure 1 also depicts the lines of best fit through the plotted series.

The top row of plots in Figure 1 shows that logical reasoning skill rose, on average, by 4.4 percentile points, relative to the 1967 distribution, across the birth cohorts from 1962 to 1975 . By contrast, vocabulary knowledge skill fell, on average, by 2.9 percentile points. Appendix Figure 8 depicts the cumulative distribution functions of skills in the 1962 and 1975 cohorts. Appendix Figure 9 compares trends in skill in our data to those measured in other countries.

The bottom row of plots in Figure 1 shows that the lifetime skill premium fell for both logical reasoning and vocabulary knowledge. The line of best fit indicates that the lifetime premium for a percentile point of logical reasoning skill fell from 0.48 to $0.40 \log$ points across the birth cohorts from 1962 to 1975, and the lifetime premium for a percentile point of vocabulary knowledge fell from 0.16 to $0.09 \log$ points. Thus, the lifetime premium for both skill dimensions fell, with a proportionately much greater decline for vocabulary knowledge. ${ }^{31}$ Appendix Figure 10 depicts estimated lifetime skill premia based on a generalization of equation (1) that allows interactions between the skill dimensions.

Figure 2 depicts the evolution of the relative skill levels $\ln \left(\bar{x}_{c 1} / \bar{x}_{c 2}\right)$ and of the relative lifetime skill premia $\ln \left(P_{c 1} / P_{c 2}\right)$ across the two dimensions. Figure 2 shows that these objects both tend to increase with later birth cohorts and are fairly close to the line of best fit, evoking a movement along a relative linear supply curve as in equation (5). Figure 3 shows that a similar qualitative pattern obtains in our survey sample, which is smaller and for which estimates tend to be less precise. Appendix Figure 11 depicts the underlying estimates of skill levels and lifetime skill premia for men in the survey sample. Appendix Figure 12 depicts the evolution of relative skill

\footnotetext{
${ }^{31}$ Prior work finding evidence of declining returns to cognitive skill includes Castex and Dechter (2014) for the US, Markussen and Røed (2020) for Norway, and Edin et al. (forthcoming) for Sweden.
} 
levels and relative lifetime skill premia for women in the survey sample. Appendix Figure 13 depicts the evolution of relative skill levels and relative lifetime skill premia in the enlistment sample by region of birth.

Under the conditions in Appendix C, our approach to identification and estimation of relative skill premia remains valid even in the presence of measurement error in skills. As an alternative exploration of the role of measurement error, requiring different assumptions from those in Appendix C, Panel A of Appendix Table 3 shows estimates of the trend in skill premia computed using the individuals present in both the enlistment and survey data, instrumenting for skills measured at enlistment with skills measured in the survey. The sample is small and the instrumental variables estimates are imprecise. The confidence intervals on the estimated trends include 0 and also include the slope of the linear fit from Figure 11. Relative to the slope of the linear fit from Figure 1, instrumental variables estimates tend to show growth in the premium to logical reasoning and more rapid decline in the premium to vocabulary knowledge, suggesting even stronger trends in labor-market incentives to invest in logical reasoning at the expense of vocabulary knowledge than in our baseline calculations. Panel B of Appendix Table 3 reports small and statistically insignificant trends in the correlation between skills measured in the survey data and those measured in the enlistment data.

\subsection{Model Estimates and Counterfactuals}

We estimate the skill supply function $\tilde{\mathbf{x}}_{c}(\cdot)$ for each cohort in the enlistment sample following the construction in the proof of Proposition 1. We take $J=2$. We take the average skill $\overline{\mathbf{x}}_{c}$ in each cohort as our estimate of $\tilde{\mathbf{x}}_{c}$. We take the linear fit in Figure 1 as our estimate of the lifetime skill premia $\mathbf{P}_{c}{ }^{32}$ We may think of the linear fit either as a way of smoothing the sampling variation in the data, or as a way of approximating the forward-looking expectations of workers at the time the skill investment decision is made. Panel A of Table 1 reports estimates of key parameters. Appendix Table 2 shows how our findings change when we use a quadratic fit and when we do not smooth premia at all.

Figure 4 shows the evolution of logical reasoning and vocabulary knowledge skill in the data and in the counterfactual scenario in which the lifetime skill premia $\mathbf{P}_{c}$ remain constant at their initial level $\mathbf{P}_{\underline{c}}$. In the counterfactual scenario, logical reasoning skill increases by 2.8 percentile

\footnotetext{
${ }^{32}$ Consistent with the regularity condition in Proposition 1 , based on the linear fit we reject the null hypothesis that $\ln \left(P_{\underline{c} 1} / P_{\underline{c} 2}\right)=\ln \left(P_{\bar{c} 1} / P_{\bar{c} 2}\right)$ at conventional significance levels $(p=0.0006)$.
} 
points instead of 4.4 as in the actual data. Vocabulary knowledge skill increases by 3.0 percentile points rather than falling by 2.9 percentile points. In this sense, according to the model, changes in the lifetime skill premia $\mathbf{P}_{c}$ account for 36.8 percent of the increase in logical reasoning skill (with a standard error of 1.7 percent), and for more than the entire decline in vocabulary knowledge skill.

To unpack the findings in Figure 4 , begin with estimation of the elasticity of substitution $\frac{1}{\rho-1}$. Under Assumption 11, all long-term change in relative skill levels across cohorts must be due to change in relative skill premia. In particular, the elasticity of substitution $\frac{1}{\rho-1}$ can be estimated as the ratio of the long-term change in relative skill levels to the long-term change in relative skill premia. Appendix Figure 14 illustrates by plotting the log of the relative estimated average skill level $\ln \left(\bar{x}_{c 1} / \bar{x}_{c 2}\right)$ against the $\log$ of the relative estimated (linearized) skill premia $\ln \left(P_{c 1} / P_{c 2}\right)$. Under Assumption 11, the linear relative supply curve $\ln \left(\tilde{x}_{\underline{c} 1}(\cdot) / \tilde{x}_{\underline{c} 2}(\cdot)\right)$ defined by the estimated skill supply function $\tilde{\mathbf{x}}_{\underline{\underline{c}}}(\cdot)$ for the 1962 birth cohort must pass through the points on the scatterplot for both the 1962 and 1975 birth cohorts. This implies an elasticity of substitution of $\frac{1}{\rho-1}=0.383$, which is in turn the slope of the line $\ln \left(\tilde{x}_{\underline{c} 1}(\cdot) / \tilde{x}_{\underline{c} 2}(\cdot)\right)$ depicted on the plot.

Next, consider estimation of the remaining parameters of the skill supply function $\tilde{\mathbf{x}}_{c}(\cdot)$. Given the data, under any elasticity of substitution less than 0.97 , the model implies that changes in relative premia alone are too small to explain the large increase in logical reasoning skill. We can therefore infer an upward shift in the first dimension of the skill supply function $\tilde{x}_{c 1}(\cdot)$ across cohorts, i.e., growth in logical reasoning skill beyond what can be explained by changes in premia alone. And, given Assumption 1, the model implies that there must also have been an upward shift in the second dimension of the skill supply function $\tilde{x}_{c 2}(\cdot)$ across cohorts, i.e., that vocabulary knowledge would have risen absent changes in skill premia.

Following the constant elasticity form of the transformation function in equation (4) and the $\log$-linear form of the relative supply function in equation (5), our discussion has focused on ratios of skill premia rather than on their differences. An alternative model that focuses instead on differences in premia might reach a different conclusion regarding the role of changes in premia in explaining cohort trends in skill levels. To illustrate why, Appendix Figure 15 presents an analogue of the scatterplot in Appendix Figure 14, but replacing log ratios of skill levels and skill premia with their differences. Appendix Figure 15 shows that the difference in premia between logical reasoning and vocabulary knowledge did not rise across successive cohorts in the way that Appendix Figure 14 shows that the ratio of premia did. Following Figure 1, we find it intuitive that as the premium to vocabulary knowledge fell to a very low level while the premium to logical reasoning 
skill remained nontrivial, individuals would substitute effort away from vocabulary knowledge, as implied by the constant elasticity form of the transformation function in equation (4).

Appendix Table 2 presents sensitivity analysis with respect to choices we have made in constructing the variables for our analysis. Rows (b) and (c) concern the set of birth cohorts we include. Rows (d) and (e) concern the measurement of skills $\mathbf{x}_{i}$. Row (f) concerns the measurement of earnings $w_{i t}$. Rows (g) through (i) concern the experience levels $a$ and individuals $i$ included in the analysis. Rows $(\mathrm{j})$ through $(\mathrm{m})$ concern the construction of estimates of lifetime skill premia $\mathbf{P}_{c}$ from estimates of period-specific premia $\mathbf{p}_{c+a, a}$. Rows (n) and (o) concern the smoothing of the estimated lifetime skill premia $\mathbf{P}_{c}$. Across these different sensitivity analyses, we estimate that changes in lifetime skill premia account for between 29.4 and 46.5 percent of the increase in logical reasoning skill, which can be compared to our baseline estimate of 36.8 percent. Appendix Figure 16 extends our analysis to a larger set of cohorts, and to women, using the survey sample. We estimate that changes in lifetime skill premia account for a larger share of the increase in logical reasoning skill than in our baseline estimate, though the estimates from the survey sample are less precise than our baseline estimate.

\subsection{Sensitivity to Assumption 1}

Figure 5 shows how our conclusions change as we depart from Assumption 1 . The upper plot is for logical reasoning skill and the lower plot is for vocabulary knowledge. Each plot shows the relationship between the estimated share of the change in the given skill dimension explained by changes in the lifetime skill premia (y-axis) and the average relative shock to the supply of skill (x-axis). We measure the shock as a fraction of the observed change in relative skill levels. A positive shock implies that changes in skill-producing technology favored fluid intelligence over crystallized intelligence, on average across the cohorts that we study. A negative shock implies the reverse. A shock of zero corresponds to the case in which Assumption 1 holds, and thus to the estimates in Figure 4 and Panel A of Table 1.

A reader can use Figure 5 to gauge the effect of a given departure from Assumption 1 on our conclusions. Figure 5 thus improves transparency in the sense of Andrews et al. $(2017,2020)$ and Andrews and Shapiro (2021).

To illustrate the utility of Figure 5 with an example, consider the possibility that changes across cohorts in time spent in school shifted the relative supply of different skills. Carlsson et al. (2015) estimate that additional time in school improves performance on the vocabulary knowledge test 
that we study, and do not find evidence that additional time in school improves performance on the logical reasoning test. We estimate that, relative to the 1962 birth cohort, members of the 1975 birth cohort spent 0.40 more years in school as of the date of test-taking. If at least some of the increase in schooling time would have occurred absent changes in skill premia, then Carlsson et al.'s (2015) analysis implies that increased schooling time can be considered a positive shock to the relative supply of crystallized intelligence, or equivalently a negative shock to the relative supply of fluid intelligence. Figure 5 shows that if there is a negative shock to the relative supply of fluid intelligence, then our baseline estimates understate the share of the change in skill levels that can be accounted for by changes in skill premia. If we take the entire increase in schooling time as a supply shock, and assume no other shocks to the relative supply of the two skill dimensions, we can use the estimates in Carlsson et al. (2015) in tandem with Figure 5 to calculate that changes in lifetime skill premia explain 53.5 percent of the observed increase in logical reasoning skill, which is 16.7 percentage points more than our baseline estimate of 36.8 obtained under Assumption $1^{33}$ A similar exercise is possible with respect to assumptions about the measurement of skill. To illustrate, Appendix Figure 17 depicts our findings regarding trends in actual and counterfactual skills under the assumption that a portion of the cohort trend in logical reasoning skill (upper panel) or vocabulary knowledge skill (lower panel) is spurious. One possible source of spurious trends is a general improvement in test-taking ability (e.g., Neisser 1997; Jensen 1998, pp. 332333), though this would not by itself explain the simultaneous rise in logical reasoning skill and decline in vocabulary knowledge. Another possible source of spurious trends, specific to vocabulary knowledge, is greater test difficulty for later cohorts due to gradual obsolescence of the words on the test (e.g., Hauser and Huang 1997; Alwin and Pacheco 2012; Roivainen 2014). Appendix Figure 17 shows that if a portion of the measured decline in vocabulary knowledge is spurious, our analysis will tend to overstate the role of labor market returns in explaining cohort trends in logical skill, though even if there were no trend in vocabulary knowledge we would still infer that 22.7

\footnotetext{
${ }^{33}$ Carlsson et al. (2015, Table 3, column 1) estimate that an additional 100 days of schooling increases performance in the vocabulary knowledge test by 0.112 standard deviations, relative to the population of test-takers in 1980-1994. Among individuals in our enlistment data, those born in 1975 completed on average 0.40 more years of schooling at enlistment than those born in 1962. As there are roughly 180 schooling days per year in Sweden (Carlsson et al. 2015, p. 538), this implies an increase of 0.0803 standard deviations in vocabulary knowledge skill. Interpolating around the median test score, we estimate that an increase of 0.0803 standard deviations in vocabulary test score is equivalent to an increase of 3.29 percentile points among those born in 1962. Based on the skill levels reported for the 1962 cohort in Panel A of Table 1 , an increase of 3.29 percentile points in vocabulary knowledge skill would have reduced the log ratio of logical reasoning and vocabulary knowledge skills by 0.063 , or by 0.426 of the observed change. Given a relative supply shock of -0.426 , Figure 5 implies that changes in skill premia account for 53.5 percent of the observed increase in logical reasoning.
} 
percent $(\mathrm{SE}=0.6)$ of the trend in logical skill was due to changes in labor market returns. As more concrete evidence on trends in word usage, Appendix Figure 18 shows estimates of the exposure of each cohort to words on example synonym questions for a recent enlistment battery, measuring word exposure based on usage in a major Swedish newspaper. The hypothesis that words on the enlistment battery are more familiar to those born closer to the time of the test design would predict an increasing trend in exposure. We do not find evidence of such a trend.

\subsection{Sensitivity to Controls}

We explore the sensitivity of our conclusions to adjusting for covariates. We adjust both the estimated trend in mean skills $\overline{\mathbf{x}}_{c}$ and the estimated trend in lifetime skill premia $\mathbf{P}_{c}$ with respect to individual-specific, time-invariant covariates $\mathbf{d}_{i}$ that are normalized to have mean zero among those born in 1967 . We adjust the estimated trend in mean skills by estimating a regression of skills $x_{i j}$ on cohort indicators and covariates $\mathbf{d}_{i}$, excluding the constant. ${ }^{34}$ We then treat the coefficients on the cohort indicators as a covariate-adjusted measure of mean skills. We adjust the estimated trend in lifetime skill premia $\mathbf{P}_{c}$ by including the covariates $\mathbf{d}_{i}$ in the time-and-age-specific earnings regressions from which we estimate $\mathbf{p}_{t, a}$.

Selection of covariates for inclusion in this exercise is delicate. For adjusting the trend in mean skills, we wish to consider adjusting only for covariates whose cohort trends do not respond to skill premia $\mathbf{P}_{c}$. For example, if a trend in mean heights would have occurred even absent changes in $\mathbf{P}_{c}$, then it may be appropriate to adjust the trend in mean skills for the trend in mean heights, and thus to study the effect of skill premia $\mathbf{P}_{c}$ on the part of the trend in skills that cannot be accounted for by the trend in height. By contrast, if trends in the content of schooling occur in response to changes in skill premia $\mathbf{P}_{c}$, then these trends are part of the skill investment process that we model, and we do not want to study the effect of skill premia $\mathbf{P}_{c}$ on only the part of the trend in skills that cannot be accounted for by the trend in the content of schooling. ${ }^{35}$ Likewise, for adjusting the trend in lifetime skill premia $\mathbf{P}_{c}$, we wish to consider adjusting only for covariates that exert a direct effect on earnings independently of their relationship to skills.

Appendix Table 4 shows how our findings change when we adjust for age at enlistment, an indicator for having completed secondary school at the time of enlistment or at age $18, \log ($ height $)$

\footnotetext{
${ }^{34}$ Within the model in Section 2, we may think of this exercise as re-normalizing the skill endowment $\mu_{i}$ to have cohort-specific mean $\Gamma \overline{\mathbf{d}}_{c}$ where $\overline{\mathbf{d}}_{c}$ is the cohort-specific mean of $\mathbf{d}_{i}$ and $\Gamma$ is a matrix whose $j^{\text {th }}$ row contains the coefficients on $\mathbf{d}_{i}$ in the regression of skills $x_{i j}$ on cohort indicators and covariates $\mathbf{d}_{i}$.

${ }^{35}$ Trends in parents' skills may likewise be attributable to (earlier) trends in labor market returns.
} 
and $\log$ (weight) measured at the time of enlistment, and an indicator for being born outside of Sweden. Across these exercises, we find that changes in labor market returns consistently account for at least 35.5 percent of the increase in logical skill, and for more than the entire decline in vocabulary knowledge skill.

\subsection{Heterogeneity}

Appendix Table 5 shows how our findings change when we estimate the model separately for workers with below- vs. above-median parental earnings. ${ }^{36}$ We estimate that changes in skill premia explain 1.3 percentage points more of the increase in logical reasoning skill for those whose parents have above-median earnings than for those whose parents have below-median earnings, though the difference is not statistically significant $(\mathrm{SE}=4.3)$.

\section{Trends in Emphasis among Parents, Schools, and Occupations}

Sections 5.1 and 5.2 explore whether parents and schools increasingly emphasize reasoning over knowledge. Section 5.3 explores whether changes in the occupation mix favor reasoning-intensive as opposed to knowledge-intensive occupations. Evidence that parents, schools, and occupations have shifted to emphasize reasoning over knowledge does not, on its own, establish that changes in production technology are driving changes in skill investment. Such evidence can, however, serve to make tangible some of the real-world processes that underlie the skill investment decision modeled in Section 2.2 and the production economy modeled in Section 2.1.

\subsection{Parents}

Panel A of Figure 6 depicts trends in the perceived importance of different skills among parents, as reported in the survey described in Section 3.2. Parents of more recent birth cohorts place more emphasis on reasoning skills and less emphasis on knowledge, compared to parents of earlier birth cohorts. Panel B depicts trends in respondents' perception of the importance of different skills in today's society, how much their own parents emphasized each skill, and how much their own primary school emphasized each skill. There is some visual evidence that younger parents perceive

\footnotetext{
${ }^{36}$ To nest this exercise within the model in Section 2, we can suppose there are two distinct labor markets, one for each group of workers, with the two markets potentially linked by a common production function $F_{t}(\cdot)$.
} 
logical skills to be more important than do older parents. Parents' perceptions of what skills were emphasized by their own parents and primary schools do not show a clear trend.

\subsection{Schools}

We can also investigate changes in school curricula over the period we study. We focus on primary schooling because Figure 3 suggests that the trends in skill levels that we study emerge at young ages. The primary school curriculum in Sweden is summarized in an official Curriculum ("Läroplan") that is revised from time to time. Meeting society's demands is an explicit goal of the primary schooling system, ${ }^{37}$ and although vocational training is not given in primary school, the needs of the workplace have sometimes played a direct role in the development of the Curricu$\operatorname{lum}^{38}$

Scholars of pedagogy in Sweden have noted a trend in the Curricula towards greater emphasis over time on problem solving and critical thinking. For example, in an investigation of longterm trends in the teaching of scientific inquiry, Johansson and Wickman (2012) conclude that, "The early Curricula of 1962 and 1969 lack the goal that students should learn to ask questions, formulate hypotheses or participate in the planning of investigations. That students should learn to formulate questions is first described in the 1980 Curriculum" (p. 205). Similar trends have been observed in other areas of study. ${ }^{39}$ These trends seem consistent with a greater emphasis on reasoning as compared to knowledge, ${ }^{40}$ though we note that, in our survey, parents' perceptions of their own primary schooling experience do not reflect such a trend (see Panel B of Figure 6).

Figure 7 presents an original quantitative analysis of trends in emphasis in the Curricula. Based on a close reading of the Curricula we selected a set of keywords related to reasoning and knowl-

\footnotetext{
${ }^{37}$ For example, the first paragraph of the first section of the 1962 Curriculum states a goal of helping students develop into "capable and responsible members of society" (Skolöverstyrelsen 1962, p. 13). The 1980 Curriculum repeats this language, quoting it as part of the Education Act (Skolöverstyrelsen 1980, p. 13).

${ }^{38}$ For example, the 1962 Curriculum partly reflected the findings from systematic interviews of supervisors and employees regarding the knowledge demands of the workplace (Thavenius 1999, p. 43; Statens offentliga utredningar 1960:15, pp. 500-508).

${ }^{39}$ Löfdahl (1987) studies the physics curriculum but also describes a more general evolution from 1962 to 1980 towards more emphasis on creativity and critical thinking (see also Johansson and Wickman 2012, p. 199). Prytz (2015, p. 317) studies the mathematics curriculum and notes a trend since the 1960 s towards less emphasis on performing calculations. Dahlbäck and Lyngfelt (2017, pp. 167-168) study the evolution of the Swedish curriculum and note that, compared to the 1969 Curriculum, the 1980 Curriculum places greater emphasis on the creative use of language.

${ }^{40}$ Larsson (2011) situates these trends in a transition from realism to progressivism in education. Trends toward greater emphasis on critical thinking and less emphasis on rote knowledge have been noted in many contexts, not only Sweden (see, e.g., Darling-Hammond et al. 2020). Bietenbeck (2014) finds using test score data from the US that modern teaching practices promote reasoning skills whereas traditional teaching practices promote factual knowledge.
} 
edge. For each cohort, we calculate the relative frequency of keywords related to reasoning vs. knowledge during the cohort's primary school years. The figure shows a trend across cohorts toward greater emphasis on reasoning relative to knowledge. Appendix Figure 19 lists the set of keywords we study and provides more details on data construction.

\subsection{Occupations}

Figure 8 shows trends across cohorts in the average reasoning vs. knowledge intensity of occupations. We construct the series as follows. First, we measure the relative reasoning vs. knowledge intensity of occupations in Sweden by matching occupations to those in the US and taking data on the importance of different abilities and knowledge from the O*NET 25.0 database (U.S. Department of Labor, Employment and Training Administration 2020). Second, we compute for each occupation the percentile rank in the distribution of reasoning vs. knowledge intensity of occupations for the 1967 cohort. Finally, we take the weighted average across occupations within each cohort using as weights either total employment or total earnings among the men in the enlistment sample.

Figure 8 shows evidence of a trend towards relatively more reasoning-intensive occupations. The average man born in 1975 is employed in an occupation that is 2.2 percentile points more reasoning-intensive (relative to knowledge-intensive) than the average man born in 1962. The average krona earned by a man born in 1975 is earned by a man in an occupation 3.3 percentile points more reasoning-intensive than the average krona earned by a man born in 1962.

It is important to caveat that the concepts of reasoning and knowledge we measure here do not correspond exactly to those measured by the enlistment tests we study, that the join between Swedish and US occupation codes is imperfect, and that the O*NET scores are static, and so do not reflect changes over time in the demands of different occupations. Still, we find the pattern in Figure 8 interesting in light of the growth in the relative premium to fluid intelligence that we document in Section 4 .

\section{Non-Cognitive Skills}

There is evidence of rising labor-market returns to non-cognitive skill (e.g., Deming 2017; Edin et al. forthcoming). We can extend our analysis to incorporate non-cognitive skills. Suppose that dimensions $j \in\{1, \ldots, L\}$, for $2 \leq L<J$ are dimensions of cognitive skill, and the remaining 
dimensions $j \in\{L+1, \ldots, J\}$ are dimensions of non-cognitive skill. Suppose further that

$$
S_{c}(\tilde{\mathbf{x}})=s_{c}\left(\left(\sum_{j=1}^{L} K_{c j}^{\rho-1} \tilde{x}_{j}^{\rho}\right)^{\frac{1}{\rho}}, \tilde{\mathbf{x}}_{L+1: J}\right)
$$

where $\tilde{\mathbf{x}}_{L+1: J}=\left(\tilde{x}_{L+1}, \ldots, \tilde{x}_{J}\right)$ is the non-cognitive skill investment and $s_{C}(\cdot)$ is an aggregator strictly increasing in its first argument. ${ }^{41}$ We suppose conditions on $s_{C}(\cdot)$ sufficient to ensure a unique, strictly positive solution $\tilde{\mathbf{x}}_{c}\left(\mathbf{P}_{c}\right)$ to the worker's skill investment problem for any $\mathbf{P}_{c}>0$. We define a cognitive skill supply function $\tilde{\mathbf{x}}_{c, 1: L}\left(\cdot ; \mathbf{x}_{L+1: J}\right)$ that describes the optimal level of cognitive skill investment $\tilde{\mathbf{x}}_{c, 1: L}=\left(\tilde{x}_{c, 1}, \ldots, \tilde{x}_{c, L}\right)$ for workers in cohort $c$ given any lifetime skill premia $\mathbf{P}_{c}>0$ and any level $\mathbf{x}_{L+1: J}$ of non-cognitive skill investment.

For each worker $i$ we observe

$$
\hat{\mathbf{x}}_{i}=\left(\mathbf{x}_{i, 1: L}, \mathbf{A}_{c(i)}\left(\mathbf{x}_{i, L+1: J}\right)\right)
$$

where $\mathbf{A}_{c}(\cdot)$ is a cohort-specific, possibly unknown affine map. The presence of the map $\mathbf{A}_{c}(\cdot)$ reflects the fact that, in our data, the measure of non-cognitive skill is standardized and thus not directly comparable across cohorts. ${ }^{42}$

Analogous to our baseline analysis, from data on each cohort's cognitive skill premia $\mathbf{P}_{c, 1: L}$ and mean observed skill levels $\hat{\mathbf{x}}_{c}$, it is possible to identify the cognitive skill supply function $\tilde{\mathbf{x}}_{c, 1: L}\left(\cdot ; \tilde{\mathbf{x}}_{c, L+1: J}\right)$ where non-cognitive skill $\tilde{\mathbf{x}}_{c, L+1: J}=\tilde{\mathbf{x}}_{c, L+1: J}\left(\mathbf{P}_{c}\right)$ is fixed at its equilibrium value for each cohort.

Proposition 3. Under Assumption 1 if $\frac{P_{\bar{c} 1}}{P_{\bar{c} 2}} \neq \frac{P_{\underline{c} 1}}{P_{\underline{c} 2}}$, then the cognitive skill supply function $\tilde{\mathbf{x}}_{c, 1: L}\left(\cdot ; \tilde{\mathbf{x}}_{c, L+1: J}\right)$ for each cohort $c$ is identified from data $\left\{\left(\alpha \mathbf{P}_{c, 1: L}, \hat{\mathbf{x}}_{c}\right)\right\}_{c=\underline{c}}^{\bar{c}}$, where the scalar $\alpha>0$ may be unknown.

Our assumptions are also sufficient to identify the lifetime cognitive skill premia up to scale.

${ }^{41}$ An example is the two-level constant elasticity function (e.g., Sato 1967, Goldin and Katz 2008, Chapter 8, equations 1 and 2):

$$
s_{c}\left(\left(\sum_{j=1}^{L} K_{c j}^{\rho-1} \tilde{x}_{j}^{\rho}\right)^{\frac{1}{\rho}}, \tilde{\mathbf{x}}_{L+1: J}\right)=\left(\lambda\left(\sum_{j=1}^{L} K_{c j}^{\rho-1} \tilde{x}_{j}^{\rho}\right)^{\frac{\sigma}{\rho}}+(1-\lambda)\left(\sum_{j=L+1}^{J} K_{c j}^{\nu-1} \tilde{x}_{j}^{v}\right)^{\frac{\sigma}{v}}\right)^{\frac{1}{\sigma}}
$$

where $\nu, \sigma$, and $\lambda$ are parameters.

${ }^{42}$ Edin et al. (forthcoming, Appendix A1.2) discuss the implications of standardization for the estimation of returns to non-cognitive skill. 
Proposition 4. Under Assumption 2 for some scalar $\alpha>0$, a multiple $\alpha \mathbf{P}_{c, 1: L}$ of the lifetime cognitive skill premia for each cohort $c$ is identified from the conditional expectation function of the log of earnings,

$$
\mathrm{E}\left(\ln \left(w_{i t}\right) \mid \hat{\mathbf{x}}_{i}=\hat{\mathbf{x}}, \mathbf{d}_{i t}=\mathbf{d}, c(i)=c\right),
$$

for each time period $t \in\{c+1, \ldots, c+A\}$.

Notice that our assumptions are not generally sufficient to identify the lifetime non-cognitive skill premia $\mathbf{P}_{c, L+1: J}$ up to scale due to the presence of the map $\mathbf{A}_{c}(\cdot)$.

Following the logic of Propositions 3 and 4 and their proofs, we estimate the cognitive skill supply function as follows. First, we re-estimate lifetime skill premia $\mathbf{P}_{c}$ following the procedure outlined in Section 4.1, but including the standardized measure of non-cognitive skill as an additional covariate in each earnings regression. Second, we estimate the cognitive skill supply function $\tilde{\mathbf{x}}_{c, 1: L}\left(\cdot ; \tilde{\mathbf{x}}_{c, L+1: J}\right)$ following the steps we used to estimate the skill supply function in Section 4.2 , but using the re-estimated lifetime skill premia.

Panel B of Table 1 presents our estimates. The estimated cognitive skill supply function implies that, fixing the level of non-cognitive skill at its equilibrium level, changes in labor market returns account for 26.2 percent of the increase in logical skill (with a standard error of 2.1 percent), and for more than the entire decline in vocabulary knowledge skill.

\section{Conclusions}

We develop a quantitative economic model of the evolution of multidimensional skills across cohorts. We estimate the model using administrative data from Sweden. The estimated model implies that a significant portion of the puzzling "Flynn effect" of rising fluid intelligence is due to substitution in investment across different dimensions of skill. The model also explains the decline in crystallized intelligence across cohorts in our setting. The model is consistent with evidence of a trend towards greater emphasis on reasoning relative to knowledge among parents, schools, and occupations. We extend our analysis to incorporate non-cognitive skill. We conclude that it is fruitful to incorporate market-driven incentives into the analysis of cohort trends in measured intelligence.

We treat the labor demand side of our model abstractly and do not offer a detailed account of the causes of cohort trends in measured labor market returns to skill. Our analysis does, however, suggest some possible explanations for trends in labor market returns to skill. We estimate an 
increase in the overall supply of skill across cohorts. All else equal, an increase in the supply of skill would tend to lower its return, consistent with our finding of declining returns to cognitive skill across cohorts. Likewise, our finding of an increase in the relative return to reasoning, as compared to knowledge, seems consistent with the trends in occupational composition that we document. We think that developing a more detailed model of skill demand that can be combined with our model of skill supply to explain cohort trends in returns to skill is an interesting direction for future work, as is extending our analysis of non-cognitive skills to incorporate measures of non-cognitive skill that can be compared across cohorts.

\section{References}

Acemoglu, Daron and David Autor. 2011. Skills, tasks and technologies: Implications for employment and earnings. In O. Ashenfelter, D. Card (eds.), Handbook of Labor Economics, Volume 4 Part B: 1043-1171. Amsterdam: North Holland.

Alwin, Duane F. and Julianna Pacheco. 2012. Population trends in verbal intelligence in the United States. In Marsden, Peter V. (ed.), Social trends in American life: Findings from the General Social Survey since 1972. Princeton, NJ: Princeton University Press.

Agostinelli, Francesco and Matthew Wiswall. 2020. Estimating the technology of children's skill formation. NBER Working Paper No. 22442.

Andrews, Isaiah, Matthew Gentzkow, and Jesse M. Shapiro. 2017. Measuring the sensitivity of parameter estimates to estimation moments. Quarterly Journal of Economics 132(4): 15531592.

Andrews, Isaiah, Matthew Gentzkow, and Jesse M. Shapiro. 2020. Transparency in structural research. Journal of Business \& Economic Statistics 38(4): 711-722.

Andrews, Isaiah and Jesse M. Shapiro. 2021. A model of scientific communication. Econometrica 89(5): 2117-2142.

Baker, David P., Paul J. Eslinger, Martin Benavides, Ellen Peters, Nathan F. Dieckmann, and Juan Leon. 2015. The cognitive impact of the education revolution: A possible cause of the Flynn Effect on population IQ. Intelligence 49: 144-158.

Bietenbeck, Jan. 2014. Teaching practices and cognitive skills. Labour Economics 30: 143-153.

Bishop, John H. 1989. Is the test score decline responsible for the productivity growth decline? American Economic Review 79(1): 178-197.

Carroll, John B. 1993. Human Cognitive Abilities. Cambridge, UK: Cambridge University Press. 
Carlsson, Magnus, Gordon Dahl, Björn Öckert, and Dan-Olof Rooth. 2015. The effect of schooling on cognitive skills. Review of Economics and Statistics 97(3): 533-547.

Carlstedt, Berit. 2000. Cognitive abilities: Aspects of structure, process and measurement. $\mathrm{PhD}$ diss., University of Gothenburg.

Carlstedt, Berit and Bertil Mårdberg. 1993. Construct validity of the Swedish enlistment battery. Scandinavian Journal of Psychology 34(4): 353-362.

Castex, Gonzalo and Evgenia Kogan Dechter. 2014. The changing roles of education and ability in wage determination. Journal of Labor Economics 32(4): 685-710.

Cattell, Raymond B. 1943. The measurement of adult intelligence. Psychological Bulletin 40(3): 153-193.

Cliffordson, Christina and Jan-Eric Gustafsson. 2008. Effects of age and schooling on intellectual performance: Estimates obtained from analysis of continuous variation in age and length of schooling. Intelligence 36(2): 143-152.

Cunha, Flavio, James J. Heckman, Lance Lochner, and Dimitriy V. Masterov. 2006. Interpreting the evidence on life cycle skill formation. In E. A. Hanushek, F. Welch (eds.), Handbook of the Economics of Education, Volume 1: 697-812. Amsterdam: North Holland.

Cunha, Flavio, James J. Heckman, and Susanne M. Schennach. 2010. Estimating the technology of cognitive and noncognitive skill formation. Econometrica 78(3): 883-931.

Cunha, Flávio, Irma Elo, and Jennifer Culhane. Forthcoming. Maternal subjective expectations about the technology of skill formation predict investments in children one year later. Journal of Econometrics.

Dahlbäck, Katharina and Anna Lyngfelt. 2017. Estetiska dimensioner i svenskämnets kursplaner från Lgr 69 till Lgr 11. Educare 1: 152-182.

Darling-Hammond, Linda, Lisa Flook, Channa Cook-Harvey, Brigid Barron, and David Osher. 2020. Implications for educational practice of the science of learning and development. Applied Developmental Science 24(2): 97-140.

Deary, Ian J. 2020. Intelligence: A Very Short Introduction. 2nd ed. New York: Oxford University Press.

Deming, David J. 2017. The growing importance of social skills in the labor market. Quarterly Journal of Economics 132(4): 1593-1640.

Dickens, William T. and James R. Flynn. 2001. Heritability estimates versus large environmental effects: the IQ paradox resolved. Psychological Review 108(2): 346-369.

Doepke, Matthias, Giuseppe Sorrenti, and Fabrizio Zilibotti. 2019. The economics of parenting. Annual Review of Economics 11: 55-84.

Edin, Per-Anders, Peter Fredriksson, Martin Nybom, and Björn Öckert. Forthcoming. The rising return to non-cognitive skill. American Economic Journal: Applied Economics. 
Falk, Armin, Anke Becker, Thomas Dohmen, Benjamin Enke, David Huffman, and Uwe Sunde. 2018. Global evidence on economic preferences. Quarterly Journal of Economics 133(4): 1645-1692.

Flanagan, Dawn P. and Shauna G. Dixon. 2014. The Cattell-Horn-Carroll theory of cognitive abilities. In Heather S. Davis, Heather L. Hatton, and Frank E. Vannest (eds.), Encyclopedia of Special Education. New York, NY: John Wiley and Sons.

Flynn, James R. 2007. What is Intelligence? Beyond the Flynn Effect. Cambridge, UK: Cambridge University Press.

Flynn, James R. 2012. Are We Getting Smarter? Rising IQ in the Twenty-First Century. Cambridge, UK: Cambridge University Press.

Flynn, James R. and Michael Shayer. 2018. IQ decline and Piaget: Does the rot start at the top? Intelligence 66: 112-121.

Flynn, James R. 2018. Reflections about intelligence over 40 years. Intelligence 70: 73-83.

Goldin, Claudia and Lawrence F. Katz. 2008. The Race between Education and Technology. Cambridge, Massachusetts: Harvard University Press.

Grönqvist, Erik and Erik Lindqvist. 2016. The making of a manager: Evidence from military officer training. Journal of Labor Economics 34(4): 869-898.

Gyllenram, André, Jörgen Hellström, and Niklas Hanes. 2015. Förmåga att hantera stress och individers beslut att äga aktier. Ekonomisk Debatt 43(1): 7-15.

Hanushek, Eric A. and Ludger Woessmann. 2008. The role of cognitive skills in economic development. Journal of Economic Literature 46(3): 607-668.

Härnqvist, Kjell. 1998. A longitudinal program for studying education and career development. University of Gothenburg Department of Education and Educational Research Report No. 1998:01.

Härnqvist, Kjell. 2000. Evaluation through follow-up. A longitudinal program for studying education and career development. In Carl-Gunnar Janson (ed.), Seven Swedish longitudinal studies in behavioral science: 76-114. Stockholm: Forskningsrådsnämnden.

Hauser, Robert M. and Min-Hsiung Huang. 1997. Verbal ability and socioeconomic success: A trend analysis. Social Science Research 26(3): 331-376.

Heckman, James J., Lance Lochner, and Christopher Taber. 1998. Explaining rising wage inequality: Explorations with a dynamic general equilibrium model of labor earnings with heterogeneous agents. Review of Economic Dynamics 1(1): 1-58.

Heckman, James J. and Stefano Mosso. 2014. The economics of human development and social mobility. Annual Review of Economics 6: 689-733.

Jensen, Arthur. 1998. The g Factor: The Science of Mental Ability. Westport, CT: Praeger.

Johansson, Annie-Maj and Per-Olof Wickman. 2012. Vad ska elever lära sig angående naturveten- 
skaplig verksamhet? En analys av svenska läroplaner för grundskolan under 50 år. Nordic Studies in Science Education 8(3): 197-212.

Jokela, Markus, Tuomas Pekkarinen, Matti Sarvimäki, Marko Terviö, and Roope Uusitalo. 2017. Secular rise in economically valuable personality traits. Proceedings of the National Academy of Sciences 114(25): 6527-6532.

Katz, Lawrence F. and Kevin M. Murphy. 1992. Changes in relative wages, 1963-1987: Supply and demand factors. Quarterly Journal of Economics 107(1): 35-78.

Lam, Long Fung and Tanya R. Lawlis. 2017. Feeding the brain - The effects of micronutrient interventions on cognitive performance among school-aged children: A systematic review of randomized controlled trials. Clinical Nutrition 36(4): 1007-1014.

Larsson, Hans Albin. 2011. Mot bättre vetande: En svensk skolhistoria. Stockholm: SNS Förlag.

Lindquist, Matthew J. 2005. Capital-skill complementarity and inequality in Sweden. Scandinavian Journal of Economics 107(4): 711-735.

Lindqvist, Erik and Roine Vestman. 2011. The labor market returns to cognitive and noncognitive ability: Evidence from the Swedish enlistment. American Economic Journal: Applied Economics 3(1): 101-128.

Löfdahl, Stellan E. 1987. Fysikämnet i svensk realskola och grundskola: kartläggning och alternativ ur fysikdidaktisk synvinkel. PhD diss., Uppsala University.

Lynn, Richard. 2009. Fluid intelligence but not vocabulary has increased in Britain, 1979-2008. Intelligence 37(3): 249-255.

Maguire, Eleanor A., Katherine Woollett, and Hugo J. Spiers. 2006. London taxi drivers and bus drivers: A structural MRI and neuropsychological analysis. Hippocampus 16(12): 10911101.

Markussen, Simen and Knut Røed. 2020. Economic mobility under pressure. Journal of the European Economic Association 18(4): 1844-1885.

Montiel Olea, José Luis and Mikkel Plagborg-Møller. 2019. Simultaneous confidence bands: Theory, implementation, and an application to SVARs. Journal of Applied Econometrics 34(1): 1-17.

Neisser, Ulric. 1997. Rising scores on intelligence tests: Test scores are certainly going up all over the world, but whether intelligence itself has risen remains controversial. American Scientist 85(5): 440-47.

Okagaki, Lynn and Robert J. Sternberg. 1993. Parental beliefs and children's school performance. Child Development 64(1): 36-56.

Pietschnig, Jakob and Martin Voracek. 2015. One century of global IQ gains: A formal metaanalysis of the Flynn effect (1909-2013). Perspectives on Psychological Science 10(3): 282306. 
Potrafke, Niklas. 2019. Risk aversion, patience and intelligence: Evidence based on macro data. Economics Letters 178: 116-120.

Prytz, Johan. 2015. Swedish mathematics curricula, 1850-2014: An overview. Proceedings of the Third International Conference on the History of Mathematics Education 309-326.

Rindermann, Heiner, David Becker, and Thomas R. Coyle. 2017. Survey of expert opinion on intelligence: The FLynn effect and the future of intelligence. Personality and Individual Differences 106: 242-247.

Roivainen, Eka. 2014. Changes in word usage frequency may hamper intergenerational comparisons of vocabulary skills: An ngram analysis of Wordsum, WAIS, and WISC test items. Journal of Psychoeducational Assessment 32(1): 83-87.

Roys, Nicolas A. and Christopher R. Taber. 2020. Skill prices, occupations, and changes in the wage structure for low skilled men. NBER Working Paper No. 26453.

Rönnlund, Michael, Berit Carlstedt, Yulia Blomstedt, Lars-Göran Nilsson, and Lars Weinehall. 2013. Secular trends in cognitive test performance: Swedish conscript data 1970-1993. Intelligence 41(1): 19-24.

Sanders, Carl and Christopher Taber. 2012. Life-cycle wage growth and heterogeneous human capital. Annual Review of Economics 4: 399-425.

Sato, Kazuo. 1967. A two-level constant-elasticity-of-substitution production function. Review of Economic Studies 34(2): 201-218.

Schaie, K. Warner, Sherry L. Willis, and Sara Pennak. 2005. An historical framework for cohort differences in intelligence. Research in Human Development 2(1-2): 43-67.

Simons, Daniel J., Walter R. Boot, Neil Charness, Susan E. Gathercole, Christopher F. Chabris, David Z. Hambrick, and Elizabeth A.L. Stine-Morrow. 2016. Do "brain-training" programs work? Psychological Science in the Public Interest 17(3): 103-186.

Skolöverstyrelsen. 1962. Läroplan för grundskolan. Skolöverstyrelsens skriftserie 60. Stockholm: SÖ-förlaget. Accessed at https: / / gupea.ub.gu.se/handle/2077/50232 on December 11, 2020.

Skolöverstyrelsen. 1969. Läroplan för grundskolan. Allmän del. Skolöverstyrelsen. Stockholm: Liber. Accessed at https://gupea.ub.gu.se/handle/2077/30902 on December $10,2020$.

Skolöverstyrelsen. 1980. Läroplan för grundskolan. Allmän del. Skolöverstyrelsen. Stockholm: Liber. Accessed at https://gupea.ub.gu.se/handle/2077/31016 on December $11,2020$.

Statens offentliga utredningar. 1957 års skolberedning; 3. 1960: 15. Kungl bibliotek.

Statistics Sweden. 2014a. Inkomst- och taxeringsregistret (IoT). https : / / www.scb.se/varatjanster/bestalla-mikrodata/vilka-mikrodata-finns/individregis 
ter/inkomst--och-taxeringsregistret-iot/. Received on October 13, 2014.

Statistics Sweden. 2014b. Flergenerationsregistret. http://www.sverigeis

iffror.scb.se/vara-tjanster/bestall-data-och-statistik/

bestalla-mikrodata/vilka-mikrodata-finns/individregister/

flergenerationsregistret/. Received on October 13, 2014.

Statistics Sweden. 2014c. Registret över slutbetyg från gymnasieskolan. https: //www.scb.se/vara-tjanster/bestalla-mikrodata/vilka-mikrodatafinns/individregister/registret-over-slutbetyg-fran-gymnasies kolan/. Received on October 13, 2014.

Statistics Sweden. 2016a. Longitudinell integrationsdatabas för Sjukförsäkringsoch Arbetsmarknadsstudier (LISA) 1990-2013. Background Facts 2016:1. Stockholm: Statistics Sweden. https://www.scb.se/contentassets /f0bc88c852364b6ea5c1654a0cc90234/dokumentation-av-lisa.pdf.

Accessed June 14, 2021.

Statistics Sweden. 2016b. Översättningsnycklar. Accessed at https://www.scb.se/ dokumentation/klassifikationer-och-standarder/standard-forsvensk-yrkesklassificering-ssyk/on January 6, 2021.

Statistics Sweden. 2020a. Registerbaserad arbetsmarknadsstatistik (RAMS). http://www.S verigeisiffror.scb.se/vara-tjanster/bestall-data-och-statistik/ bestalla-mikrodata/vilka-mikrodata-finns/individregister/regis terbaserad-arbetsmarknadsstatistik-rams/. Received on April 8, 2020.

Statistics Sweden. 2021. Longitudinell integrationsdatabas för sjukförsäkrings- och arbetsmarknadsstudier (LISA). https://www.scb.se/LISA/, Received on April 8, 2020. Last updated on April 9, 2021.

Svensson, Allan. 2011. Utvärdering genom uppföljning. Longitudinell individforskning under ett halvsekel. Gothenburg: Acta Universitatis Gothoburgensis.

Thavenius, Jan, ed. 1999. Svenskämnets historia. Lund: Studentlitteratur.

Trahan, Lisa, Karla K. Stuebing, Merril K. Hiscock, and Jack M. Fletcher. 2014. The Flynn effect: A meta-analysis. Psychological Bulletin 140(5): 1332-1360.

U.S. Bureau of Labor Statistics. 2015. Crosswalk between the 2008 International Standard Classification of Occupations to the 2010 SOC. Accessed at https://www.bls.gov/soc/ soccrosswalks.htm on December 28, 2020.

U.S. Bureau of Labor Statistics. 2019. May 2018 National Occupational Employment and Wage Estimates, United States. Accessed at https://www.bls.gov/oes/2018/may/oes nat.htm on November 14, 2020.

U.S. Department of Labor, Employment and Training Administration. 2020. O*NET 25.0 Database. 
Accessed at https: / / www.onetcenter.org/license_db.html on October 14, 2020. Wai, Jonathan and Martha Putallaz. 2011. The Flynn effect puzzle: A 30-year examination from the right tail of the ability distribution provides some missing pieces. Intelligence 39(6): 443455.

War Archives. 2016. Krigsarkivets Mönstringsregister. Received on October 27, 2016. 
Figure 1: Trends in skills and skill premia across birth cohorts 1962-1975, military enlistment sample
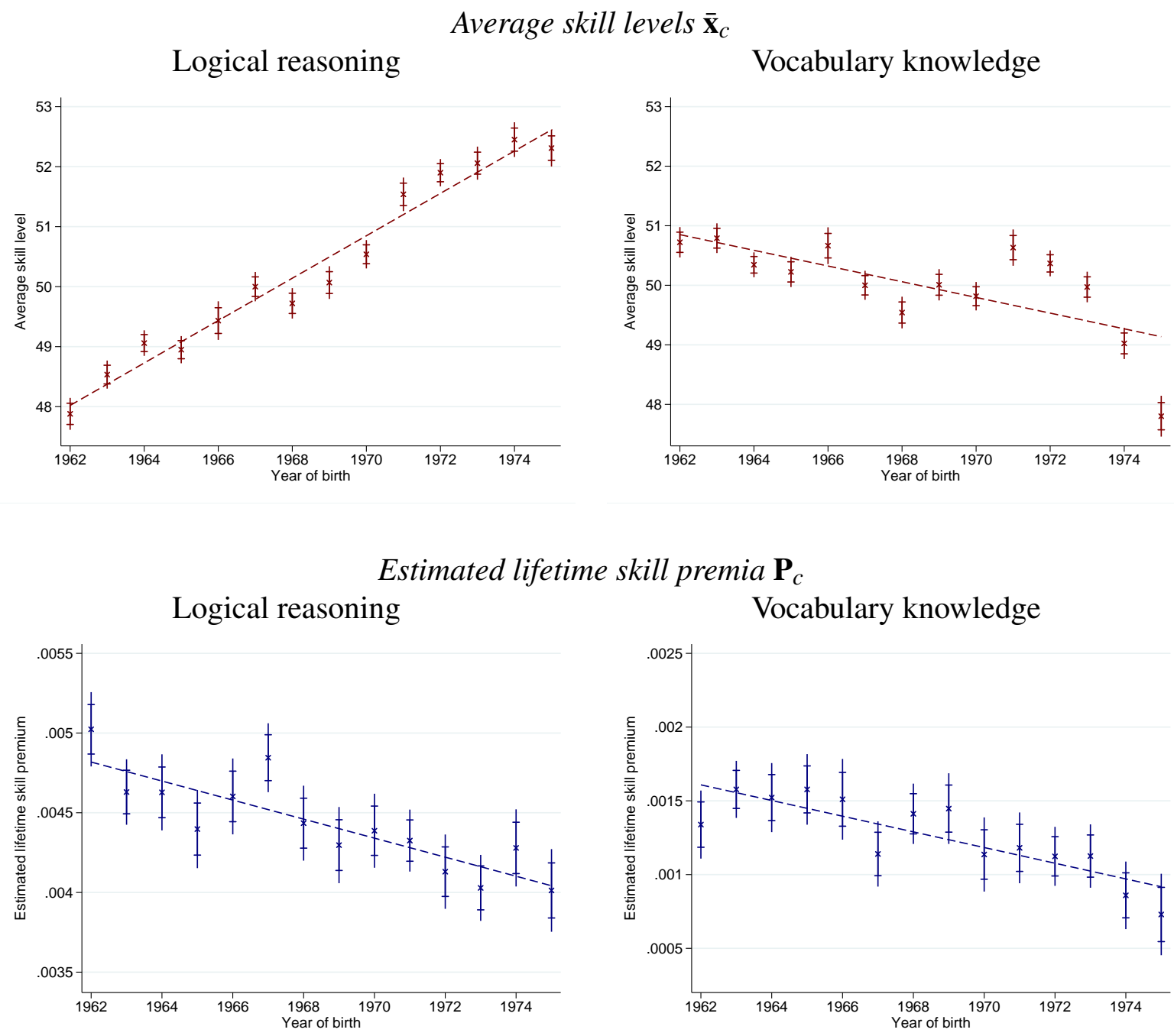

Notes: Data are from the military enlistment sample covering birth cohorts 1962-1975, with tests typically taken at age 18 or 19. The first row of plots depicts the average skill $\mathbf{x}_{c}$ for each birth cohort $c$. Skills are expressed as a percentile of the distribution for the 1967 birth cohort. The second row of plots depicts the estimated lifetime skill premia $\mathbf{P}_{c}$ for each birth cohort, constructed as described in Section 4.1. Each plot depicts both 95 percent pointwise confidence intervals (inner intervals, marked by dashes) and 95 percent uniform confidence intervals (outer intervals, marked by line segments). Pointwise confidence intervals are based on standard errors from a nonparametric bootstrap with 50 replicates. Uniform confidence intervals are computed as sup-t bands following Montiel Olea and Plagborg-Møller (2019). Each plot depicts the line of best fit through the estimated points. 
Figure 2: Evolution of relative skill levels and relative skill premia, military enlistment sample

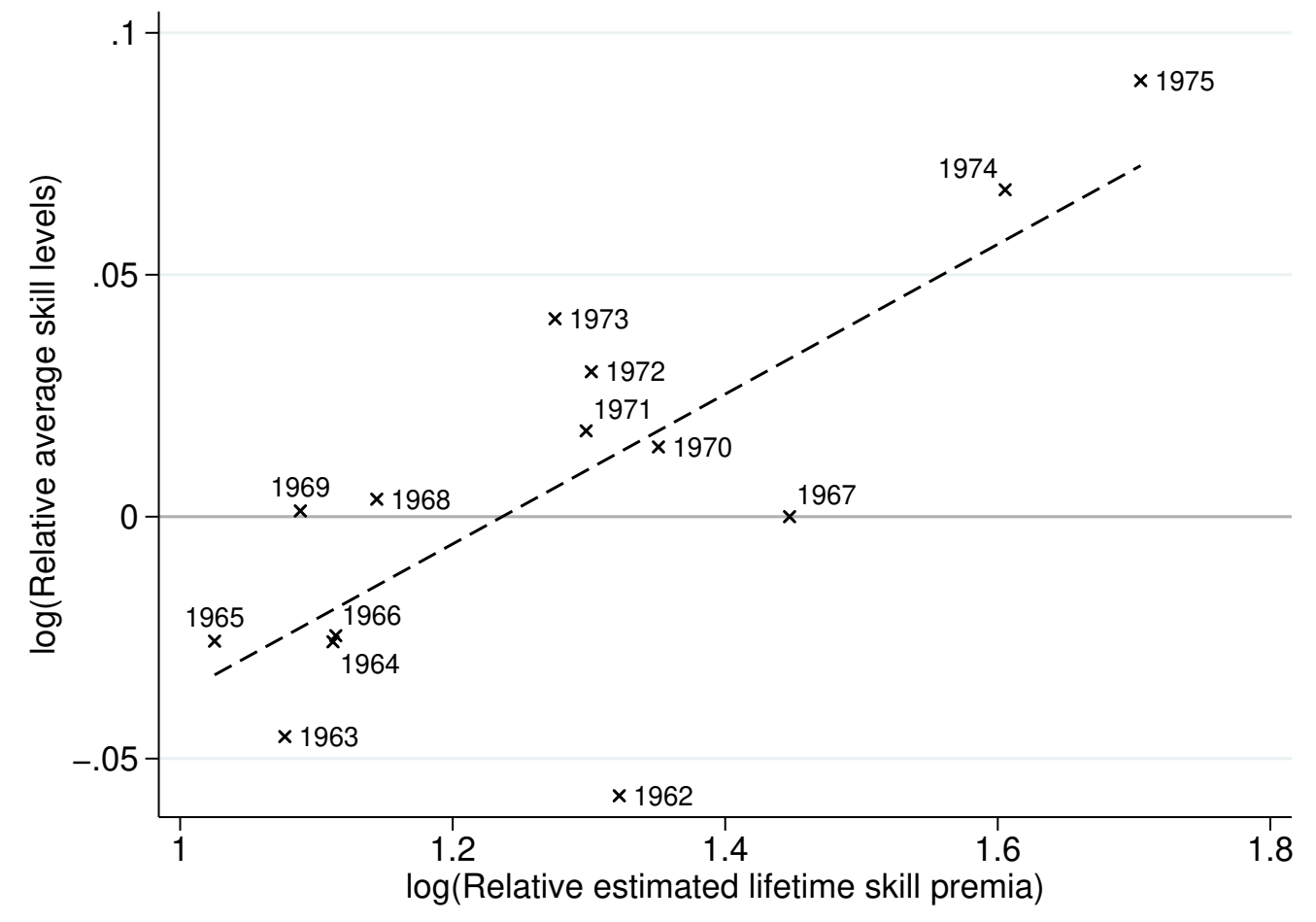

Notes: Data are from the military enlistment sample covering birth cohorts 1962-1975, with tests typically taken at age 18 or 19 . The plot shows a scatterplot of the natural logarithm of the relative average skill levels, $\ln \left(\bar{x}_{c 1} / \bar{x}_{c 2}\right)$, against the natural logarithm of the relative estimated lifetime skill premia, $\ln \left(P_{c 1} / P_{c 2}\right)$. The dashed line depicts the line of best fit. 
Figure 3: Evolution of relative skill levels and relative skill premia, survey sample

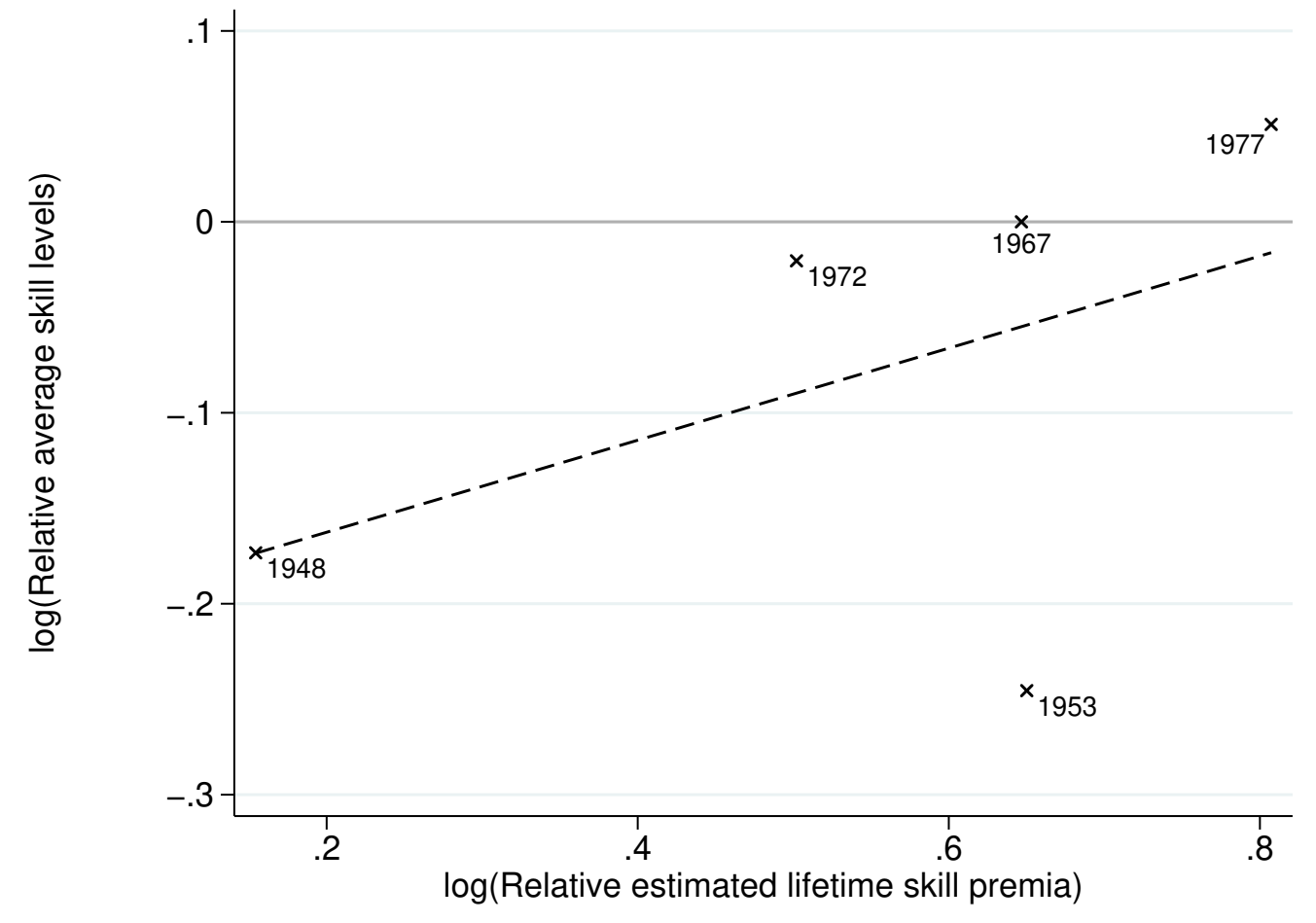

Notes: Data are from the survey sample covering birth cohorts 1948, 1953, 1967, 1972, and 1977, with tests typically taken at age 13. The plot shows a scatterplot of the natural logarithm of the relative average skill levels, $\ln \left(\bar{x}_{c 1} / \bar{x}_{c 2}\right)$, against the natural logarithm of the relative estimated lifetime skill premia, $\ln \left(P_{c 1} / P_{c 2}\right)$. The dashed line depicts the line of best fit. 
Figure 4: Decomposition of change in average skill level, military enlistment sample

\section{Logical reasoning}

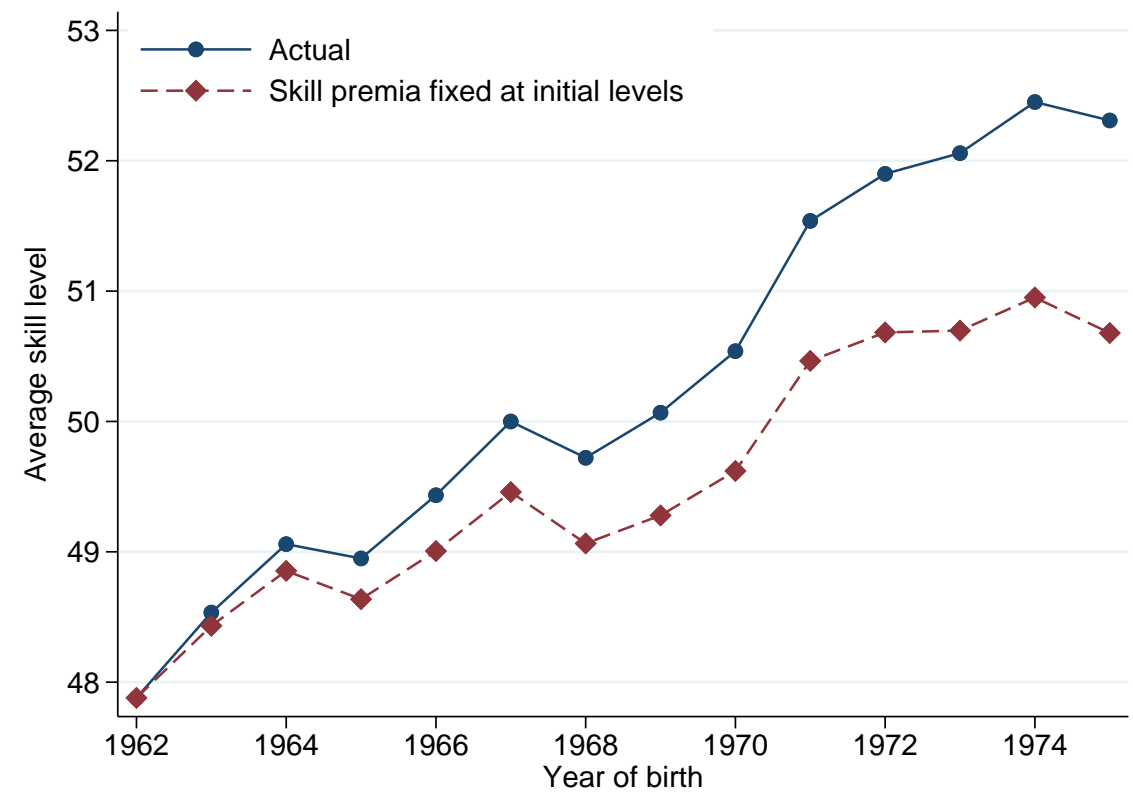

\section{Vocabulary knowledge}

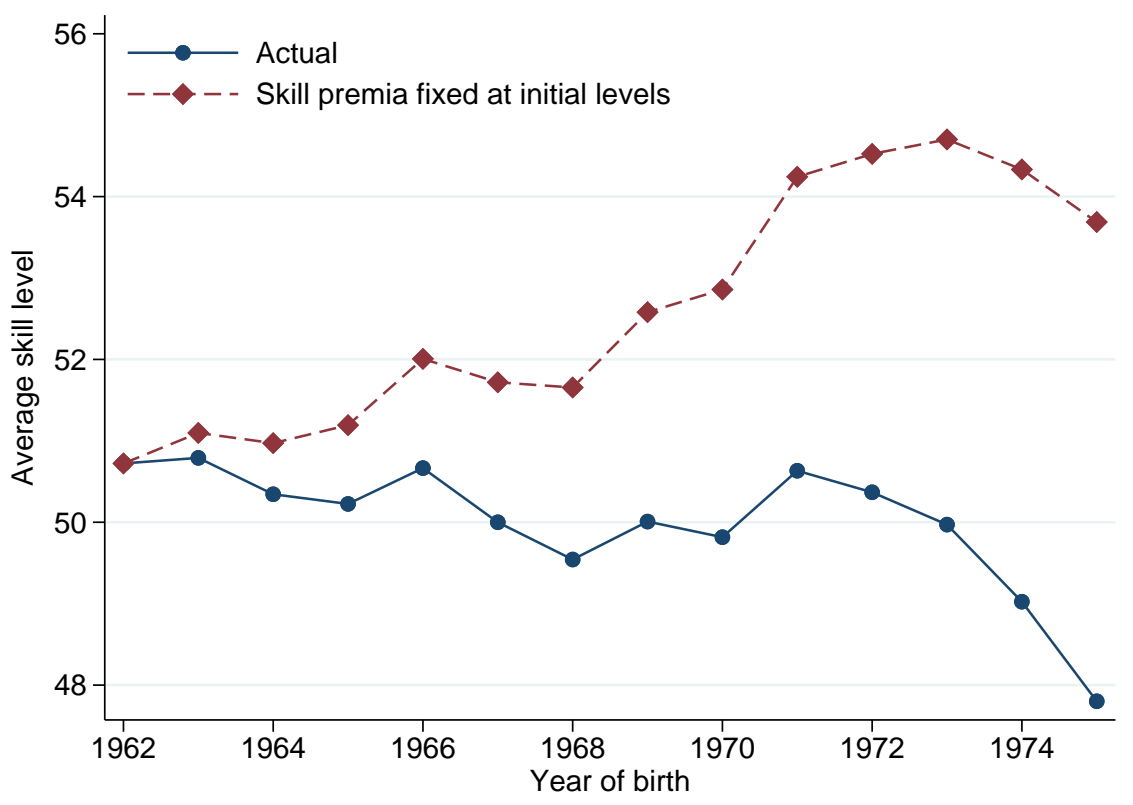

Notes: Data are from the military enlistment sample covering birth cohorts 1962-1975, with tests typically taken at age 18 or 19. Each plot depicts the average skill $\overline{\mathbf{x}}_{c}$ for each birth cohort $c$ ("Actual") and the predicted average skill $\tilde{\mathbf{x}}_{c}\left(\mathbf{P}_{\underline{c}}\right)$ under the counterfactual in which lifetime skill premia remain at the level estimated for the 1962 birth cohort ("Skill premia fixed at initial levels"). Skills are expressed as a percentile of the distribution for the 1967 birth cohort. 
Figure 5: Sensitivity to departures from zero average relative supply shock

\section{Logical reasoning}

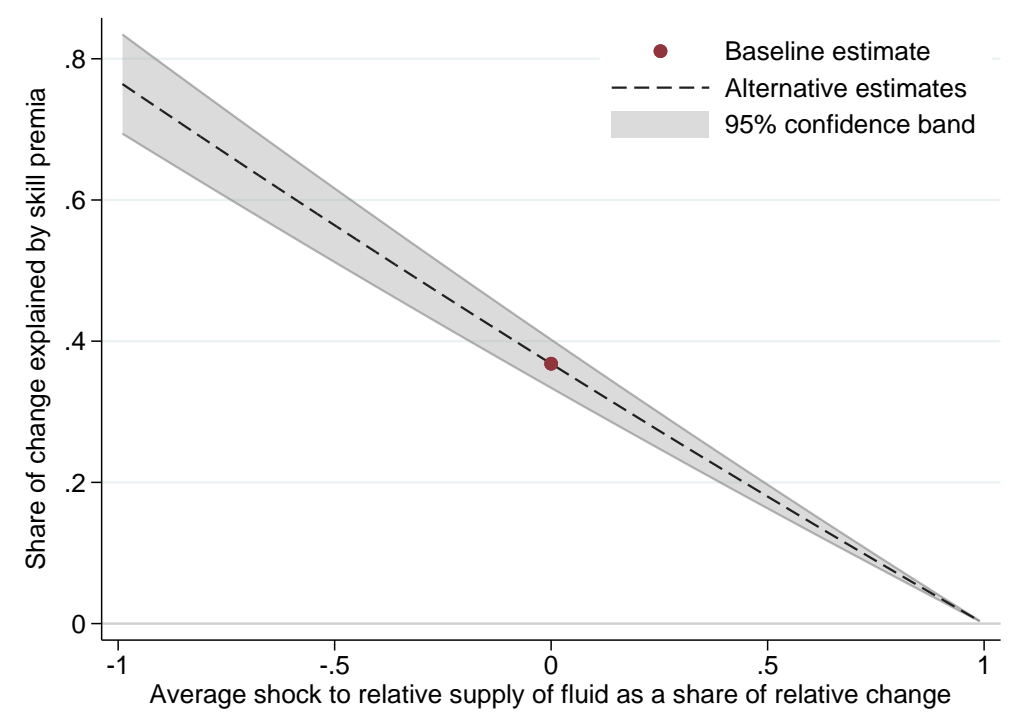

\section{Vocabulary knowledge}

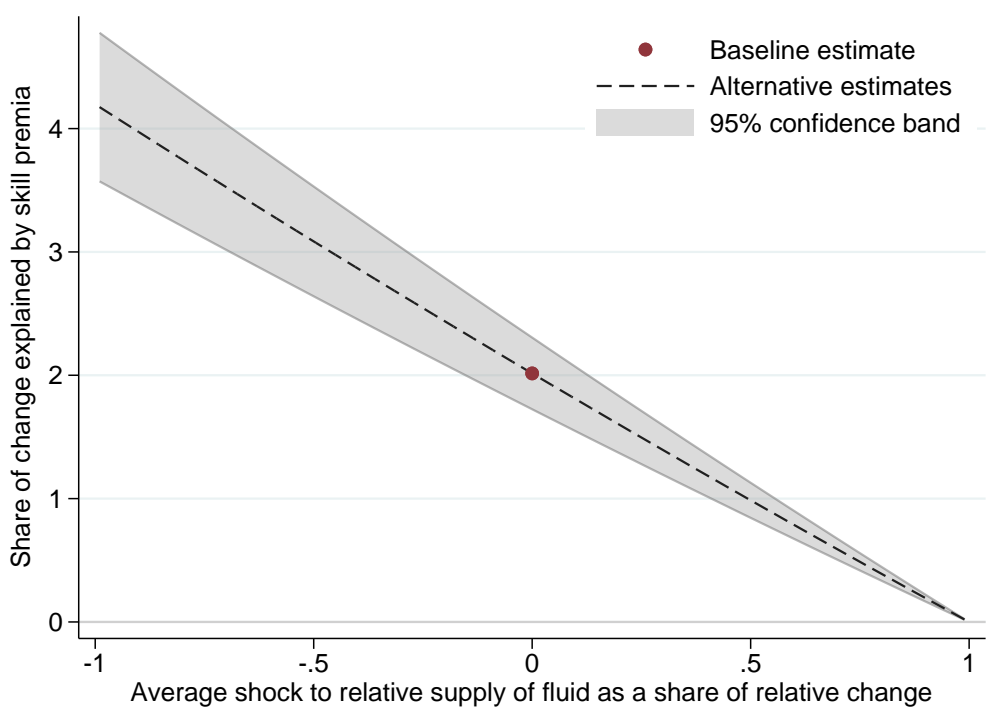

Notes: Data are from the military enlistment sample covering birth cohorts 1962-1975, with tests typically taken at age 18 or 19. In each plot, the curve labeled "Alternative estimates" depicts the estimated share $1-\frac{\tilde{x}_{\bar{c} j}\left(\mathbf{P}_{\underline{c}}\right)-\tilde{x}_{\underline{c}}\left(\mathbf{P}_{\underline{c}}\right)}{\bar{x}_{\bar{c} j}-\bar{x}_{\underline{c} j}}$ of the change in observed skills on dimension $j$ explained by the change in skill premia (y-axis) as a function of the average relative supply shock $-\frac{1}{\bar{c}-\underline{c}} \sum_{c=\underline{c}}^{\bar{c}-1}\left[\ln \left(\frac{K_{c+1,1}}{K_{c+1,2}}\right)-\ln \left(\frac{K_{c 1}}{K_{c 2}}\right)\right]$ (x-axis). The average relative supply shock is expressed as a share of the estimated change $\ln \left(\frac{\tilde{x}_{\bar{c} 1}}{\tilde{x}_{\bar{c} 2}}\right)-\ln \left(\frac{\tilde{x}_{c 1}}{\tilde{x}_{c 2}}\right)$ in relative skill levels between the 1962 and 1975 birth cohorts, with positive values implying changes in skill-producing technology that favor fluid relative to crystallized intelligence. The shaded region collects pointwise $95 \%$ confidence intervals obtained via a nonparametric bootstrap with 50 replicates. The estimate labeled "Baseline estimate" corresponds to the estimate in Panel A of Table 1 , obtained under Assumption 1 . 
Figure 6: Trends in the perceived importance of different skills in the survey of parents' perceptions

\section{Panel A: Which skill did parents encourage more in their own children?}

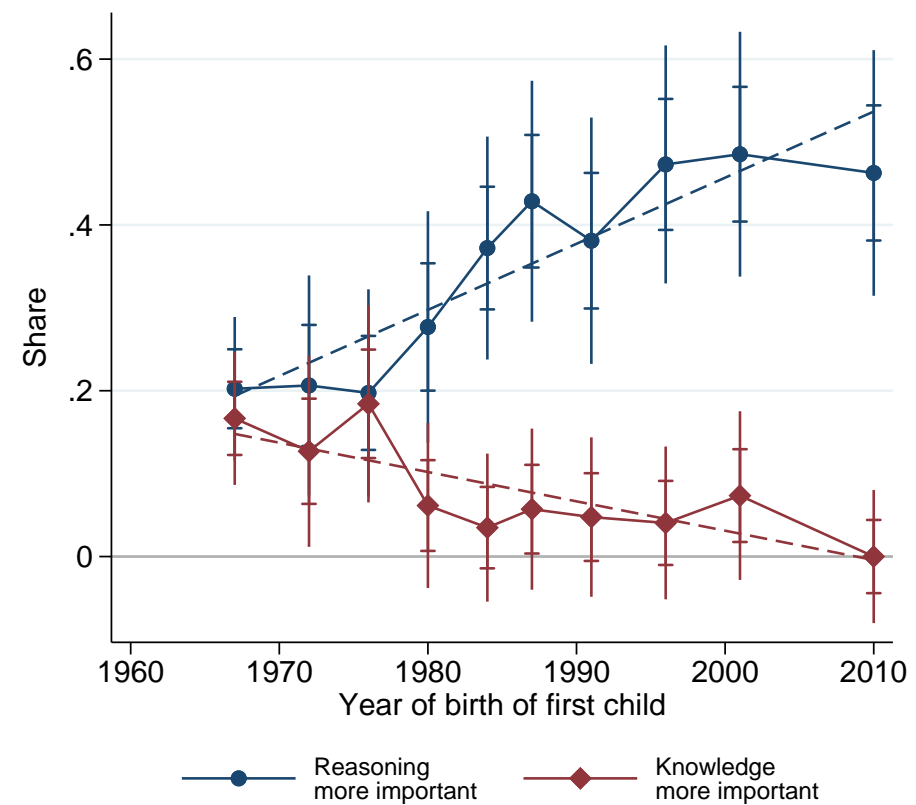

Panel B: Other measures of importance

Which is important today?

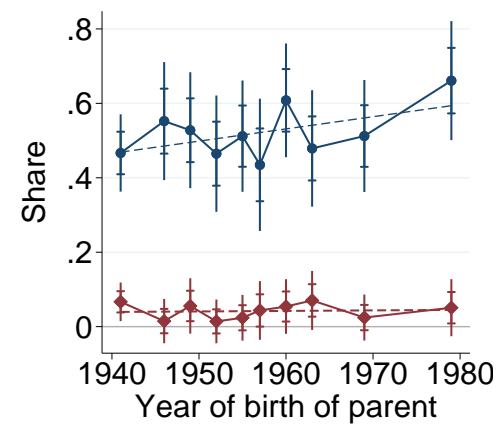

Which did own parents

emphasize?

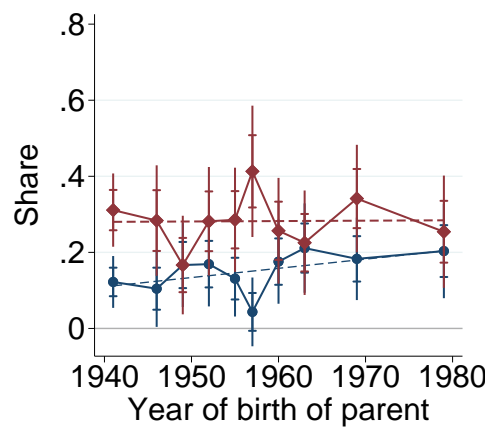

Which did own primary school emphasize?

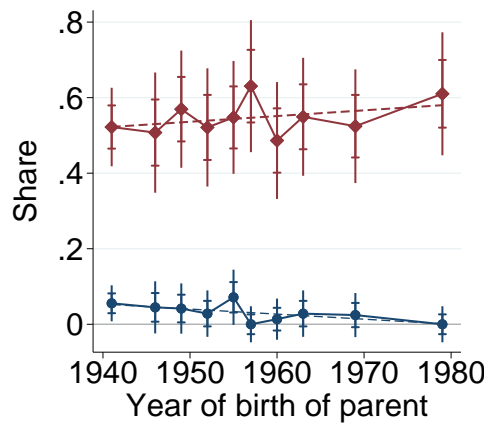

Notes: Data are from the original survey of parents' perceptions described in Section 3.2 Each figure shows the fraction of respondents rating reasoning as more important (blue circles) and the fraction rating knowledge as more important (red diamonds), separately by decile of the birth cohort of the respondent's first child (Panel A) or of the respondent (Panel B). Each plot depicts both 95 percent pointwise confidence intervals (inner intervals, marked by dashes) and 95 percent uniform confidence intervals (outer intervals, marked by line segments). Uniform confidence intervals are computed as sup-t bands following Montiel Olea and Plagborg-Møller (2019). Each plot depicts the line of best fit through the estimated points. 
Figure 7: Trends in emphasis on reasoning vs. knowledge in Swedish primary school Curricula

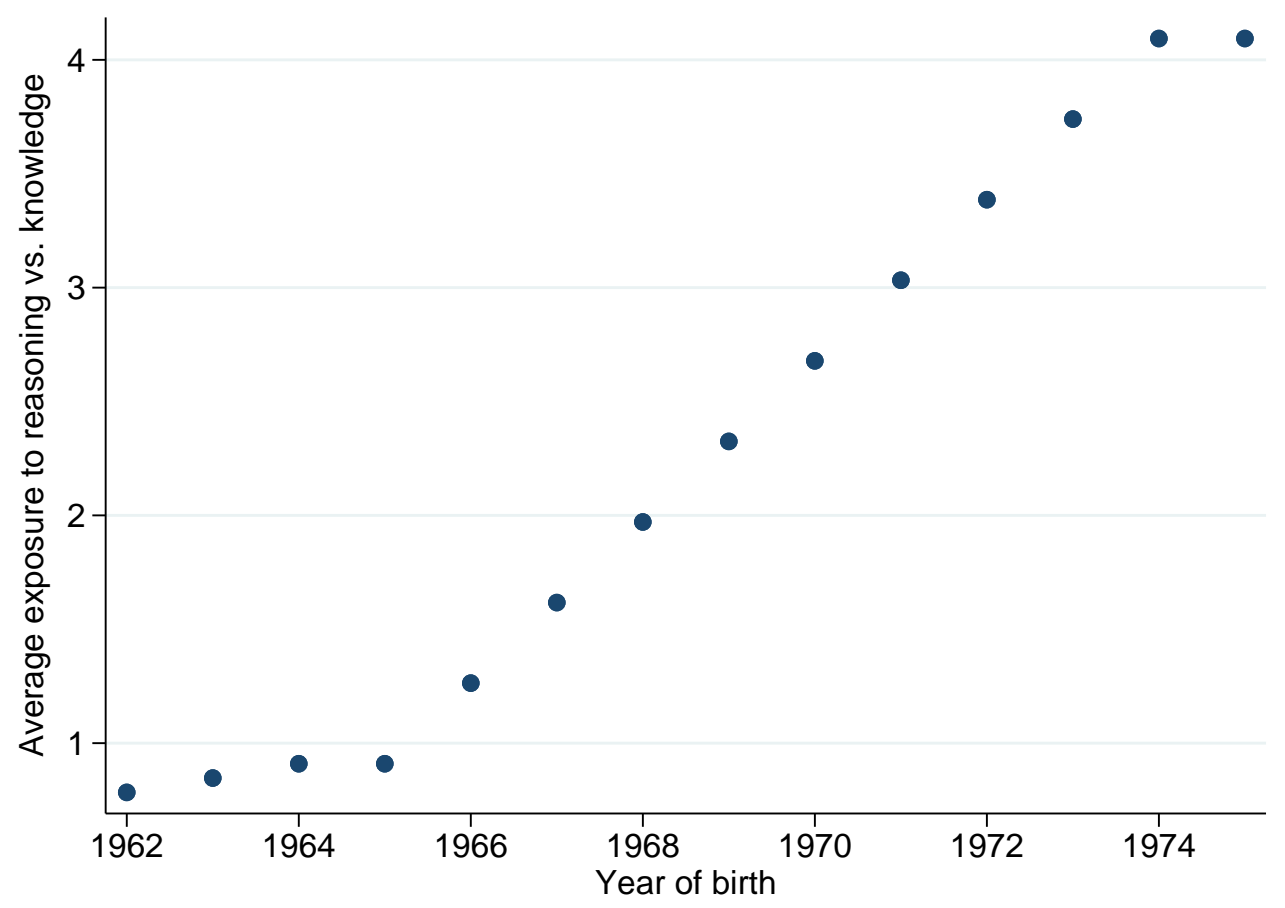

Notes: The plot shows the trend across birth cohorts in the emphasis on reasoning relative to knowledge in the Swedish primary school Curricula (Läroplan for grundskolan) prevailing during each cohort's primary schooling. We construct the series as follows. First, we associate each school year from 1963 through 1991 with the prevailing Curriculum, treating the 1962 Curriculum (Skolöverstyrelsen 1962) as prevailing from 1963 through 1971, the 1969 Curriculum (Skolöverstyrelsen 1969) as prevailing from 1972 through 1981, and the 1980 Curriculum (Skolöverstyrelsen 1980) as prevailing from 1982 through 1991. Second, for each Curriculum we obtain the ratio of the number of appearances of keywords related to reasoning to the number of appearances of keywords related to knowledge. We choose these keywords based on a close reading of the Curricula; see Appendix Figure 19 for details. Third, for each cohort, we define the average exposure to reasoning vs. knowledge as the average of the ratio of keyword appearances over the cohort's primary school years, which we take to be the school years beginning in the fall of the year that members of the cohort turn age 7 and ending in the spring of the year that members of the cohort turn age 16. 
Figure 8: Trends in the reasoning vs. knowledge intensity of men's occupations in Sweden

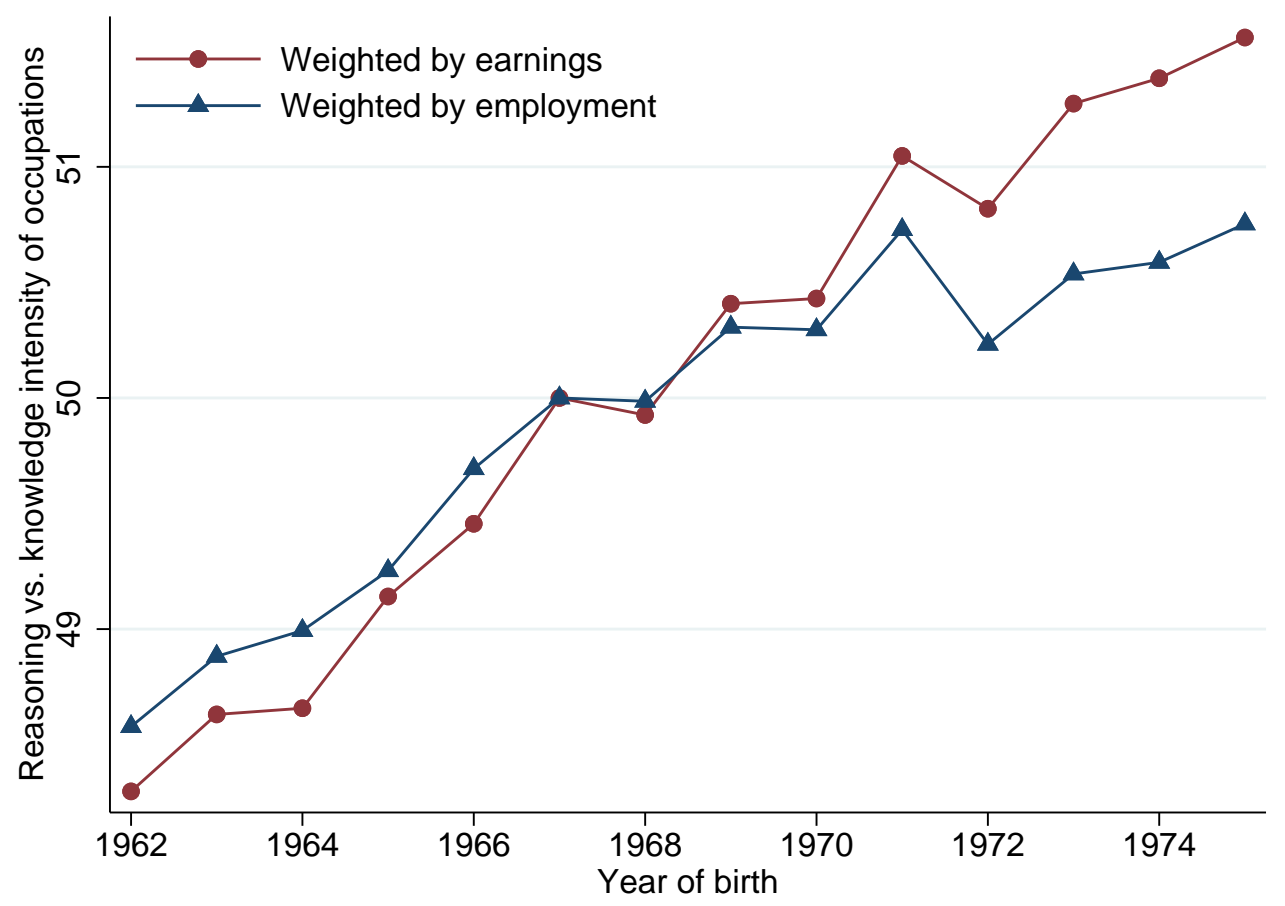

Notes: The plot shows the trend across birth cohorts in the reasoning vs. knowledge intensity of occupations in the Swedish Occupational Register, measured as the mean percentile rank of the reasoning vs. knowledge intensity of the given cohort's occupations in the distribution of either total employment ("weighted by employment") or total earnings ("weighted by earnings") for the cohort 1967. We measure the distribution of employment and earnings across occupations in the Swedish Occupational Register using data on employment histories from 2004 onwards from Statistics Sweden (2021), using 4-digit Swedish Standard Classification of Occupations 96 (SSYK 96) codes, and taking each individual's occupation to be the one observed in the available year closest to the year the individual turns 40 . For each O*NET 25.0 (2020) occupation we define the total importance of reasoning abilities by summing the importance scores of Inductive, Deductive, and Mathematical Reasoning abilities and dividing by the highest possible sum. Similarly, we define the total importance of knowledge by summing the importance scores of all knowledge categories and dividing by the highest possible sum. We then define the reasoning vs. knowledge intensity of each O*NET 25.0 (2020) occupation by taking the $\log$ of the ratio of the total importance of reasoning abilities to the total importance of knowledge. We define the reasoning vs. knowledge intensity of each Standard Occupational Classification 2010 (SOC 2010) occupation by taking the unweighted average reasoning vs. knowledge intensity of all corresponding occupations in O*NET 25.0 (2020). We match the occupations in the Swedish Occupational Register to SOC 2010 occupations by using the crosswalks from Statistics Sweden (2016b) and BLS (2015), manually excluding some matches to improve accuracy. We define the reasoning vs. knowledge intensity of each occupation in the Swedish Occupational Register by taking the employment-weighted mean reasoning vs. knowledge intensity of all corresponding SOC 2010 occupations, using May 2018 OES employment estimates (BLS 2019) as weights. Each series is normalized by adding a constant so that its value for the 1967 cohort is 50. This figure includes information from the O*NET 25.0 Database by the U.S. Department of Labor, Employment and Training Administration (USDOL/ETA). Used under the CC BY 4.0 license. $\mathrm{O} * \mathrm{NET} \circledast$ is a trademark of USDOL/ETA. We have modified all or some of this information. USDOL/ETA has not approved, endorsed, or tested these modifications. 
Table 1: Summary of data and model implications

Panel A: Baseline

\begin{tabular}{lcc} 
& Logical reasoning & Vocabulary knowledge \\
\hline Initial lifetime skill premium, 1962 & 0.0048 & 0.0016 \\
$P_{\underline{c} j}$ & $(0.0001)$ & $(0.0001)$ \\
Change in lifetime skill premium, 1962-1975 & -0.0007 \\
$P_{\bar{c} j}-P_{\underline{c} j}$ & -0.0008 & $(0.0001)$ \\
Initial average skill rank, 1962 & $(0.0001)$ & 50.72 \\
$\bar{x}_{\bar{c} j}$ & 47.88 & $(0.13)$ \\
Change in average skill rank 1962-1975 & $(0.14)$ & -2.92 \\
$\bar{x}_{\bar{c} j}-\bar{x}_{\underline{c} j}$ & 4.43 & $(0.21)$ \\
Under estimated model: & $(0.22)$ & 2.97 \\
Change in average skill rank, 1962-1975 at initial skill premia & & $(0.22)$ \\
$\tilde{x}_{\bar{c} j}\left(\mathbf{P}_{\underline{c}}\right)-\tilde{x}_{\underline{c} j}\left(\mathbf{P}_{\underline{c}}\right)$ & 2.80 & 2.0151 \\
Share of observed change explained by change in skill premia & $(0.21)$ & $(0.1483)$ \\
$1-\tilde{x}_{\bar{c} j}\left(\mathbf{P}_{\underline{c}}\right)-\tilde{x}_{\underline{c} j}\left(\mathbf{P}_{\underline{c}}\right)$ & 0.3681 & $(0.0175)$ \\
$\bar{x}_{\bar{c} j}-\bar{x}_{\underline{c} j}$ & & \\
Substitution parameter & & 3.61 \\
$\rho$ & & $(0.76)$ \\
{$[$ Implied elasticity of substitution $1 /(\rho-1)]$} & $0.3830]$ \\
\hline
\end{tabular}

Panel B: Accounting for Non-Cognitive Skills

\begin{tabular}{|c|c|c|}
\hline & Logical reasoning & Vocabulary knowledge \\
\hline Initial lifetime skill premium, 1962 & 0.0037 & 0.0009 \\
\hline$P_{\underline{c j}}$ & $(0.0001)$ & $(0.0001)$ \\
\hline Change in lifetime skill premium, 1962-1975 & -0.0009 & -0.0006 \\
\hline$P_{\bar{c} j}-P_{\underline{c} j}$ & $(0.0001)$ & $(0.0001)$ \\
\hline Initial average skill rank, 1962 & 47.88 & 50.72 \\
\hline $\bar{x}_{\bar{c} j}$ & $(0.14)$ & $(0.13)$ \\
\hline Change in average skill rank 1962-1975 & 4.43 & -2.92 \\
\hline $\bar{x}_{\bar{c} j}-\bar{x}_{\underline{c j}}$ & $(0.22)$ & $(0.21)$ \\
\hline \multicolumn{3}{|l|}{ Under estimated model: } \\
\hline Change in average skill rank, $1962-1975$ at initial skill premia & 3.27 & 3.46 \\
\hline$\tilde{x}_{\bar{c} j}\left(\mathbf{P}_{\underline{c}} ; \tilde{\mathbf{x}}_{\bar{c}, L+1: J}\right)-\tilde{x}_{\underline{c} j}\left(\mathbf{P}_{\underline{c}} ; \tilde{\mathbf{x}}_{\underline{c}, L+1: J}\right)$ & $(0.22)$ & $(0.24)$ \\
\hline Share of observed change explained by change in skill premia & 0.2617 & 2.1860 \\
\hline $1-\frac{\tilde{x}_{\bar{c} j}\left(\mathbf{P}_{\underline{c}} ; \tilde{\mathbf{x}}_{\bar{c}, L+1: J}\right)-\tilde{x}_{\underline{c} j}\left(\mathbf{P}_{\underline{c}} ; \tilde{\mathbf{x}}_{\underline{c}, L+1: J}\right)}{\bar{x}_{\bar{c} j}-\bar{x}_{\underline{c} j}}$ & $(0.0206)$ & $(0.1636)$ \\
\hline Substitution parameter & \multirow{3}{*}{\multicolumn{2}{|c|}{$\begin{array}{c}5.72 \\
(1.65) \\
{[0.2120]}\end{array}$}} \\
\hline$\rho$ & & \\
\hline [Implied elasticity of substitution $1 /(\rho-1)$ ] & & \\
\hline
\end{tabular}

Notes: Data are from the military enlistment sample covering birth cohorts 1962-1975. Standard errors in parentheses are obtained via a nonparametric bootstrap with 50 replicates. In Panel A, estimates of $\overline{\mathbf{x}}_{c}$ and $\mathbf{P}_{c}$ follow Figure 1 with the linear fit used as our estimate of $\mathbf{P}_{c}$. Estimates of $\tilde{\mathbf{x}}_{c}(\cdot)$ follow the proof of Proposition 11 . The unknown parameters are $\rho$ and $\left\{\mathbf{K}_{c}, \bar{S}_{c}\right\}_{c=c}^{\bar{c}}$. Take $\overline{\mathbf{x}}_{c}$ as our estimate of $\tilde{\mathbf{x}}_{c}$. Then estimate the elasticity of substitution $\frac{1}{\rho-1}$ following equation (7). Next, estimate the relative cost parameters $K_{c 2} / K_{c 1}$ in each cohort $c$ following equation (8). From the normalization used in the proof of Proposition 11, estimate $K_{c 1}$ following equation (9), from which estimate $K_{c 2}$ using the ratio $K_{c 2} / K_{c 1}$. Finally, estimate the skill budget $\bar{S}_{c}$ following equation $(10)$. In Panel B, estimates follow Section 6 with $L=2$ and $J=3$. We estimate $\mathbf{P}_{c, 1: L}$ from earnings regressions that control for a standardized measure of non-cognitive skill, excluding from the sample any worker missing information on non-cognitive skill. The rest of the analysis follows similarly to Panel A, following the logic in the proof of Proposition 3 . 


\section{A Proofs}

Proof of Proposition 1

From Assumption 1 and equation (5) we have that

$$
\frac{1}{\rho-1}=\frac{\ln \left(\frac{\tilde{x}_{\bar{c} 1}}{\tilde{x}_{\bar{c} 2}}\right)-\ln \left(\frac{\tilde{x}_{\underline{c} 1}}{\tilde{x}_{\underline{c} 2}}\right)}{\ln \left(\frac{P_{\bar{c} 1}}{P_{\bar{c} 2}}\right)-\ln \left(\frac{P_{\underline{c} 1}}{P_{\underline{c} 2}}\right)}
$$

where the existence of the ratio on the right is guaranteed because $\frac{P_{\bar{c} 1}}{P_{\bar{c} 2}} \neq \frac{P_{c 1}}{P_{\underline{c} 2}}$. Thus $\rho$ is identified.

Because $\mathbf{P}_{c}>0$, an analogue of equation (5) holds for any pair of dimensions $(1, j)$. Thus given $\rho$ the ratio $K_{c j} / K_{c 1}$ is identified for all $c$ and $j$ via the relation

$$
\ln \left(\frac{K_{c j}}{K_{c 1}}\right)=\ln \left(\frac{\tilde{x}_{c 1}}{\tilde{x}_{c j}}\right)-\frac{1}{\rho-1} \ln \left(\frac{P_{c 1}}{P_{c j}}\right) .
$$

From the budget constraint in (2) and the transformation function in (4), observe that multiplying $\mathbf{K}_{c}$ by any positive constant $\kappa$ is equivalent to multiplying $\bar{S}_{c}$ by $\kappa^{\frac{1-\rho}{\rho}}$. Therefore fix the scale of $\mathbf{K}_{c}$ by supposing that its average element equals one, i.e., $\sum_{j=1}^{J} K_{c j}=J$. Then $\sum_{j=1}^{J} K_{c j}=$ $\sum_{j=1}^{J}\left(K_{c j} / K_{c 1}\right) K_{c 1}=K_{c 1} \sum_{j=1}^{J}\left(K_{c j} / K_{c 1}\right)=J$, which from $(8)$ implies

$$
K_{c 1}=\frac{J}{\sum_{j=1}^{J} \frac{\tilde{x}_{c 1}}{\tilde{x}_{c j}}\left(\frac{P_{c j}}{P_{c 1}}\right)^{\frac{1}{\rho-1}}} .
$$

Thus $\mathbf{K}_{c}$ is identified for each cohort $c$ given $\rho$ and the ratios $K_{c j} / K_{c 1}$.

Finally, $\bar{S}_{c}$ is identified for all $c$ given $\rho$ and $\mathbf{K}_{c}$ because, from the solution to the worker's problem,

$$
\bar{S}_{c}=\frac{\tilde{x}_{c 1}\left(\sum_{j=1}^{J} P_{c j}^{\frac{\rho}{\rho-1}} K_{c j}^{-1}\right)^{\frac{1}{\rho}}}{P_{c 1}^{\frac{1}{\rho-1}} K_{c 1}^{-1}}
$$

Proof of Corollary 1

Let $\hat{\mathbf{P}}_{c}=\left|\alpha \mathbf{P}_{c}\right|=|\alpha| \mathbf{P}_{c}$ for $\alpha \neq 0$. Because $\hat{P}_{c 1} / \hat{P}_{c j}=P_{c 1} / P_{c j}$ for all $c$ and $j$, the arguments in the proof of Proposition 1 directly establish identification of $\rho$ and identification of $\mathbf{K}_{c}$ up to a 
normalization. Then $\bar{S}_{c}$ is identified for all $c$ given $\rho$ and $\mathbf{K}_{c}$ because

$$
\bar{S}_{c}=\frac{\tilde{x}_{c 1}\left(\sum_{j=1}^{J} P_{c j}^{\frac{\rho}{\rho-1}} K_{c j}^{-1}\right)^{\frac{1}{\rho}}}{P_{c 1}^{\frac{1}{\rho-1}} K_{c 1}^{-1}}=\frac{\tilde{x}_{c 1}\left(\sum_{j=1}^{J} \hat{P}_{c j}^{\frac{\rho}{\rho-1}} K_{c j}^{-1}\right)^{\frac{1}{\rho}}}{\hat{P}_{c 1}^{\frac{1}{\rho-1}} K_{c 1}^{-1}} .
$$

Proof of Proposition 2

From equation (1) we have that for each period $t$

$$
\begin{aligned}
\mathrm{E}\left(\ln \left(w_{i t}\right) \mid \mathbf{x}_{i}=\mathbf{x}, \mathbf{d}_{i t}=\mathbf{d}, c(i)=c\right) & =\mathrm{E}\left(B_{t, a(i, t)}+\mathbf{p}_{t, a(i, t)}^{\prime} \mathbf{x}_{i}+\ln \left(z_{i t}\right) \mid \mathbf{x}_{i}=\mathbf{x}, \mathbf{d}_{i t}=\mathbf{d}, c(i)=c\right) \\
& =B_{t, t-c}+\mathbf{p}_{t, t-c}^{\prime} \mathbf{x}+\mathrm{E}\left(\ln \left(z_{i t}\right) \mid \mathbf{x}_{i}=\mathbf{x}, \mathbf{d}_{i t}=\mathbf{d}, c(i)=c\right) .
\end{aligned}
$$

Because $\mathbf{x}_{i}=\tilde{\mathbf{x}}_{c(i)}+\mu_{i}$ for all $i$, we also have that

$$
\begin{aligned}
\mathrm{E}\left(\ln \left(z_{i t}\right) \mid \mathbf{x}_{i}=\mathbf{x}, \mathbf{d}_{i t}=\mathbf{d}, c(i)=c\right) & =\mathrm{E}\left(\ln \left(z_{i t}\right) \mid \tilde{\mathbf{x}}_{c}+\mu_{i}=\mathbf{x}, \mathbf{d}_{i t}=\mathbf{d}, c(i)=c\right) \\
& =\mathrm{E}\left(\ln \left(z_{i t}\right) \mid \mu_{i}=\mathbf{x}-\tilde{\mathbf{x}}_{c}, \mathbf{d}_{i t}=\mathbf{d}, c(i)=c\right) \\
& =\zeta_{t, t-c}+\tilde{\alpha} \mathbf{p}_{t, t-c}^{\prime}\left(\mathbf{x}-\tilde{\mathbf{x}}_{c}\right)+\mathbf{d}^{\prime} \beta_{t, t-c}
\end{aligned}
$$

where the last equality uses Assumption 2 It follows that

$$
\mathrm{E}\left(\ln \left(w_{i t}\right) \mid \mathbf{x}_{i}=\mathbf{x}, \mathbf{d}_{i t}=\mathbf{d}, c(i)=c\right)=\tilde{B}_{t, t-c}+\alpha \mathbf{p}_{t, t-c}^{\prime} \mathbf{x}+\mathbf{d}^{\prime} \beta_{t, t-c}
$$

where $\tilde{B}_{t, t-c}=\left(B_{t, t-c}+\zeta_{t, t-c}-\tilde{\alpha} \mathbf{p}_{t, t-c}^{\prime} \tilde{\mathbf{x}}_{c}\right)$ and $\alpha=1+\tilde{\alpha}$. Since $\tilde{\alpha} \neq-1$, we have $\alpha \neq 0$. Identification of $\mathbf{p}_{t, t-c}$ up to scale is then immediate, from which identification of $\mathbf{P}_{c}$ up to scale follows directly from equation (3).

\section{Proof of Proposition 3}

Recall that the worker maximizes $\mathbf{P}_{c(i)}^{\prime} \tilde{\mathbf{x}}_{i}$ subject to $\tilde{\mathbf{x}}_{i} \geq 0$ and $S_{c(i)}\left(\tilde{\mathbf{x}}_{i}\right) \leq \bar{S}_{c(i)}$, where $\tilde{\mathbf{x}}_{i}=\mathbf{x}_{i}-\mu_{i}$. Fixing non-cognitive skill investment at $\tilde{\mathbf{x}}_{i, L+1: J}=\tilde{\mathbf{x}}_{c(i), L+1: J} \geq 0$, and taking account of the form of the transformation function in (6), we can rewrite the worker's problem as maximizing $\mathbf{P}_{c(i), 1: L}^{\prime} \tilde{\mathbf{x}}_{i, 1: L}$ subject to $\tilde{\mathbf{x}}_{i, 1: L} \geq 0$ and $\left(\sum_{j=1}^{L} K_{c(i) j}^{\rho-1} \tilde{x}_{j}^{\rho}\right)^{\frac{1}{\rho}} \leq s_{c(i)}^{-1}\left(\bar{S}_{c(i)}, \tilde{\mathbf{x}}_{c(i), L+1: J}\right)$, where $s_{c(i)}^{-1}\left(\bar{S}_{c(i)}, \tilde{\mathbf{x}}_{c(i), L+1: J}\right)$ solves $s_{c(i)}\left(s_{c(i)}^{-1}\left(\bar{S}_{c(i)}, \tilde{\mathbf{x}}_{c(i), L+1: J}\right), \tilde{\mathbf{x}}_{c(i), L+1: J}\right)=\bar{S}_{c(i)}$, is unique by the strict monotonicity of $s_{c}(\cdot)$ in its first argument, and is strictly positive because the worker's problem is assumed to have a strictly positive solution. We have demonstrated that the worker's problem of choosing cognitive skills given non-cognitive skills is equivalent to the worker's problem in Section 2.3, replacing $J$ 
with $L$ and $\bar{S}_{c(i)}$ with $s_{c(i)}^{-1}\left(\bar{S}_{c(i)}, \tilde{\mathbf{x}}_{c(i), L+1: J}\right)$. The results of Proposition 1 and Corollary 1 thus apply given Assumption 1 .

Proof of Proposition 4

We have that

$$
\begin{aligned}
\mathrm{E}\left(\ln \left(w_{i t}\right) \mid \hat{\mathbf{x}}_{i}=\hat{\mathbf{x}}, \mathbf{d}_{i t}=\mathbf{d}, c(i)=c\right) & =\mathrm{E}\left(\mathrm{E}\left(\ln \left(w_{i t}\right) \mid \mathbf{x}_{i}=\mathbf{x}, \mathbf{d}_{i t}=\mathbf{d}, c(i)=c\right) \mid \hat{\mathbf{x}}_{i}=\hat{\mathbf{x}}\right) \\
& =\mathrm{E}\left(\tilde{B}_{t, t-c}+\alpha \mathbf{p}_{t, t-c}^{\prime} \mathbf{x}+\mathbf{d}^{\prime} \beta_{t, t-c} \mid \hat{\mathbf{x}}_{i}=\hat{\mathbf{x}}\right) \\
& =\tilde{B}_{t, t-c}+\alpha \mathbf{p}_{t, t-c, 1: L}^{\prime} \mathbf{x}_{1: L}+\alpha \mathbf{p}_{t, t-c, L+1: J}^{\prime} \mathbf{A}_{c}^{-1}\left(\hat{\mathbf{x}}_{L+1: J}\right)+\mathbf{d}^{\prime} \beta_{t, t-c}
\end{aligned}
$$

where the first step follows from the law of total expectation, the second from the proof of Proposition 2 , and the third from the invertibility of $\mathbf{A}_{c}$. Because $\mathbf{A}_{c}^{-1}(\cdot)$ is linear in $\hat{\mathbf{x}}_{L+1: J}$, identification of $\mathbf{p}_{t, t-c, 1: L}^{\prime}$ up to scale is immediate, from which identification of $\mathbf{P}_{c, 1: L}$ up to scale follows directly from equation (3). 


\section{B Identification of the Skill Supply Function with a Social Multiplier}

Suppose that $K_{c j}=\bar{K}_{c j} \bar{x}_{c j}^{-v}$ where $v \in[0,1)$ is a parameter governing the strength of social spillovers in skill investment and $\overline{\mathbf{K}}_{c} \in \mathbb{R}_{>0}^{J}$ is a vector of cost parameters. Each worker chooses skill investment taking the average skill $\overline{\mathbf{x}}_{c(i)}$ of their cohort $c(i)$ as given.

Assumption 3. (Zero average relative supply shock.) We assume that

$$
\frac{1}{\bar{c}-\underline{c}} \sum_{c=\underline{c}}^{\bar{c}-1}\left[\ln \left(\frac{\bar{K}_{c+1,1}}{\bar{K}_{c+1,2}}\right)-\ln \left(\frac{\bar{K}_{c 1}}{\bar{K}_{c 2}}\right)\right]=0 .
$$

Proposition 5. Under Assumption 3 if $\frac{P_{\bar{c} 1}}{P_{\bar{c} 2}} \neq \frac{P_{c 1}}{P_{\underline{c} 2}}$, then the skill supply function $\tilde{\mathbf{x}}_{c}(\cdot)$ for each cohort $c$ is identified from data $\left\{\left(\mathbf{P}_{c}, \tilde{\mathbf{x}}_{c}\right)\right\}_{c=\underline{c}}^{\bar{c}}$.

\section{Proof of Proposition 5}

In the model in Section 2.3 the skill supply function is given by

$$
\tilde{x}_{c j}\left(\mathbf{P}_{c}\right)=\frac{P_{c j}^{\frac{1}{\rho-1}} K_{c j}^{-1}}{\left(\sum_{j^{\prime}=1}^{J} P_{c j^{\prime}}^{\frac{\rho}{\rho-1}} K_{c j^{\prime}}^{-1}\right)^{\frac{1}{\rho}}} \bar{S}_{c}
$$

for each skill $j \in\{1, \ldots, J\}$. Recalling that $K_{c j}=\bar{K}_{c j} \bar{x}_{c j}^{-v}$ and imposing the equilibrium condition that $\tilde{\mathbf{x}}_{c}=\overline{\mathbf{x}}_{c}$ we have that

$$
\tilde{x}_{c j}\left(\mathbf{P}_{c}\right)=\frac{P_{c j}^{\frac{1}{\rho-1}} \bar{K}_{c j}^{-1}\left(\tilde{x}_{c j}\left(\mathbf{P}_{c}\right)\right)^{v}}{\left(\sum_{j^{\prime}=1}^{J} P_{c j^{\prime}}^{\frac{\rho}{\rho-1}} \bar{K}_{c j^{\prime}}^{-1}\left(\tilde{x}_{c j^{\prime}}\left(\mathbf{P}_{c}\right)\right)^{v}\right)^{\frac{1}{\rho}}} \bar{S}_{c}
$$

for each skill $j \in\{1, \ldots, J\}$. Define $\tilde{\mathbf{K}}_{c}$ such that $\tilde{K}_{c j}=\bar{K}_{c j}^{\frac{1}{1-v}}$ and notice that $\tilde{\mathbf{K}}_{c} \in \mathbb{R}_{>0}^{J}$ and that

$$
\frac{1}{\bar{c}-\underline{c}} \sum_{c=\underline{c}}^{\bar{c}-1}\left[\ln \left(\frac{\tilde{K}_{c+1,1}}{\tilde{K}_{c+1,2}}\right)-\ln \left(\frac{\tilde{K}_{c 1}}{\tilde{K}_{c 2}}\right)\right]=0
$$

by Assumption 3. Define $\tilde{\rho}$ such that

$$
\frac{1}{\tilde{\rho}-1}=\frac{1}{(\rho-1)(1-v)}
$$


and notice that $\tilde{\rho}>1$. Define $\tilde{S}_{c}=\bar{S}_{c}^{\frac{\rho}{\tilde{\rho}}}$ and notice that $\tilde{S}_{c}>0$. Then the unique solutions to the $J$ equations in 12 are given by

$$
\tilde{x}_{c j}\left(\mathbf{P}_{c}\right)=\frac{P_{c j}^{\frac{1}{\tilde{\rho}-1}} \tilde{K}_{c j}^{-1}}{\left(\sum_{j^{\prime}=1}^{J} P_{c j^{\prime}}^{\frac{\tilde{\rho}}{\rho}-1} \tilde{K}_{c j^{\prime}}^{-1}\right)^{\frac{1}{\tilde{\rho}}}} \tilde{S}_{c}
$$

for each skill $j \in\{1, \ldots, J\}$. Because (13) is isomorphic to (11), replacing $\mathbf{K}_{c}$ with $\tilde{\mathbf{K}}_{c}$, $\rho$ with $\tilde{\rho}$, and $\bar{S}_{c}$ with $\tilde{S}_{c}$, and because an analogue of Assumption 1 holds for $\tilde{\mathbf{K}}_{c}$, Proposition 1 applies directly. 


\section{Identification of Lifetime Skill Premia with Mismeasured Skills}

Let $\hat{\mathbf{x}}_{i}$ denote a measurement of $\mathbf{x}_{i}$. For simplicity we set aside the role of covariates $\mathbf{d}_{i t}$.

Assumption 4. The measurement error in each cohort c obeys

$$
\mathrm{E}\left(\hat{\mathbf{x}}_{i}-\mathbf{x}_{i} \mid \mu_{i}=\mu, c(i)=c\right)=0
$$

and

$$
\operatorname{Var}\left(\hat{\mathbf{x}}_{i}-\mathbf{x}_{i} \mid c(i)=c\right)=\hat{\alpha} \operatorname{Var}\left(\hat{\mathbf{x}}_{i} \mid c(i)=c\right),
$$

where the scalar $\hat{\alpha} \in[0,1)$ may be unknown.

Assumption 4 implies that the measurement error in $\hat{\mathbf{x}}_{i}$ has mean zero conditional on true skills and has variance proportional to both measured and true skills.

Assumption 5. The values of $z_{i t}$ in each period t obey

$$
\mathrm{E}\left(\ln \left(z_{i t}\right) \mid \hat{\mathbf{x}}_{i}-\mathbf{x}_{i}=\xi, \mu_{i}=\mu, c(i)=c\right)=\mathrm{E}\left(\ln \left(z_{i t}\right) \mid \mu_{i}=\mu, c(i)=c\right)=\zeta_{t, t-c}+\tilde{\alpha} \mathbf{p}_{t, t-c}^{\prime} \mu,
$$

where the scalars $\zeta_{t, t-c}$ and $\tilde{\alpha} \geq 0$ may be unknown.

Assumption 5 implies that a version of Assumption 2 holds, and that unobserved determinants of log earnings are mean-independent of the measurement error in skills.

Assumptions 4 and 5 are sufficient to identify the cohort-and-period-specific skill premia $\mathbf{p}_{t, t-c}$, and hence the lifetime skill premia $\mathbf{P}_{c}$, up to scale, from the conditional expectation function of the log of earnings given measured skills.

Proposition 6. Under Assumptions 4 and 5, for some scalar $\alpha>0$, a multiple $\alpha \mathbf{P}_{c}$ of the lifetime skill premia for each cohort $c$ is identified from the conditional expectation function of the log of earnings given measured skills,

$$
\mathrm{E}\left(\ln \left(w_{i t}\right) \mid \hat{\mathbf{x}}_{i}=\hat{\mathbf{x}}, c(i)=c\right),
$$

for each time period $t \in\{c+1, \ldots, c+A\}$.

Proof of Proposition 6

Fix a cohort $c$ and period $t$. From (14) and (15) we have that

$$
\operatorname{Var}\left(\hat{\mathbf{x}}_{i} \mid c(i)=c\right)=(1-\hat{\alpha})^{-1} \operatorname{Var}\left(\mathbf{x}_{i} \mid c(i)=c\right)
$$


From (1), (14), and (16) we have that

$$
\begin{aligned}
\operatorname{Cov}\left(\hat{\mathbf{x}}_{i}, \ln \left(w_{i t}\right) \mid c(i)=c\right) & =\operatorname{Cov}\left(\hat{\mathbf{x}}_{i}, \mathbf{p}_{t, t-c}^{\prime} \mathbf{x}_{i}+\ln \left(z_{i t}\right) \mid c(i)=c\right) \\
& =\operatorname{Cov}\left(\mathbf{x}_{i},(1+\tilde{\alpha}) \mathbf{p}_{t, t-c}^{\prime} \mathbf{x}_{i} \mid c(i)=c\right) \\
& =(1+\tilde{\alpha}) \operatorname{Var}\left(\mathbf{x}_{i} \mid c(i)=c\right) \mathbf{p}_{t, t-c}
\end{aligned}
$$

The population regression of $\ln \left(w_{i t}\right)$ on $\hat{\mathbf{x}}_{i}$ and a constant therefore yields coefficients

$$
\operatorname{Var}\left(\hat{\mathbf{x}}_{i} \mid c(i)=c\right)^{-1} \operatorname{Cov}\left(\hat{\mathbf{x}}_{i}, \ln \left(w_{i t}\right) \mid c(i)=c\right)=\alpha \mathbf{p}_{t, t-c}
$$

for $\alpha=(1-\hat{\alpha})(1+\tilde{\alpha})>0$. Because the population regression is available from the conditional expectation function, identification of $\mathbf{p}_{t, t-c}$ up to scale is then immediate, from which identification of $\mathbf{P}_{c}$ up to scale follows directly from equation (3). 


\section{Additional Tables and Figures}

Appendix Table 1: Number of individuals by birth cohort, military enlistment and survey samples

(a) Military enlistment data

\begin{tabular}{|c|c|c|c|}
\hline Birth cohort & Number of individuals & Birth cohort & Number of individuals \\
\hline 1962 & 52,317 & 1948 & 5,361 \\
\hline 1963 & 55,526 & 1953 & 4,699 \\
\hline 1964 & 58,639 & 1967 & 3,907 \\
\hline 1965 & 55,018 & 1972 & 3,899 \\
\hline 1966 & 39,056 & 1977 & 1,966 \\
\hline 1967 & 47,767 & Total & 19,832 \\
\hline 1968 & 49,965 & & \\
\hline 1969 & 48,850 & & \\
\hline 1970 & 48,815 & & \\
\hline 1971 & 51,108 & & \\
\hline 1972 & 50,824 & & \\
\hline 1973 & 47,353 & & \\
\hline 1974 & 47,923 & & \\
\hline 1975 & 38,069 & & \\
\hline Total & 691,230 & & \\
\hline
\end{tabular}

Notes: Each panel shows the number of individuals in each birth cohort for whom we measure valid logical reasoning and vocabulary knowledge test scores. Panel (a) shows counts for the military enlistment data. Panel (b) shows counts for the survey data. 


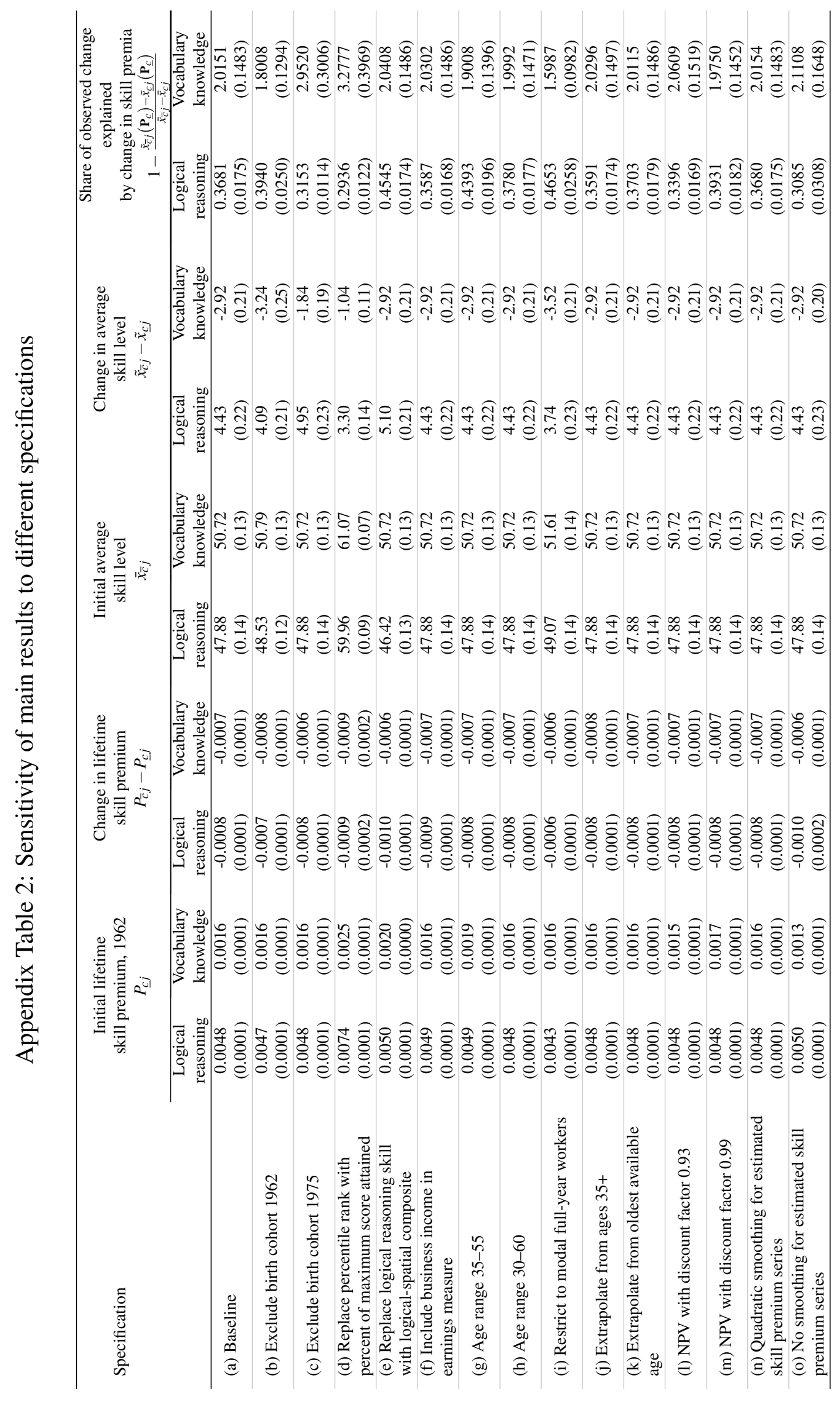

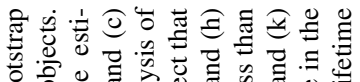

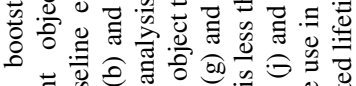

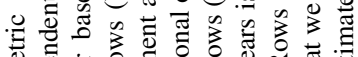
政 弪

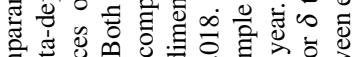

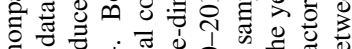

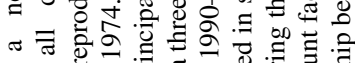

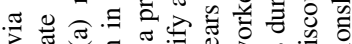

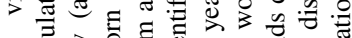
ఫ 는

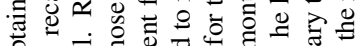

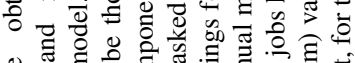
흐 ส

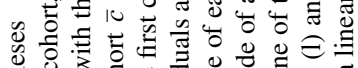

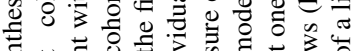

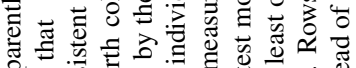
. $\cong \overline{0}$

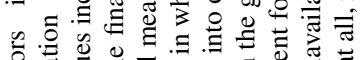

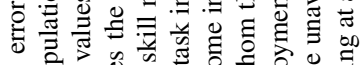
-

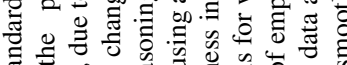

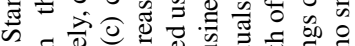

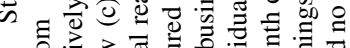

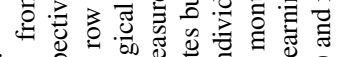

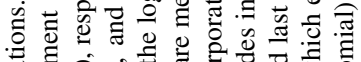

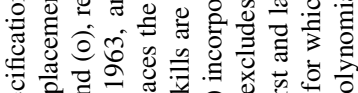

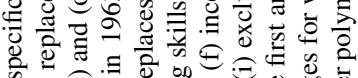

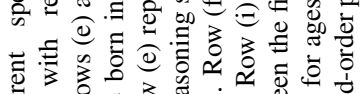

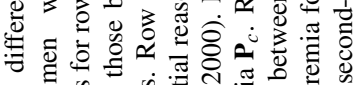

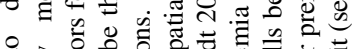

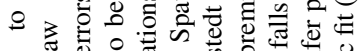

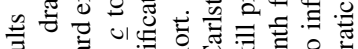

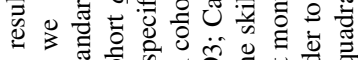

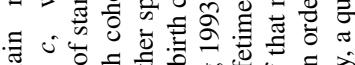
要 亏

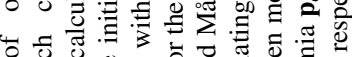

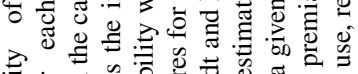

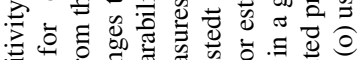

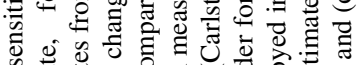

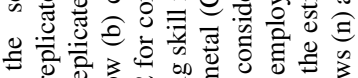

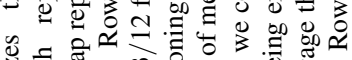

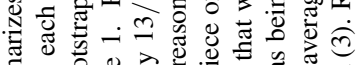
言

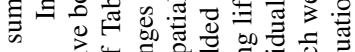
은 ब过

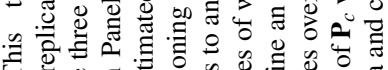

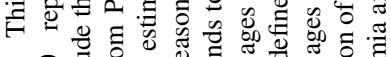

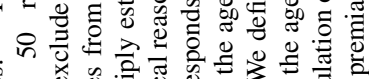

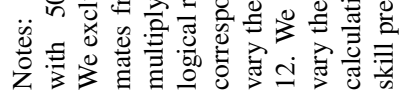


Appendix Table 3: Trends in lifetime skill premia using survey test scores as instruments

Panel A: Trends in lifetime skill premia

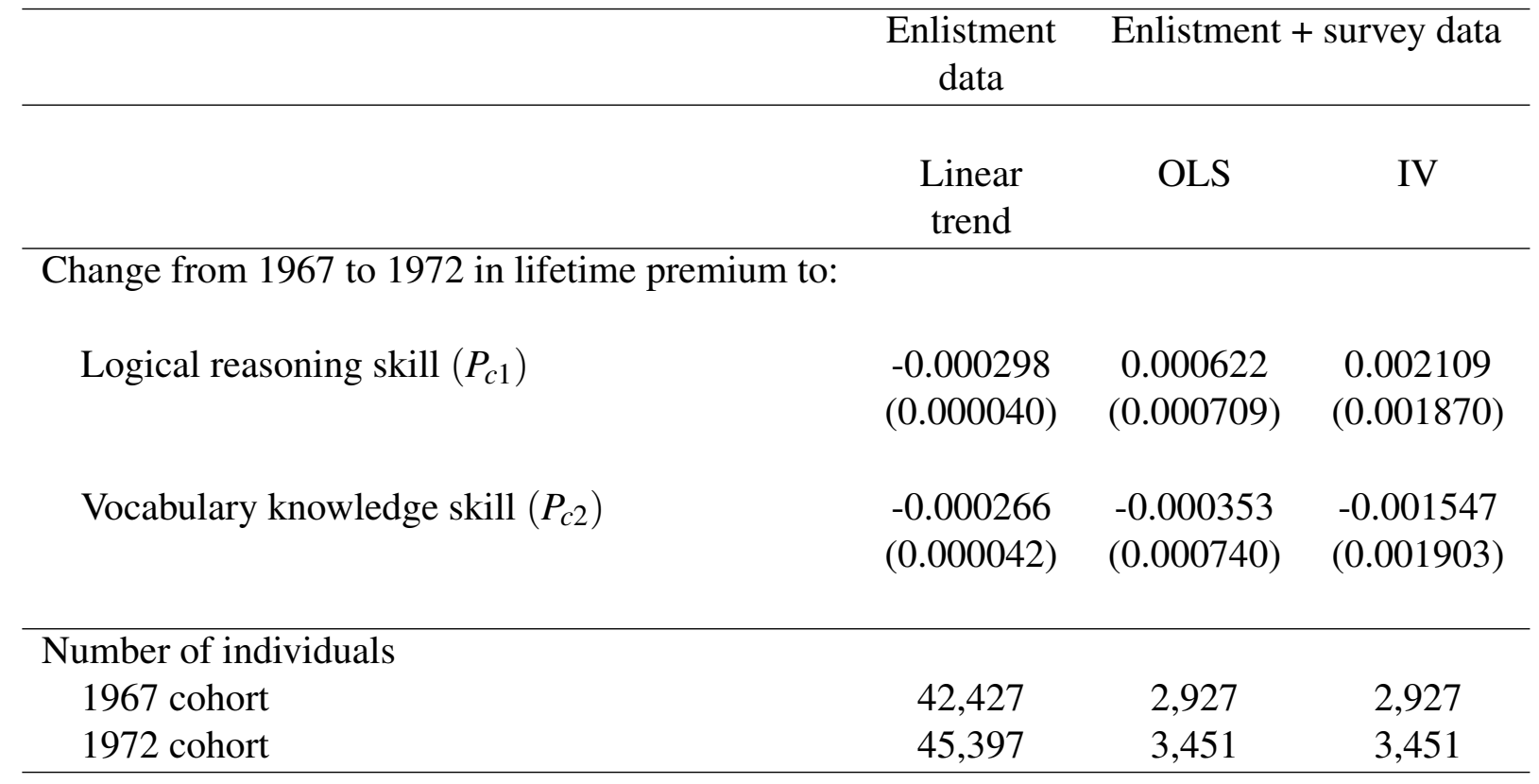

Panel B: Correlations in skill measures

\begin{tabular}{lccc}
\hline & \multicolumn{2}{c}{ Cohort } & \\
& 1967 & 1972 & Difference \\
\hline Correlation between survey and enlistment data in: & & & \\
Logical reasoning skill $\left(x_{i 1}\right)$ & 0.6557 & 0.6795 & 0.0237 \\
& $(0.0119)$ & $(0.0085)$ & $(0.0157)$ \\
Vocabulary knowledge skill $\left(x_{i 2}\right)$ & & & \\
& 0.6738 & 0.6910 & 0.0172 \\
& $(0.0106)$ & $(0.0080)$ & $(0.0129)$ \\
\hline Number of individuals & & & \\
\hline
\end{tabular}

Notes: Panel A compares the estimated change in lifetime skill premia between birth cohorts 1967 and 1972 based on different estimation methods. The first column is based on the linear trend fitted to the series of estimated lifetime skill premia for the enlistment data, where tests were typically taken at age 18 or 19, as shown in Figure 1 . The second and third columns are the differences between the lifetime skill premia for the two cohorts, as estimated on the set of individuals who have valid logical reasoning and vocabulary knowledge test scores in both the enlistment and survey data, where tests were typically taken at age 13. In the second (OLS) column, we estimate the lifetime skill premia for each cohort as the net present value of age-specific skill premia estimated via OLS, following the approach in Section 4.1. In the third (IV) column, we estimate the lifetime skill premia for each cohort as the net present value of age-specific skill premia estimated via IV, treating age-13 test scores as instruments for age-18/19 test scores. Panel B compares, between birth cohorts 1967 and 1972, the Pearson correlation of skills measured in the survey data with skills measured in the enlistment data. In both panels, standard errors in parentheses are obtained via a nonparametric bootstrap with 50 replicates. 


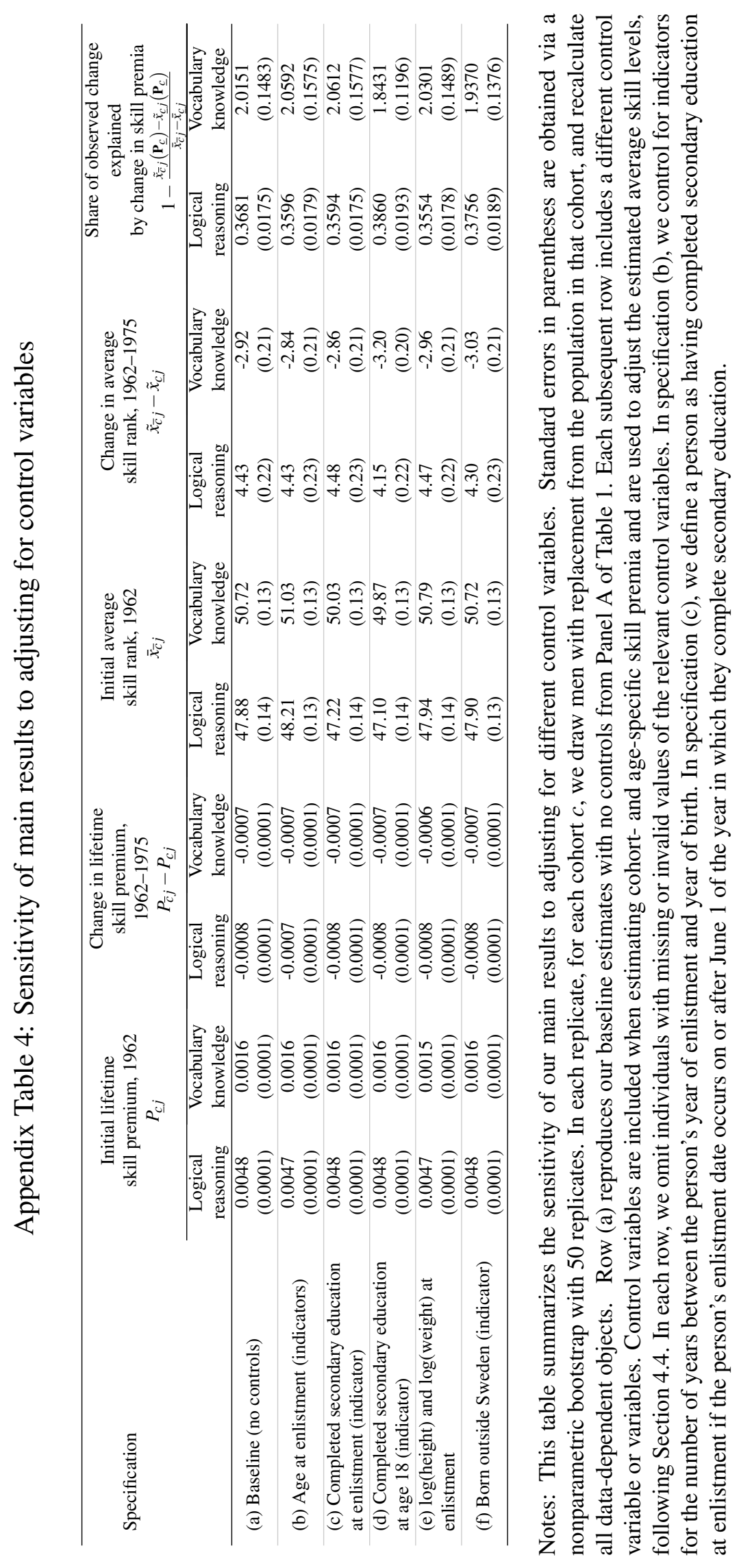




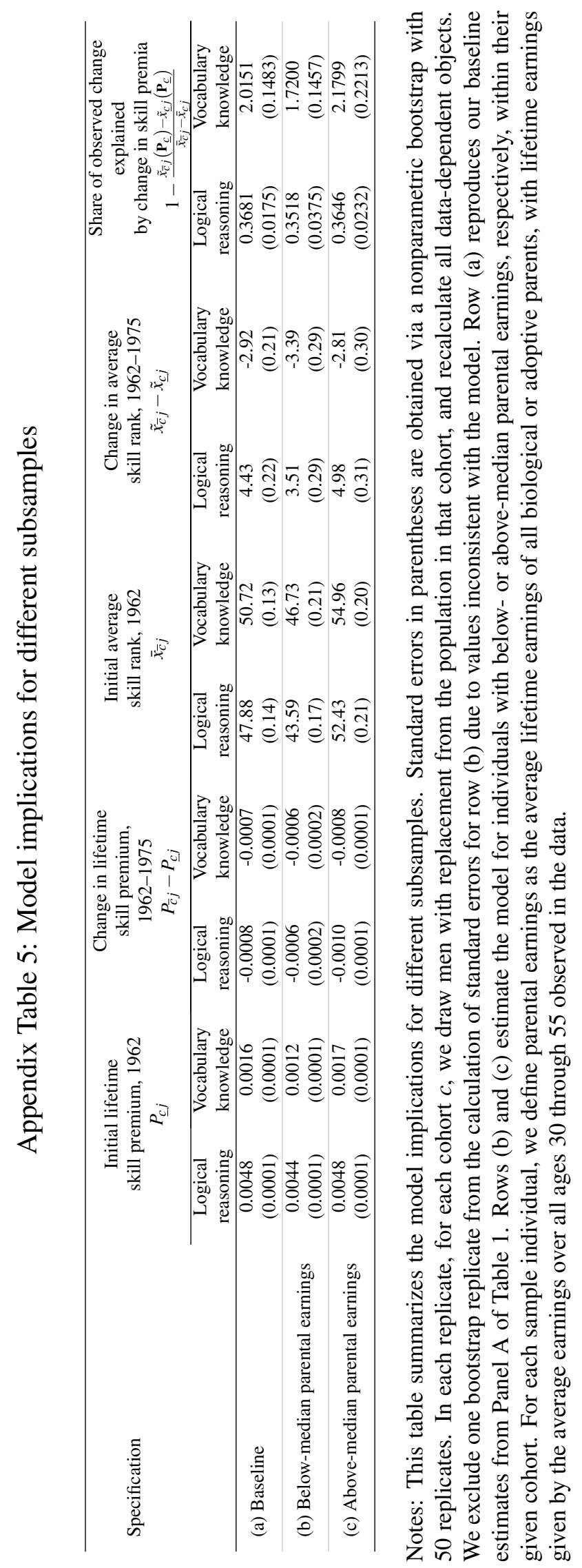


Appendix Figure 1: Trends in technical knowledge and technical knowledge premia across birth cohorts 1962-1973, military enlistment sample
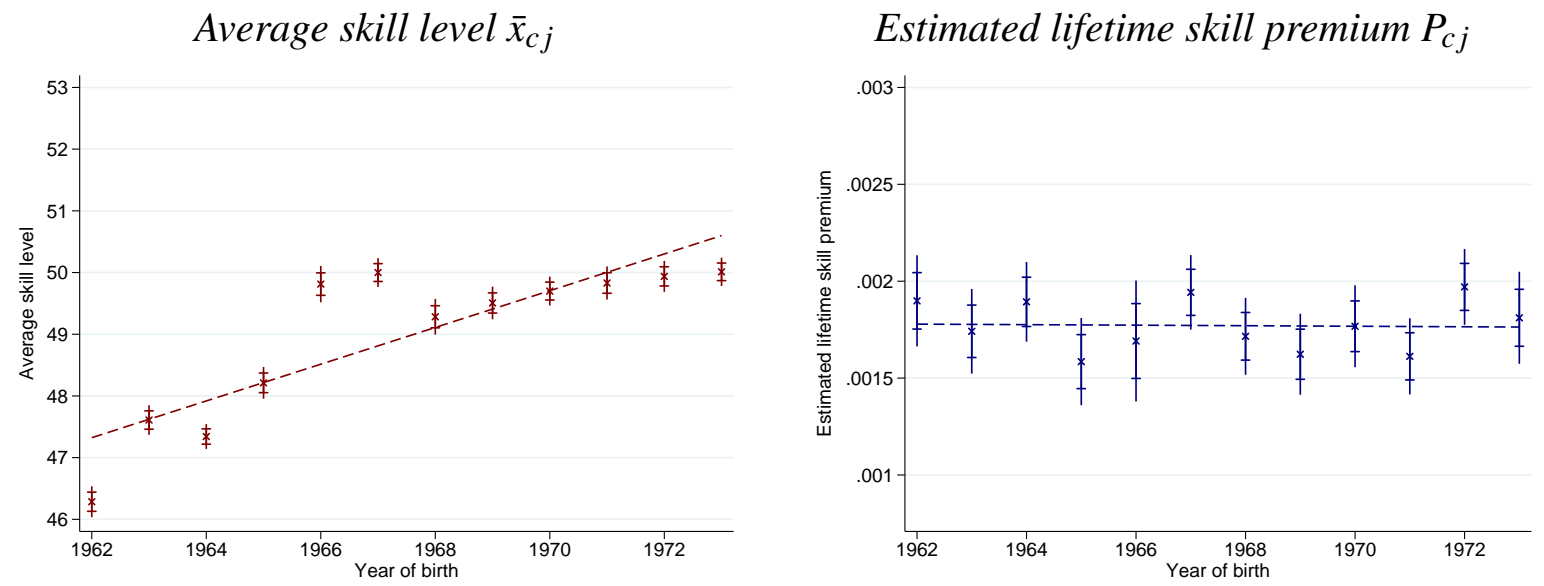

Notes: Data are from the military enlistment sample for birth cohorts 1962-1973. We exclude birth cohorts 1974 and 1975 because of significant amounts of missing data on technical knowledge test scores for these cohorts. The left plot depicts the average technical knowledge skill $\bar{x}_{c j}$ for each birth cohort $c$. Skills are expressed as a percentile of the distribution for the 1967 birth cohort. The right plot depicts the estimated lifetime skill premium $P_{c j}$ for technical knowledge for each birth cohort, constructed as described in Section 4.1. These skill premia are estimated controlling for logical reasoning and vocabulary knowledge skills. Each plot depicts both 95 percent pointwise confidence intervals (inner intervals, marked by dashes) and 95 percent uniform confidence intervals (outer intervals, marked by line segments). Uniform confidence intervals are computed as sup-t bands following Montiel Olea and Plagborg-Møller (2019). Each plot depicts the line of best fit through the estimated points. 
Appendix Figure 2: Trends in skills and skill premia across birth cohorts 1954-1961, military enlistment sample
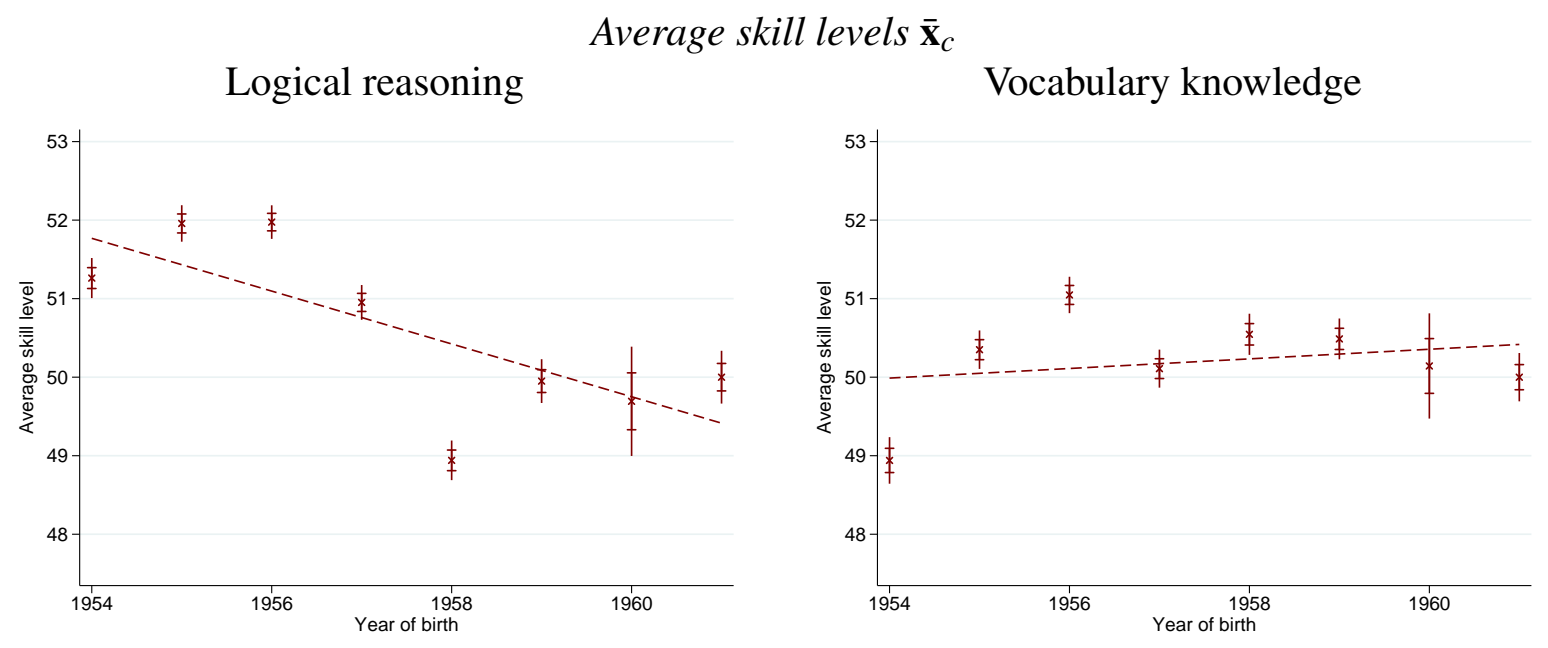

Estimated lifetime skill premia $\mathbf{P}_{c}$

Logical reasoning

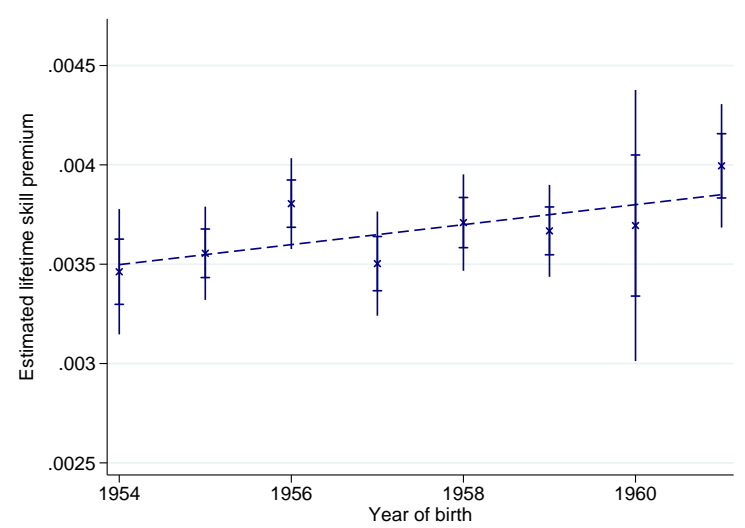

Vocabulary knowledge

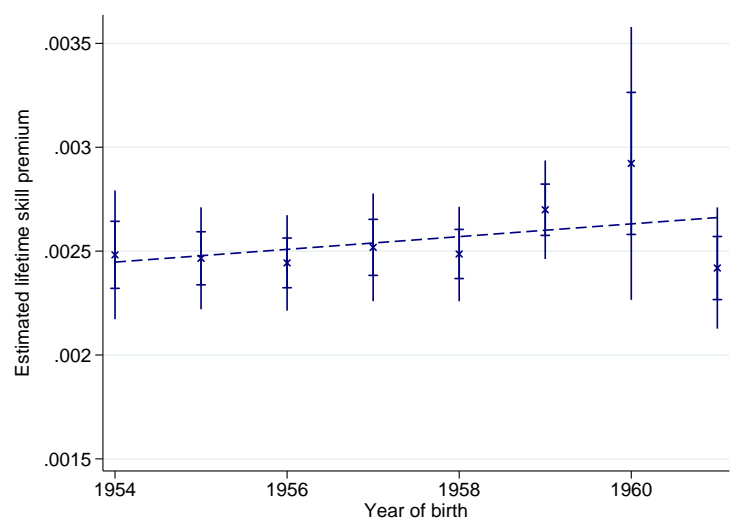

Notes: Data are from the military enlistment sample covering Swedish men born between 1954 and 1961 and who enlisted before 1980. For these birth cohorts, information on logical reasoning and vocabulary knowledge skills is based on scores from tests administered at military enlistment, called the Enlistment Battery 67. The first row of plots depicts the average skill $\overline{\mathbf{x}}_{c}$ for each birth cohort $c$. Skills are expressed as a percentile of the distribution for the 1961 birth cohort. The second row of plots depicts the estimated lifetime skill premia $\mathbf{P}_{c}$ for each birth cohort, constructed as described in Section 4.1. Each plot depicts both 95 percent pointwise confidence intervals (inner intervals, marked by dashes) and 95 percent uniform confidence intervals (outer intervals, marked by line segments). Uniform confidence intervals are computed as sup-t bands following Montiel Olea and Plagborg-Møller (2019). Each plot depicts the line of best fit through the estimated points. 


\section{Appendix Figure 3: Structure of the survey of parents' perceptions}

\section{Panel A: Consent form}
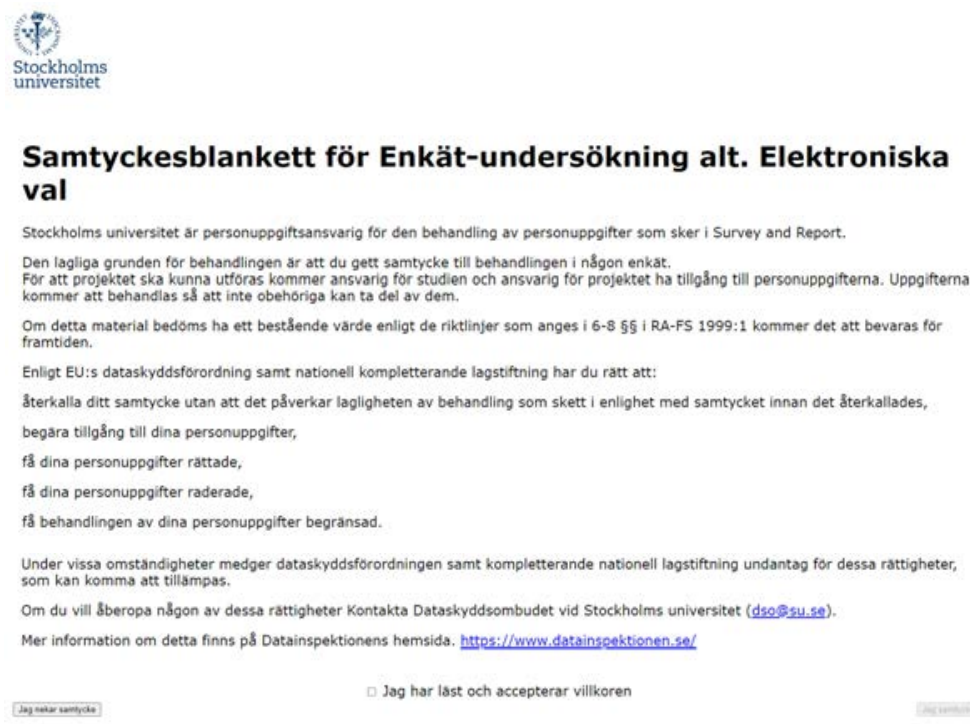

Panel B: Survey form

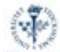

Stockholms
universitet
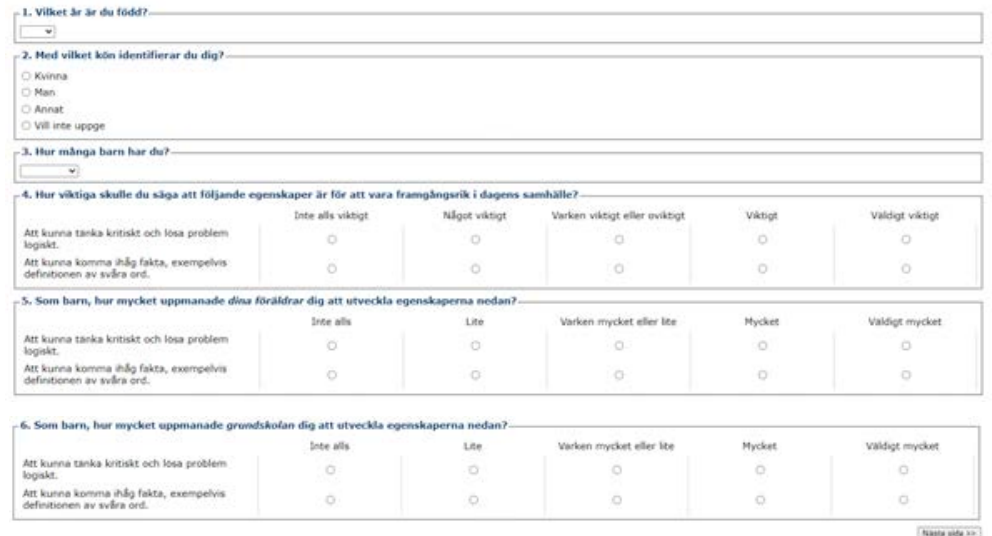

\section{(*)}

Stockholms
universitet

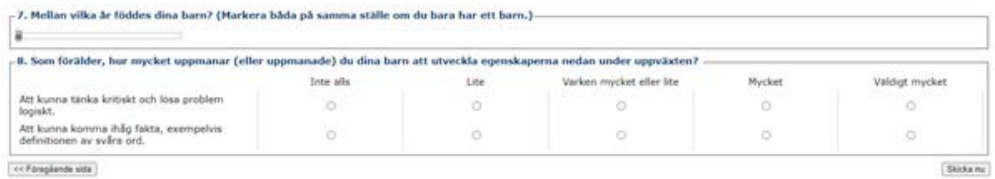

Notes: This figure shows the content and structure of the survey on parents' perceptions described in Section 3.2 Panel A displays the consent form and Panel B displays the survey form, both in the original Swedish. 
Appendix Figure 4: Distributions of year of birth of respondent and first child in the survey of parents' perceptions

\section{Panel A: Respondent}

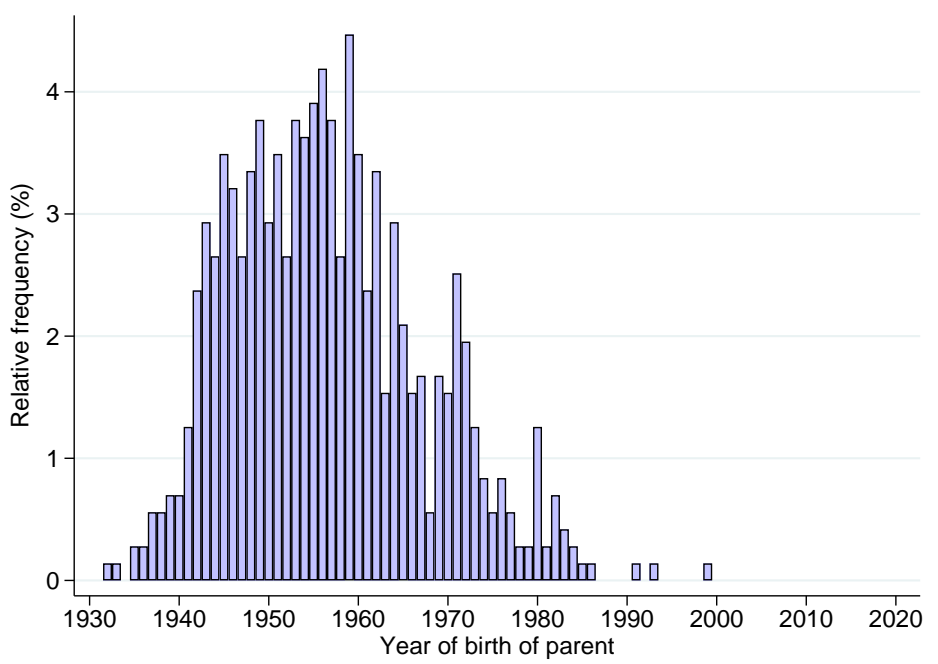

Panel B: Respondent's first child

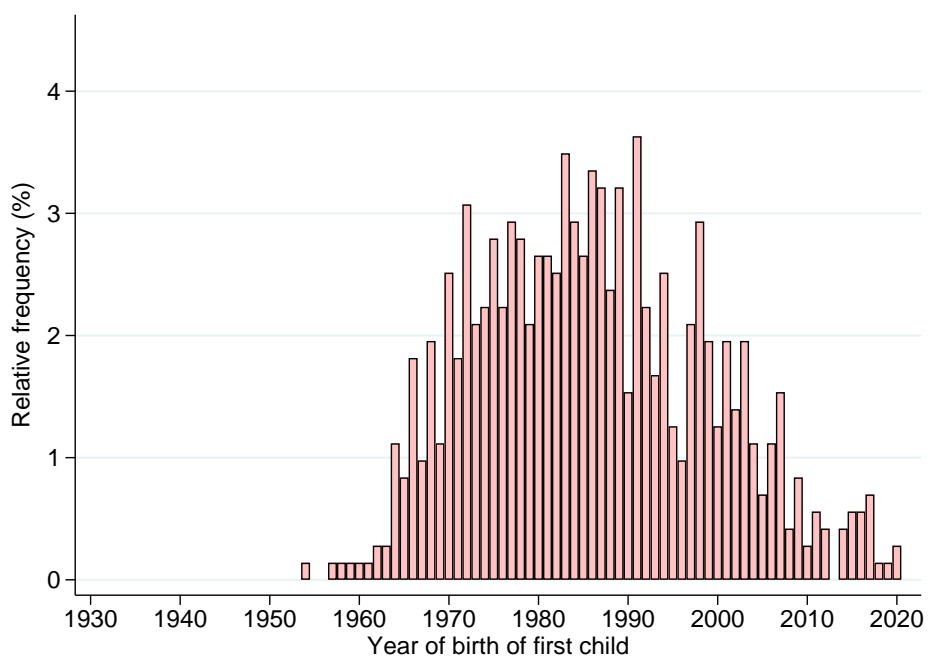

Notes: Data come from the survey of parents' perceptions described in Section 3.2. Panel A shows the distribution of the year of birth of the respondent. Panel B shows the distribution of the year of birth of the respondent's first child. 


\section{Appendix Figure 5: Male employment rates by age group for selected years}

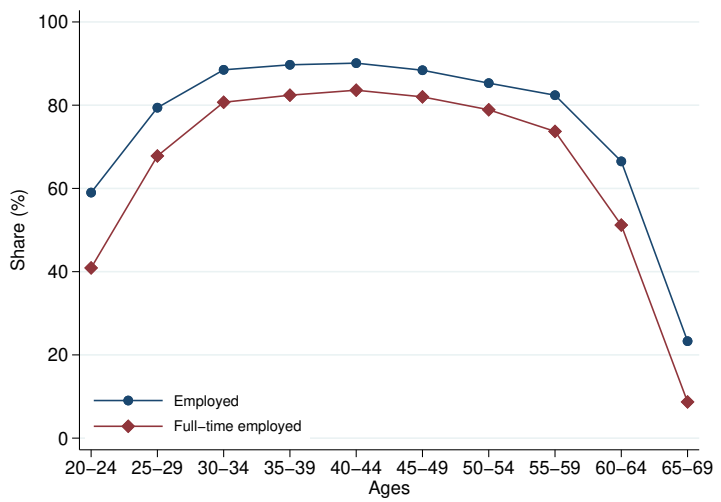

(a) 2010

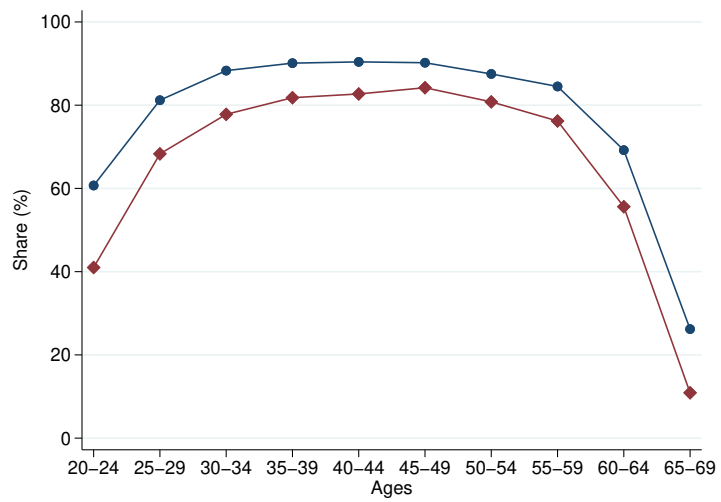

(b) 2015

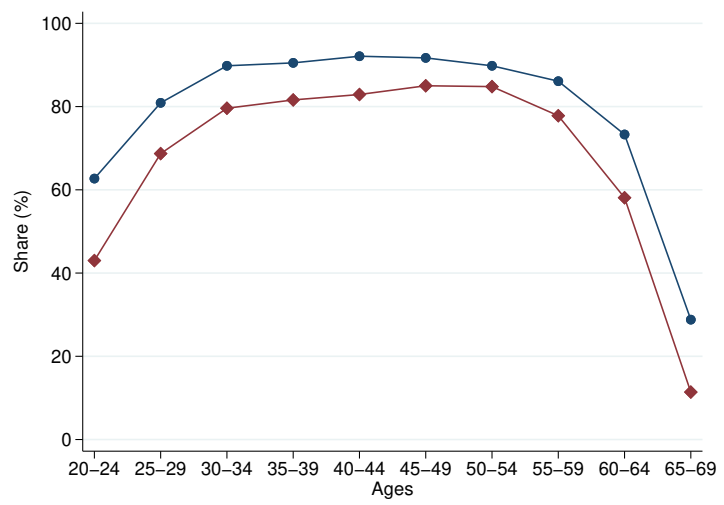

(c) 2019

Notes: This figure shows the rates of employment and full-time employment among men in Sweden in 2010, 2015, and 2019, separately by age group, based on data from the Swedish Labour Force Surveys (Statistics Sweden 2020b). We define an individual as employed if he meets the definition of employment used by the International Labor Organization (see, e.g., Eurostat 2021). We define an employed individual as full-time employed if he reports working full-time in the survey. 
Appendix Figure 6: Illustrating the relationship between $\log$ (earnings) and skill percentile, military enlistment sample

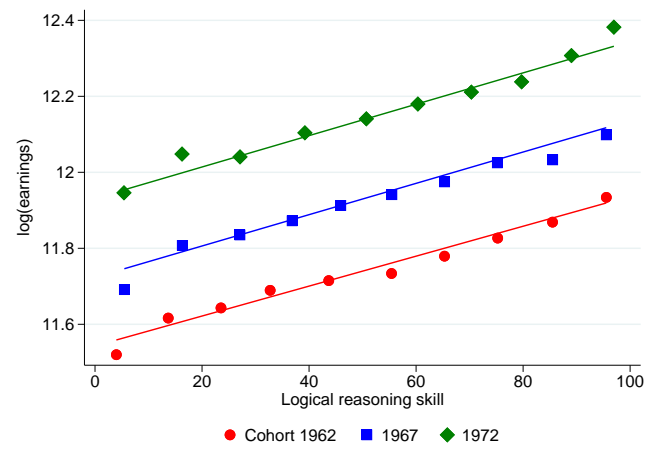

(a) Logical reasoning, age 30

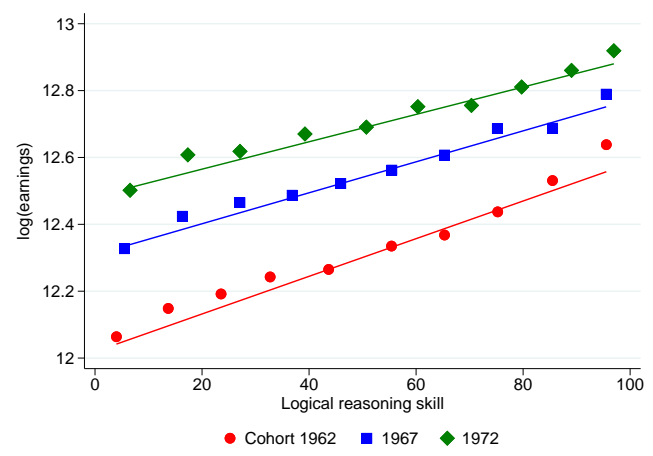

(c) Logical reasoning, age 40

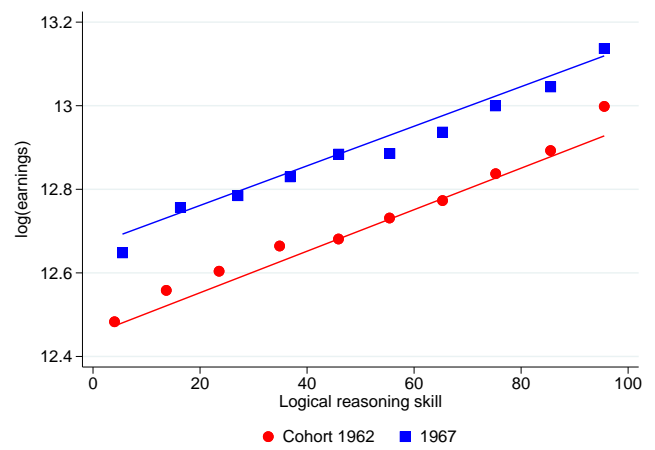

(e) Logical reasoning, age 50

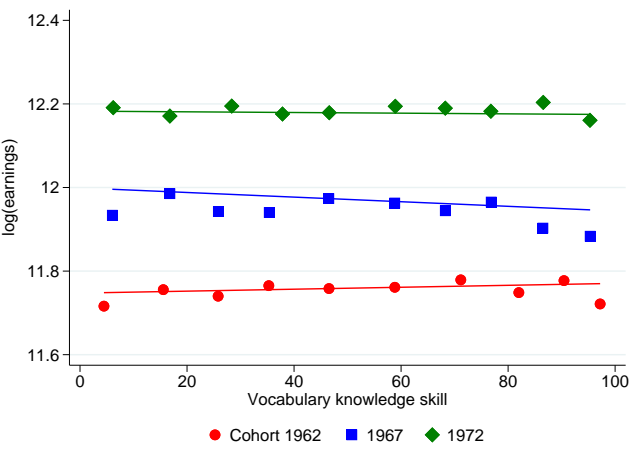

(b) Vocabulary knowledge, age 30

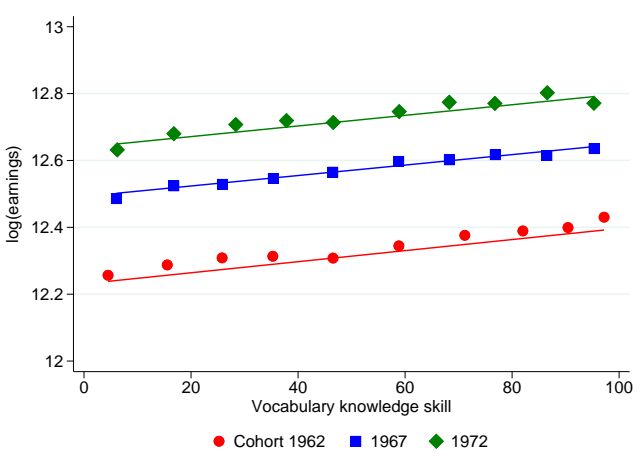

(d) Vocabulary knowledge, age 40

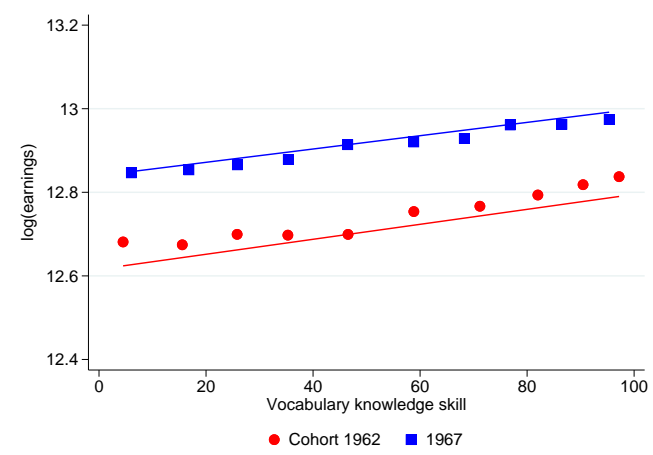

(f) Vocabulary knowledge, age 50

Notes: Data are from the military enlistment sample covering birth cohorts 1962-1975, with tests typically taken at age 18 or 19. This figure illustrates the relationship between the mean of log annual earnings and logical reasoning and vocabulary knowledge skill for birth cohorts 1962, 1967, and 1972, at ages 30, 40, and 50. For each cohort, age, and skill dimension, we estimate a regression of $\log$ (earnings) on indicators for decile of skill. We plot the coefficients on the decile indicators, shifted by a constant so that their mean value coincides with the sample mean of log(earnings), against the average value of the given skill within the decile. We also plot a line whose slope is equal to the estimated premium $p_{c+a, a, j}$ of the given skill dimension, estimated from a regression of $\log \left(\right.$ earnings) on skills $\mathbf{x}_{i}$, and whose intercept is chosen so that the line coincides with the decile coefficient at the fifth decile. 

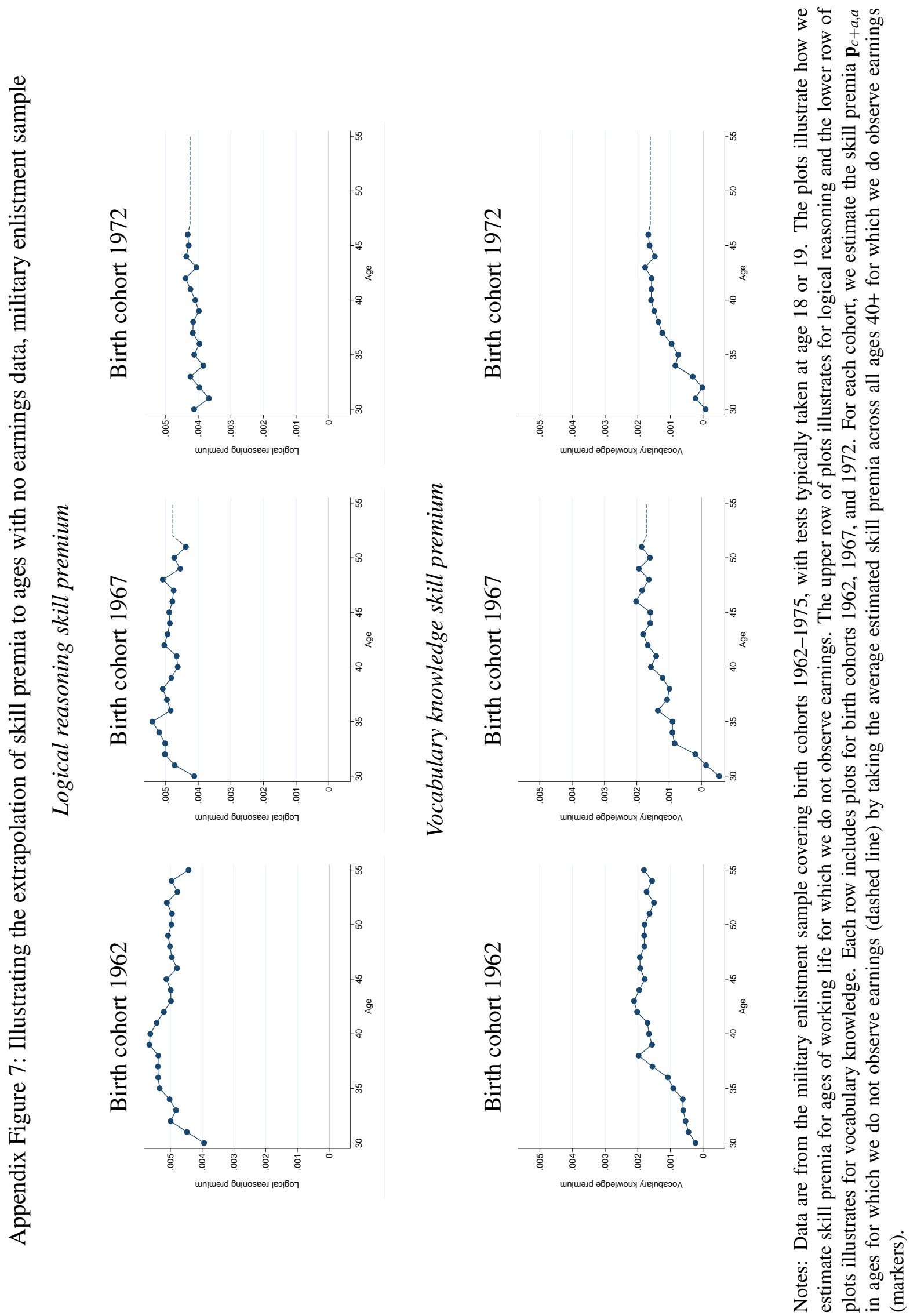
Appendix Figure 8: Distributions of skills in the 1962 and 1975 birth cohorts, military enlistment sample

\section{Logical reasoning}

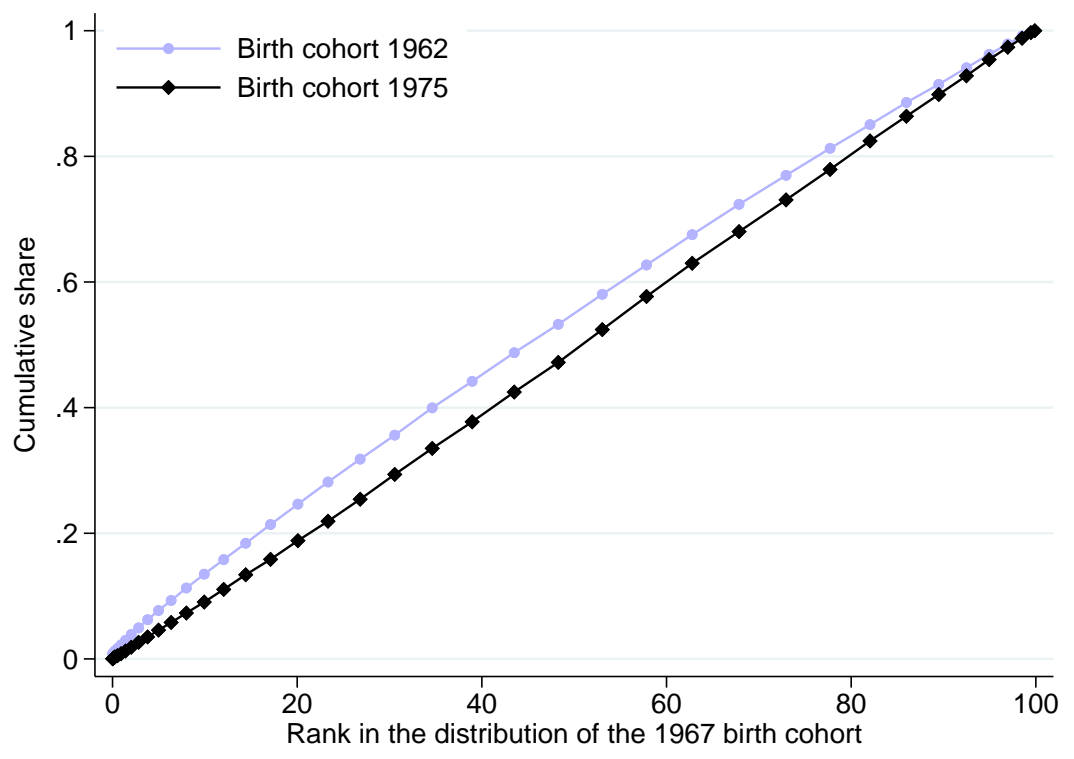

\section{Vocabulary knowledge}

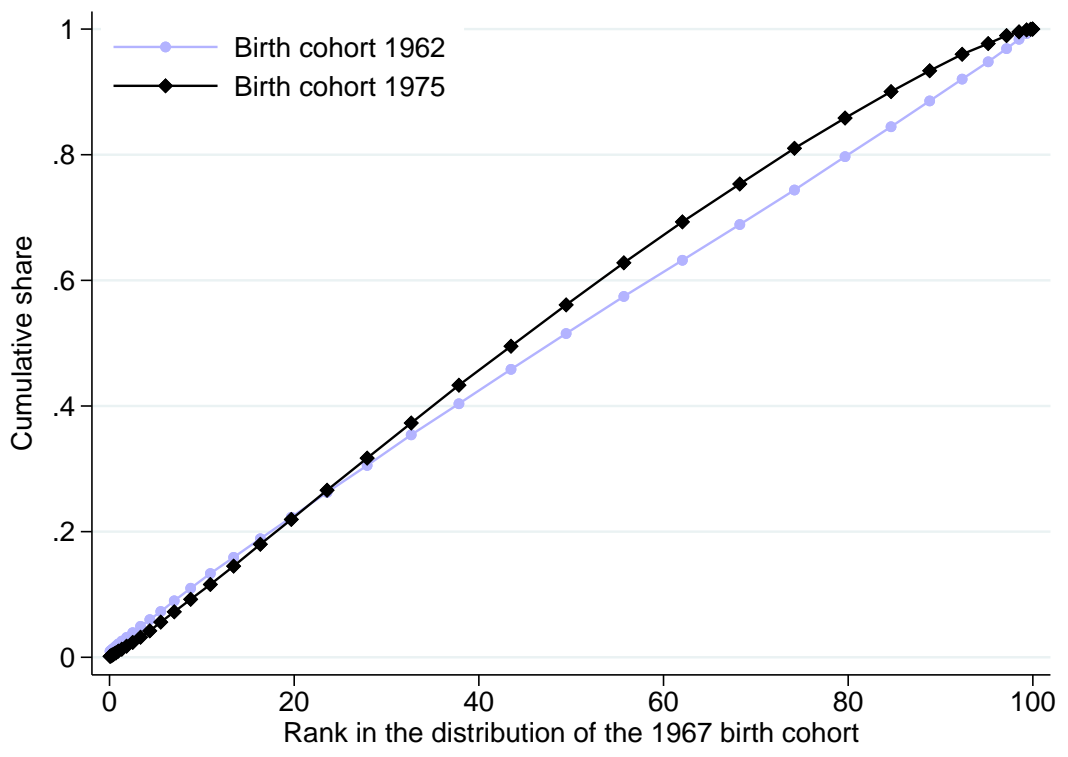

Notes: Data are from the military enlistment sample covering birth cohorts 1962 and 1975, with tests typically taken at age 18 or 19. Each plot depicts the empirical cumulative distribution function of skills $x_{i j}$ for a given dimension $j$ for members $i$ of the 1962 and 1975 birth cohorts. Skills are expressed as a percentile of the distribution for the 1967 birth cohort. 


\section{Appendix Figure 9: Measured trends in fluid and crystallized IQ}

\section{Fluid IQ}

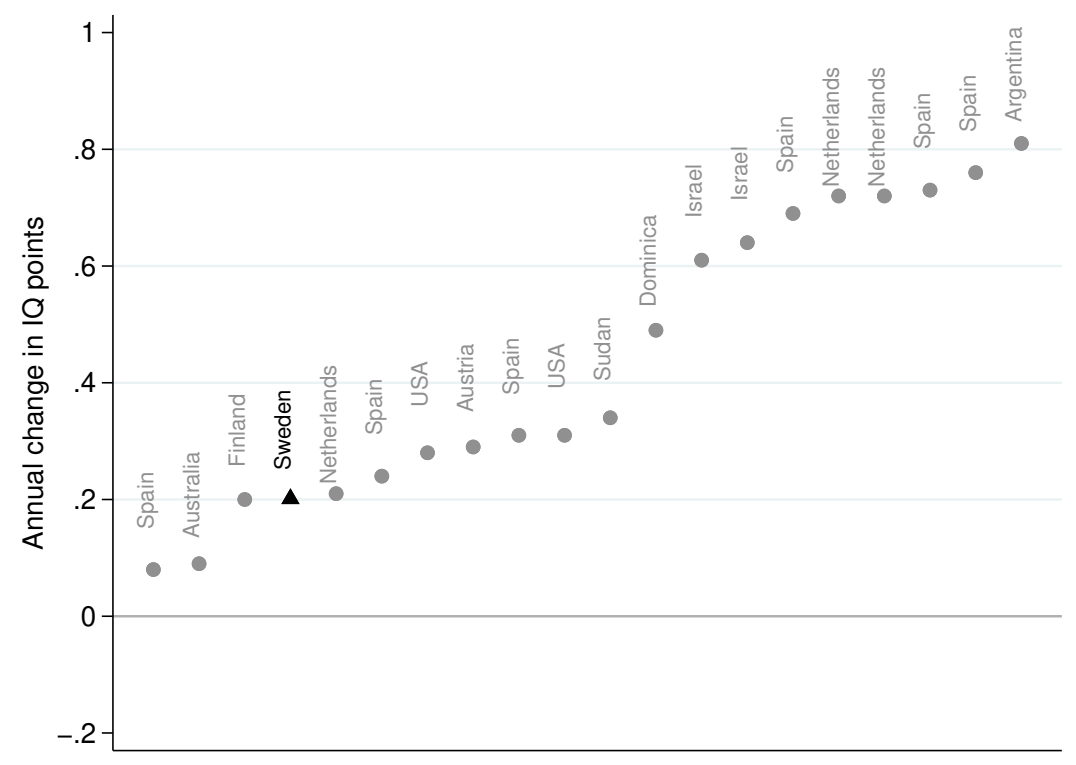

\section{Crystallized IQ}

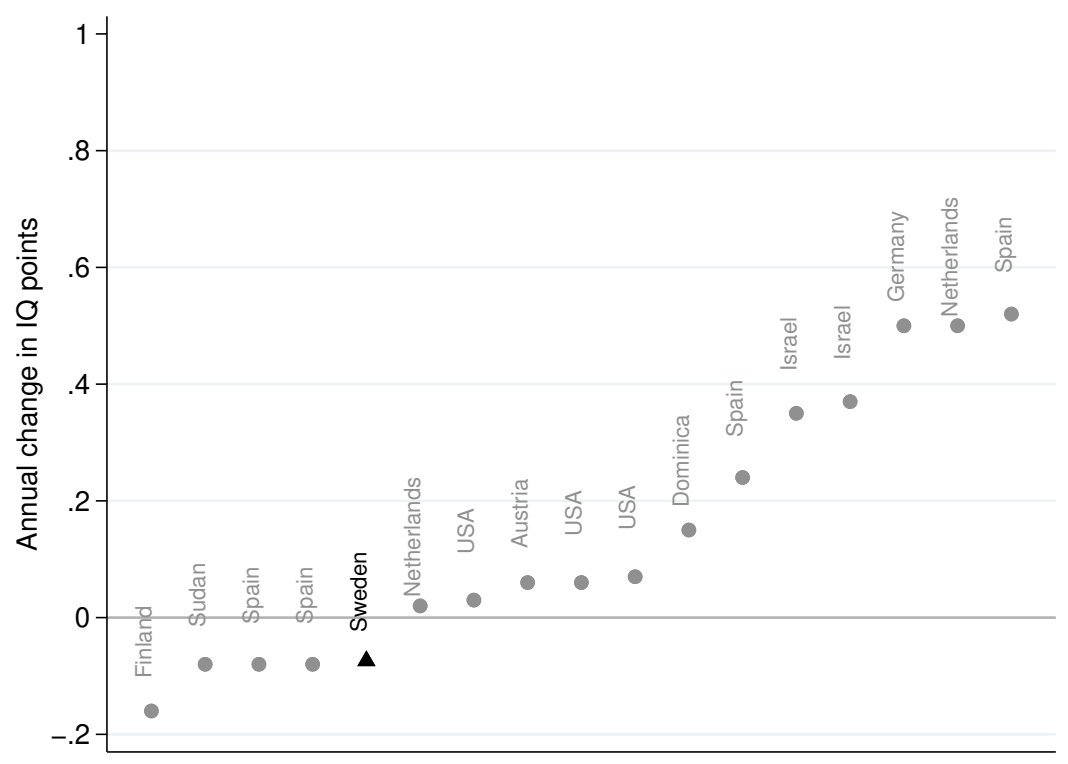

Notes: Data are from Pietschnig and Voracek (2015, Table S1, circles) or from the military enlistment sample covering birth cohorts 1962-1975 (triangles). We select from Pietschnig and Voracek's meta-analysis (2015, Table S1) all single-country studies of fluid or crystallized intelligence covering healthy adults with a sample size of at least 100 and a study period ending in 1980 or later. We classify studies of PIQ as fluid and studies of VIQ or verbal as crystallized. We plot the annual IQ gain in each study, labeling each study with the country in which the sample was obtained. For comparison, we also plot the annual IQ gain in the enlistment sample, which we calculate by standardizing the raw score on the logical reasoning (fluid) and vocabulary knowledge (crystallized) tests to have a mean of 100 and a standard deviation of 15 in the 1967 cohort. 
Appendix Figure 10: Trends in skill premia across birth cohorts 1962-1975, allowing for interactions, military enlistment sample
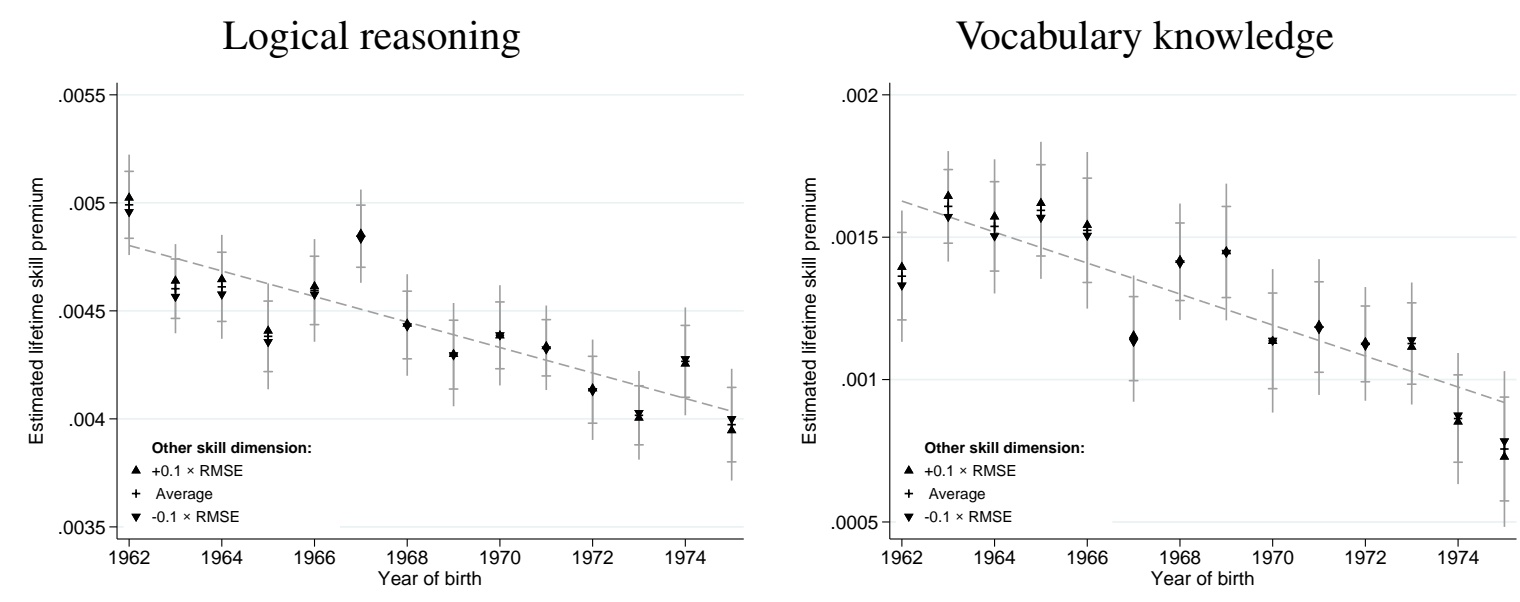

Notes: Data are from the military enlistment sample covering birth cohorts 1962-1975, with tests typically taken at age 18 or 19. We construct the plots as follows. For each cohort $c$ and each year $t$ for which we measure earnings, we estimate a generalization of equation (1) that includes an interaction $x_{i 1} x_{i 2}$ between the two skill dimensions. From these estimates we calculate cohort-and-year-specific skill premia for each skill dimension $j$, evaluated at three different levels of skill on the other dimension $j^{\prime} \neq j$ : the cohort average, 0.1 root mean squared error (RMSE) above the cohort average, and 0.1 RMSE below the cohort average, where the RMSE is calculated from a cohort-specific regression of skill $x_{i j^{\prime}}$ on indicators for skill $x_{i j}$. We then follow the approach described in Section 4.1 to estimate the cohort-and-year-specific premia for years outside of our sample, and we compute lifetime premia following equation (3). For each dimension $j$, the plot depicts the lifetime premium for an individual in each cohort $c$ whose skill on the other dimension $j^{\prime} \neq j$ is equal to the cohort average ("Average"), an individual whose skill on the other dimension is 0.1 RMSE above the cohort average ("+0.1 $\times$ RMSE"), and an individual whose skill on the other dimension is 0.1 RMSE below the cohort average (“- $-0.1 \times$ RMSE"). Each plot includes a line of best fit, 95 percent pointwise confidence intervals (inner grey intervals, marked by dashes), and uniform confidence intervals (outer grey intervals, marked by line segments) corresponding to the "Average" series. Pointwise confidence intervals are based on standard errors from a nonparametric bootstrap with 50 replicates. Uniform confidence intervals are computed as sup-t bands following Montiel Olea and Plagborg-Møller (2019). 


\section{Appendix Figure 11: Trends in skills and skill premia across birth cohorts, survey sample}
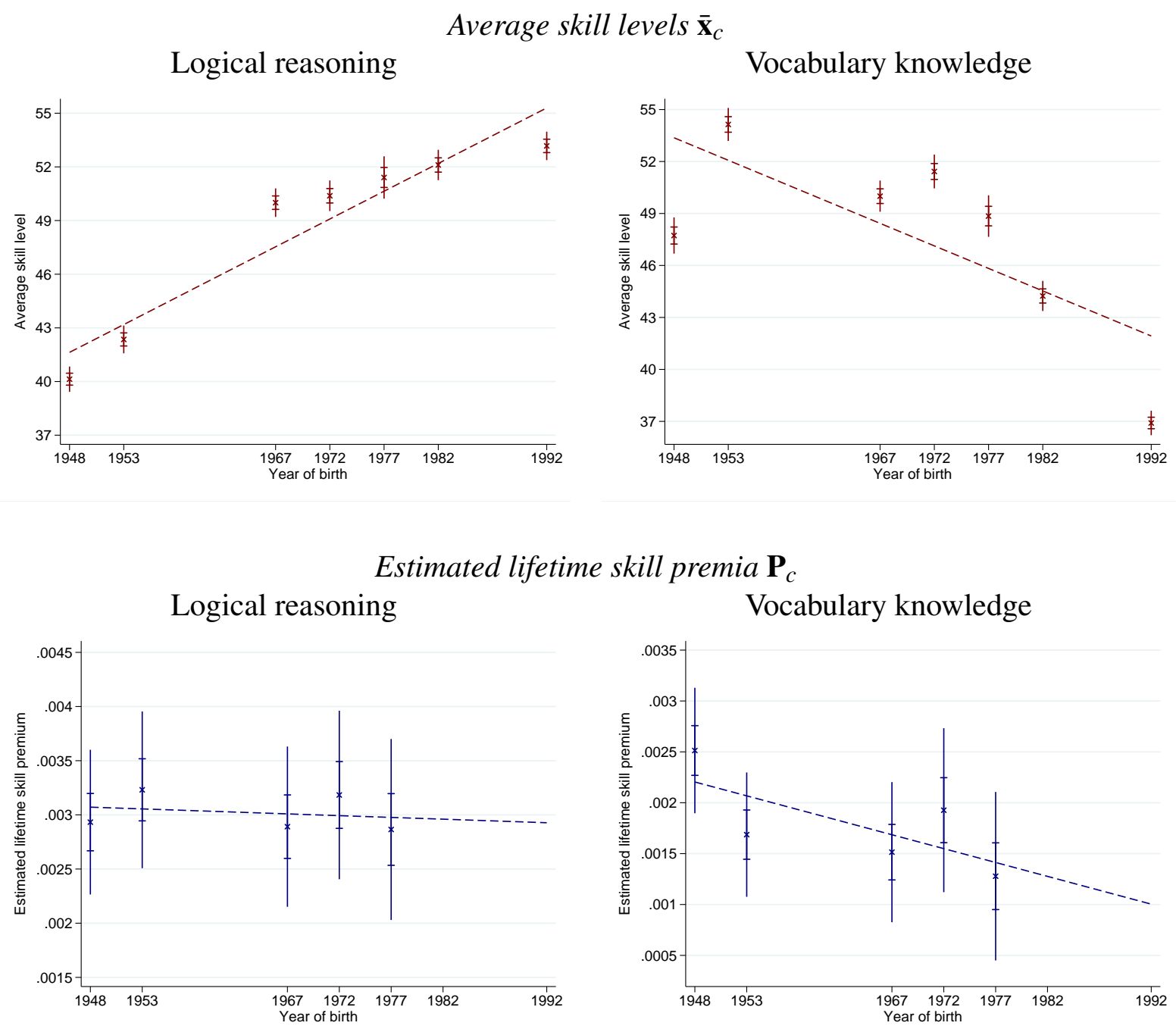

Notes: Data are from the survey sample covering birth cohorts 1948, 1953, 1967, 1972, 1977, 1982, and 1992. The first row of plots depicts the average skill $\overline{\mathbf{x}}_{c}$ for each birth cohort $c$. Skills are expressed as a percentile of the distribution for the 1967 birth cohort. The second row of plots depicts the estimated lifetime skill premia $\mathbf{P}_{c}$ for each birth cohort $c$ in 1948, 1953, 1967, 1972, and 1977, constructed as described in Section 4.1. Each plot depicts both 95 percent pointwise confidence intervals (inner intervals, marked by dashes) and 95 percent uniform confidence intervals (outer intervals, marked by line segments). Uniform confidence intervals are computed as sup-t bands following Montiel Olea and Plagborg-Møller (2019). Each plot depicts the line of best fit through the estimated points. 
Appendix Figure 12: Evolution of relative skill levels and relative skill premia, women in survey sample

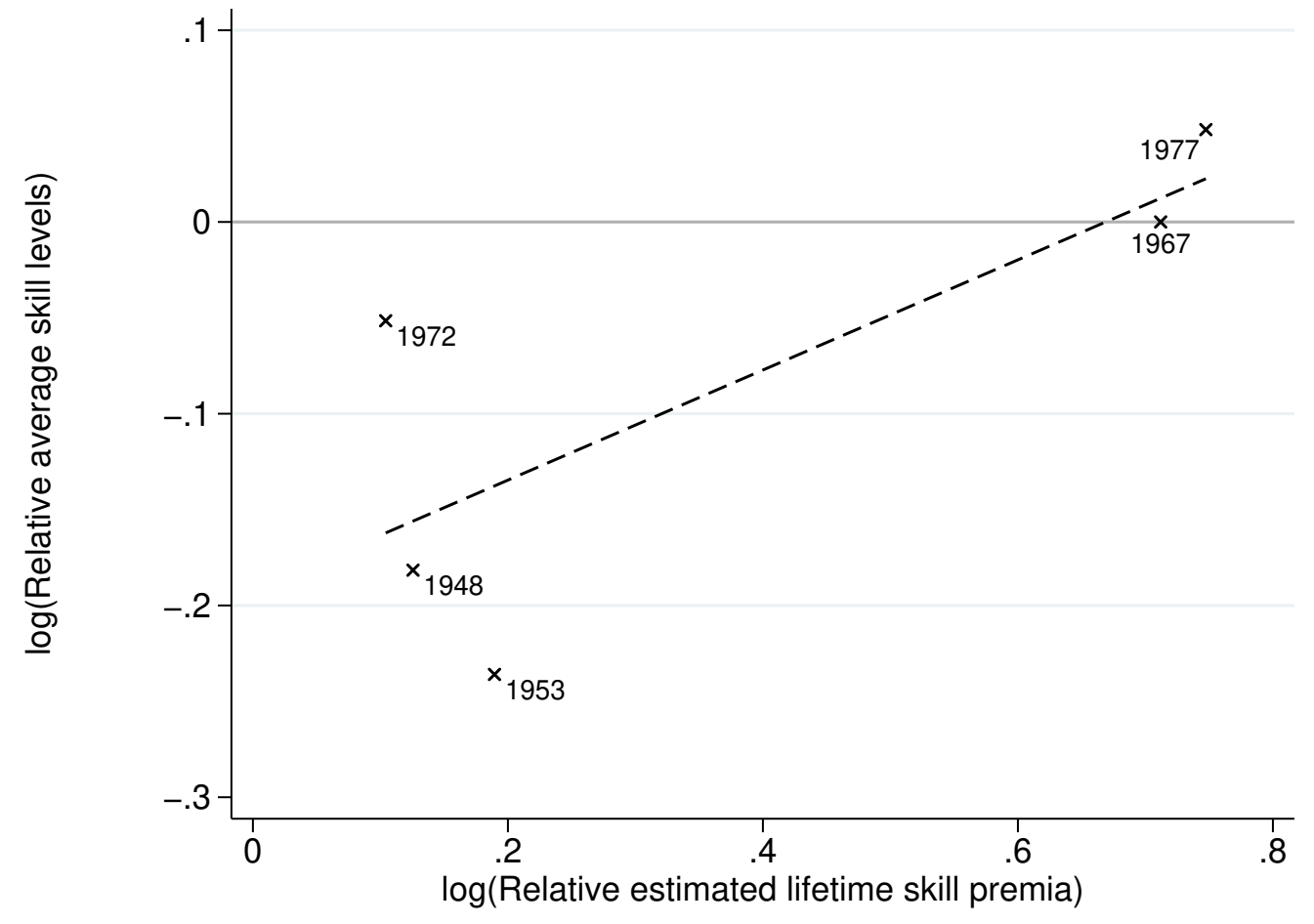

Notes: Data are from the survey sample covering birth cohorts 1948, 1953, 1967, 1972, and 1977, with tests typically taken at age 13, for female respondents. The plot shows a scatterplot of the natural logarithm of the relative average skill levels, $\ln \left(\bar{x}_{c 1} / \bar{x}_{c 2}\right)$, against the natural logarithm of the relative estimated lifetime skill premia, $\ln \left(P_{c 1} / P_{c 2}\right)$. The dashed line depicts the line of best fit. 


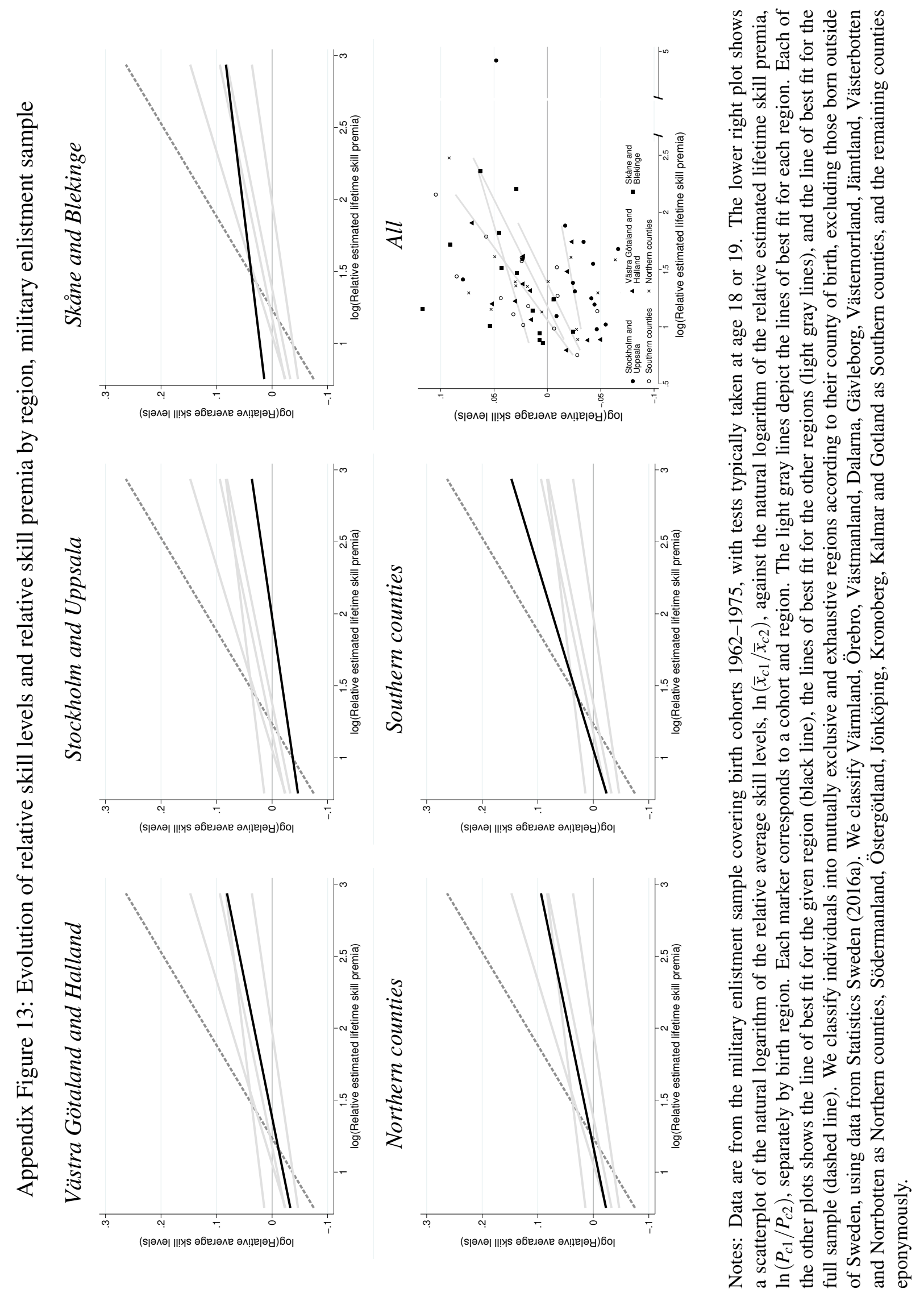




\section{Appendix Figure 14: Illustration of relative supply function, military enlistment sample}

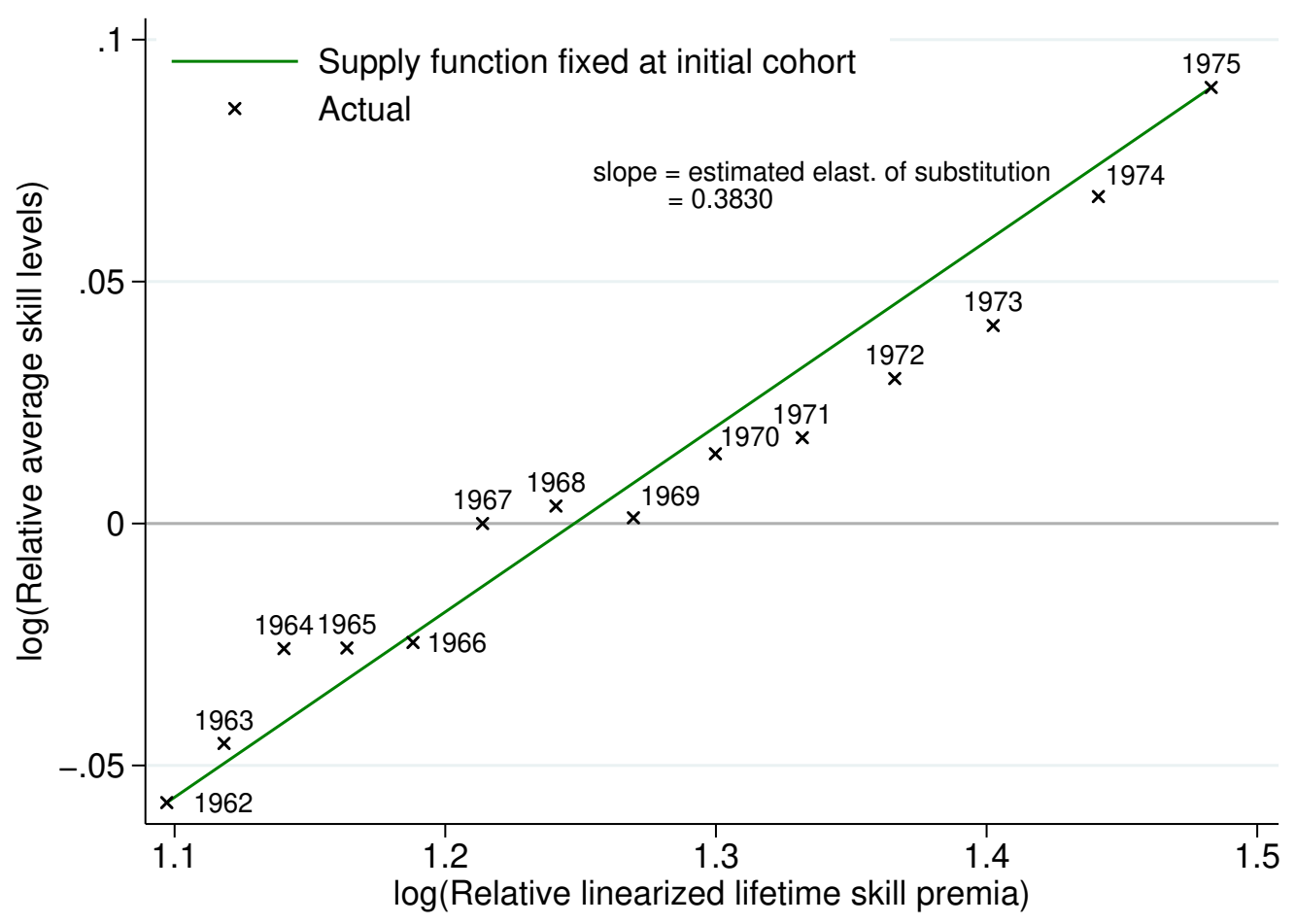

Notes: Data are from the military enlistment sample covering birth cohorts 1962-1975, with tests typically taken at age 18 or 19. The plot shows a scatterplot of the natural logarithm of the relative average skill levels, $\ln \left(\bar{x}_{c 1} / \bar{x}_{c 2}\right)$, against the natural $\operatorname{logarithm}$ of the relative estimated lifetime skill premia, $\ln \left(P_{c 1} / P_{c 2}\right)$, based on the linearized skill premia depicted in Figure 1. The green line shows the relative skill supply function estimated for the 1962 birth cohort, i.e., the relationship between $\ln \left(P_{c 1} / P_{c 2}\right)$ and $\ln \left(\tilde{x}_{c, 1}\left(\mathbf{P}_{c}\right) / \tilde{x}_{\underline{c}, 2}\left(\mathbf{P}_{c}\right)\right)$. The slope of the green line is equal to the estimated elasticity of substitution $\frac{1}{\rho-1}$. 
Appendix Figure 15: Differences in skills and differences in skill premia, military enlistment sample

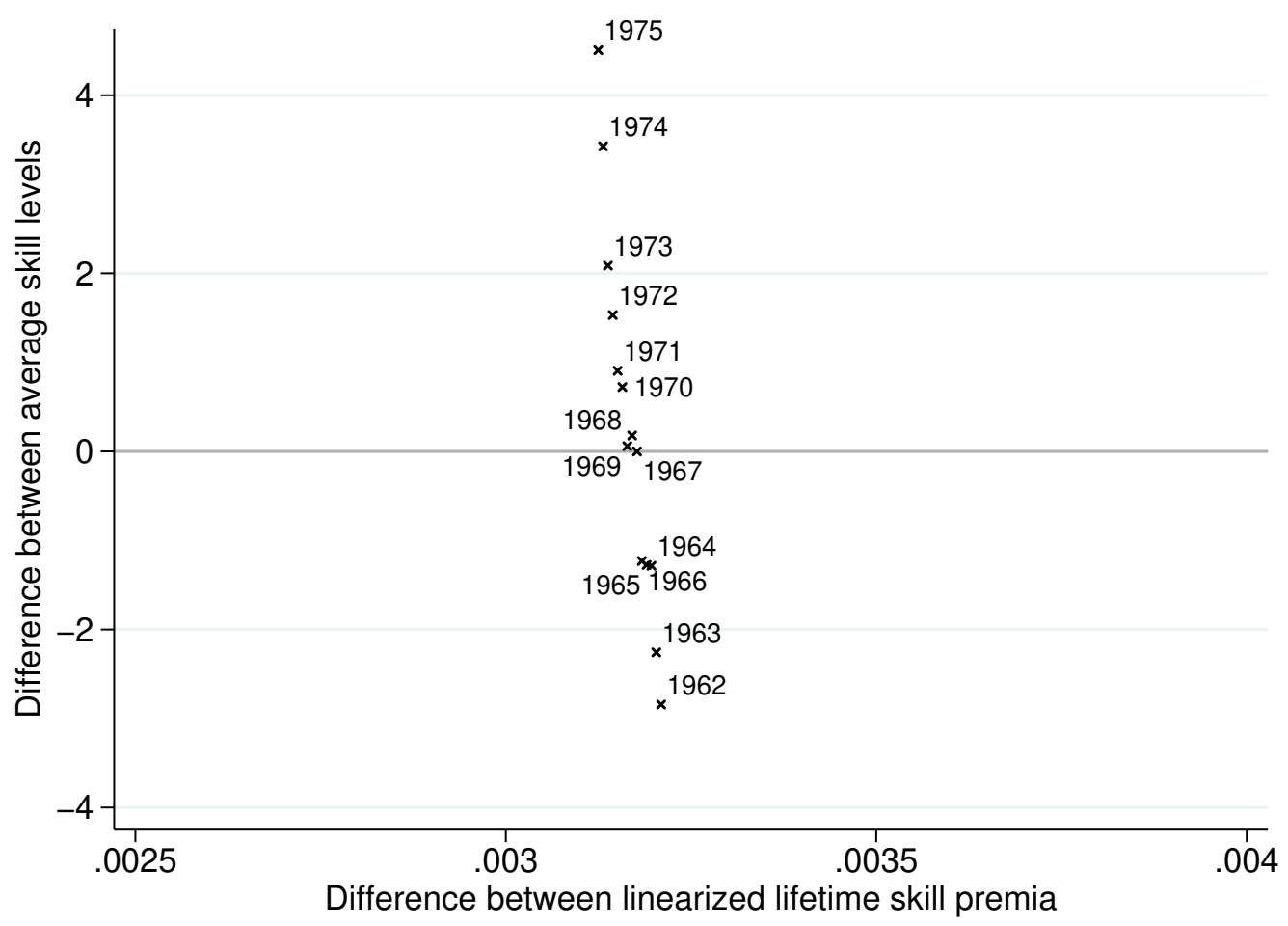

Notes: Data are from the military enlistment sample covering birth cohorts 1962-1975, with tests typically taken at age 18 or 19. The plot shows a scatterplot of the difference between average skill levels, $\bar{x}_{c 1}-\bar{x}_{c 2}$, against the difference between estimated lifetime skill premia, $P_{c 1}-P_{c 2}$, based on the linearized skill premia depicted in Figure 1 The ratio of the x-axis range to the $\mathrm{x}$-axis value for the 1962 birth cohort is equal to the analogous ratio in Appendix Figure 14 
Appendix Figure 16: Decomposition of change in average logical reasoning skill, survey sample

\section{Men}

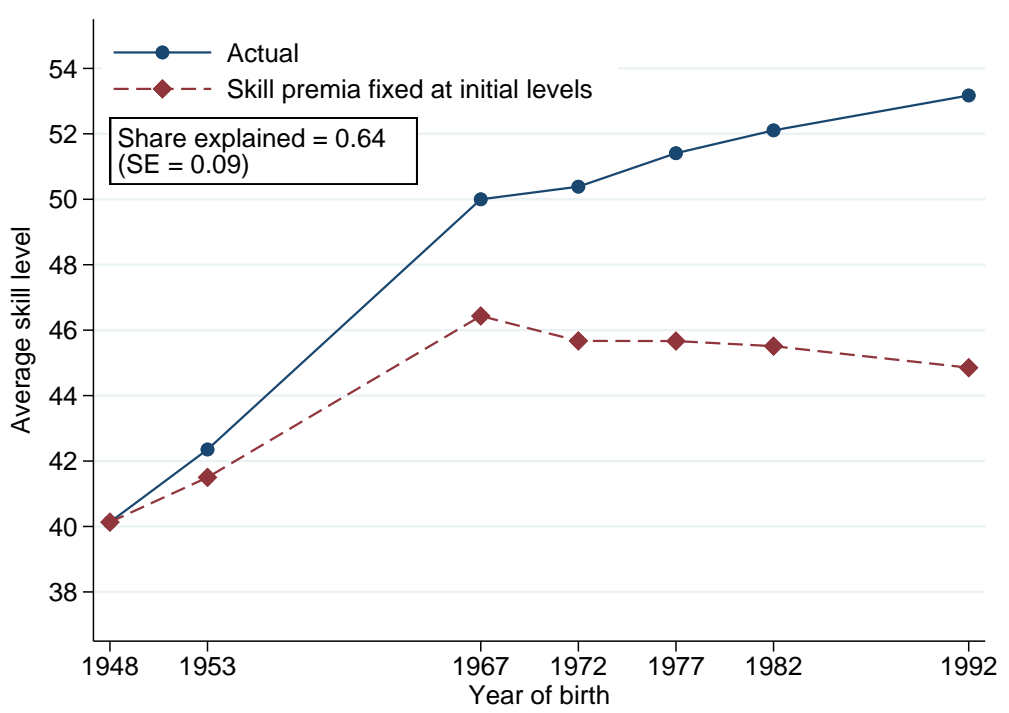

Women

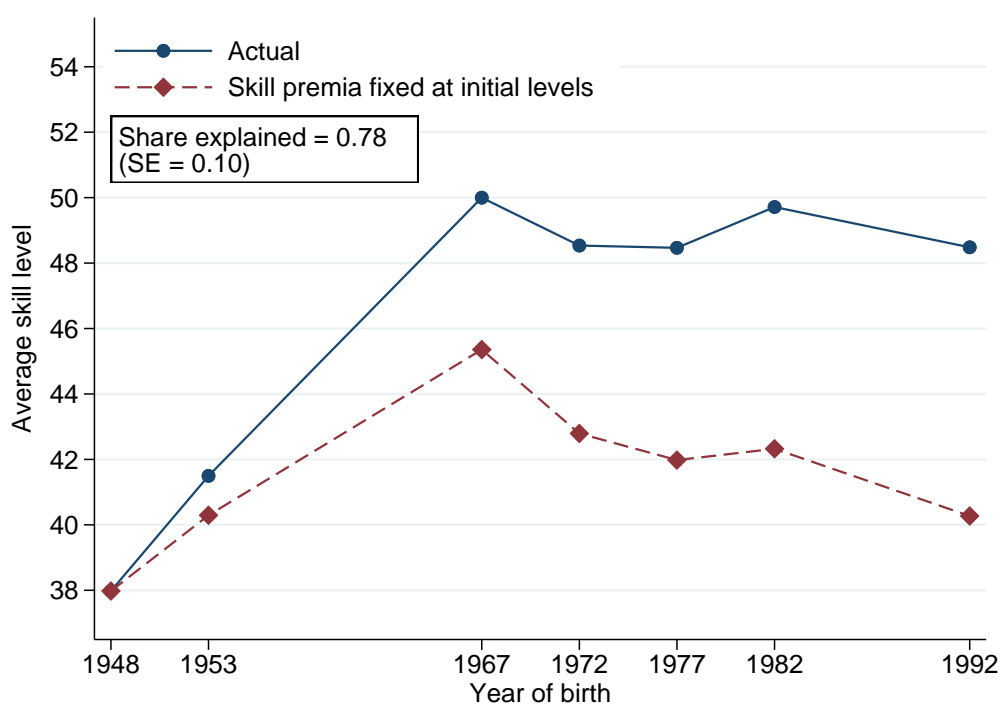

Notes: Data are from the survey sample of male respondents (upper panel) and female respondents (lower panel) covering birth cohorts 1948, 1953, 1967, 1972, 1977, 1982, and 1992, with tests typically taken at age 13. Each plot depicts the average logical skill $\bar{x}_{c 1}$ for each birth cohort $c$ ("Actual") and the predicted average skill $\tilde{x}_{c 1}\left(\overline{\mathbf{P}}_{c}\right)$ under the counterfactual in which lifetime skill premia remain at the level estimated for the 1948 birth cohort ("Skill premia fixed at initial levels"). Skills are expressed as a percentile of the distribution for the 1967 birth cohort. We fit the model as in Figure 4, separately for men and women, taking the linear fit for the cohorts through 1977 (depicted for men in Appendix Figure 11) as our estimate of the lifetime skill premia $\mathbf{P}_{c}$ for all cohorts. The text box in each plot shows the estimated share $1-\frac{\tilde{x}_{\bar{c} 1}\left(\mathbf{P}_{\underline{c}}\right)-\tilde{x}_{\underline{1}}\left(\mathbf{P}_{\underline{c}}\right)}{\bar{x}_{\bar{c} 1}-\bar{x}_{c 1}}$ of the observed change from 1948 through 1992 that is accounted for by changes in skill premia ("Share explained"). The standard errors in parentheses are obtained via a nonparametric bootstrap with 50 replicates. We exclude seven and three bootstrap replicates from the calculation of standard errors for the upper and lower plots, respectively, due to values inconsistent with the model. 


\section{Appendix Figure 17: Sensitivity to spurious cohort trends in skills}

\section{Logical reasoning}

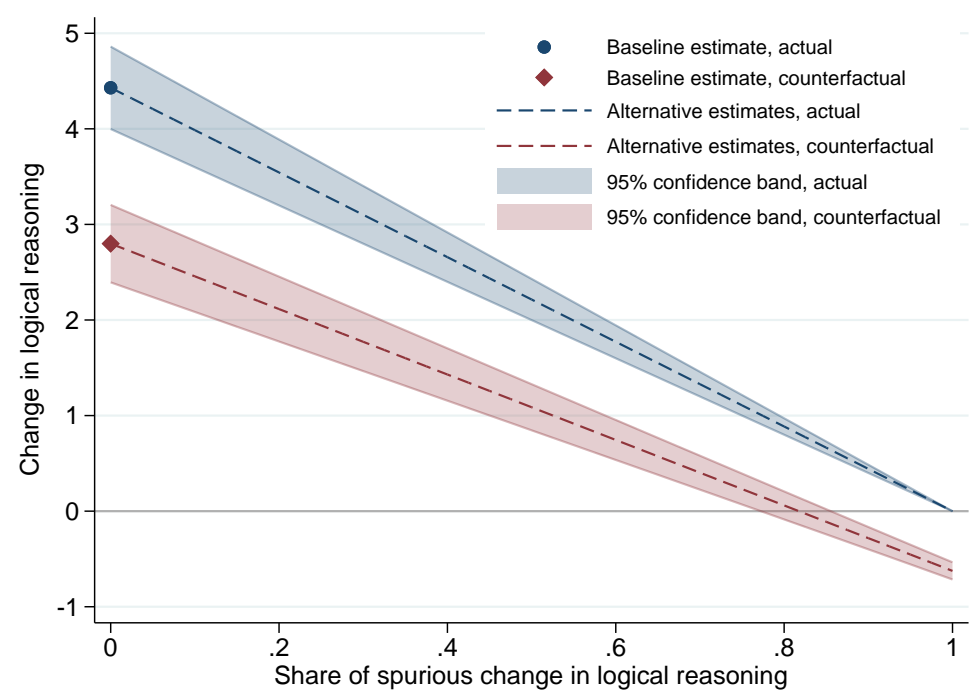

Vocabulary knowledge

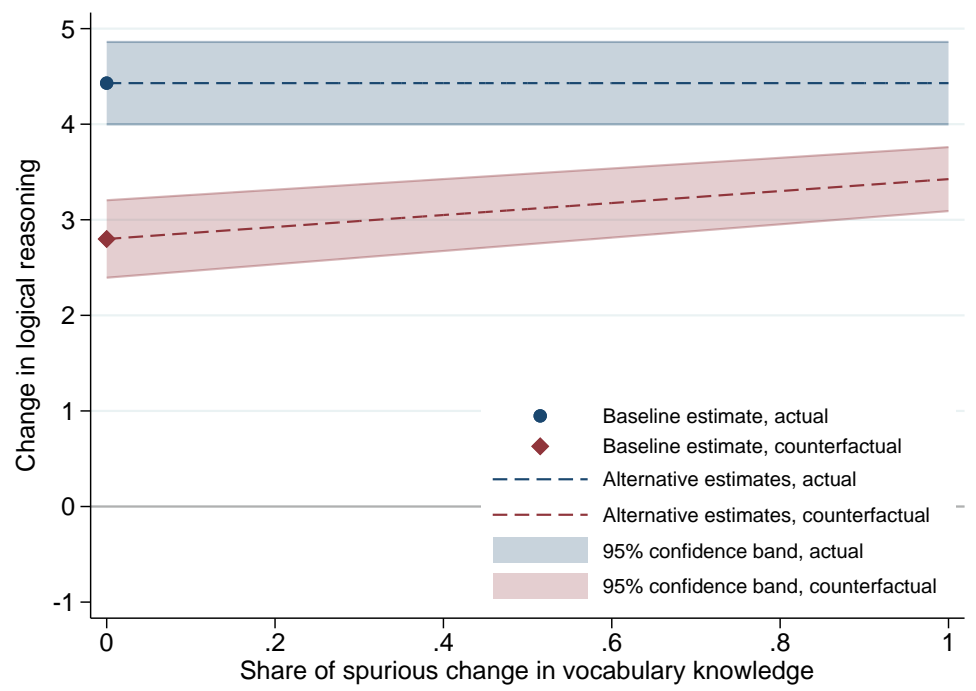

Notes: Data are from the military enlistment sample covering birth cohorts 1962-1975, with tests typically taken at age 18 or 19. To construct each plot, we assume that the true mean skill level $\tilde{x}_{\bar{c} j}$ on dimension $j$ in the 1975 birth cohort $\bar{c}$ is given by $\omega_{j} \bar{x}_{\underline{c} j}+\left(1-\omega_{j}\right) \bar{x}_{\bar{c} j}$, such that $\omega_{j} \in[0,1]$ denotes the fraction of the observed change $\bar{x}_{\bar{c} j}-\bar{x}_{\underline{c} j}$ that is spurious. We then re-estimate our model following the methods in Table 1 and calculate, for each $\omega_{j}$, the implied actual change in logical reasoning skill $\tilde{x}_{\bar{c} 1}\left(\mathbf{P}_{\bar{c}}\right)-\tilde{x}_{\underline{c} 1}\left(\mathbf{P}_{\underline{c}}\right)$ and the implied counterfactual change in logical reasoning skill $\tilde{x}_{\bar{c} 1}\left(\mathbf{P}_{\underline{c}}\right)-\tilde{x}_{\underline{c} 1}\left(\mathbf{P}_{\underline{c}}\right)$ if skill premia had remained constant at their level for the 1962 birth cohort. Each plot depicts the actual and counterfactual change in logical reasoning skill (y-axis) as a function of the fraction of the observed change that is spurious (x-axis). The upper plot depicts the implications of a spurious change in logical reasoning skill $\left(\omega_{1} \in[0,1], \omega_{2}=0\right)$. The lower plot depicts the implications of a spurious change in vocabulary knowledge $\left(\omega_{1}=0\right.$, $\left.\omega_{2} \in[0,1]\right)$. For each depicted series, the shaded region collects pointwise $95 \%$ confidence intervals obtained via a nonparametric bootstrap with 50 replicates. The estimates labeled "Baseline estimate" correspond to the estimates in Panel A of Table 1, i.e., the case in which $\omega_{1}=\omega_{2}=0$. 


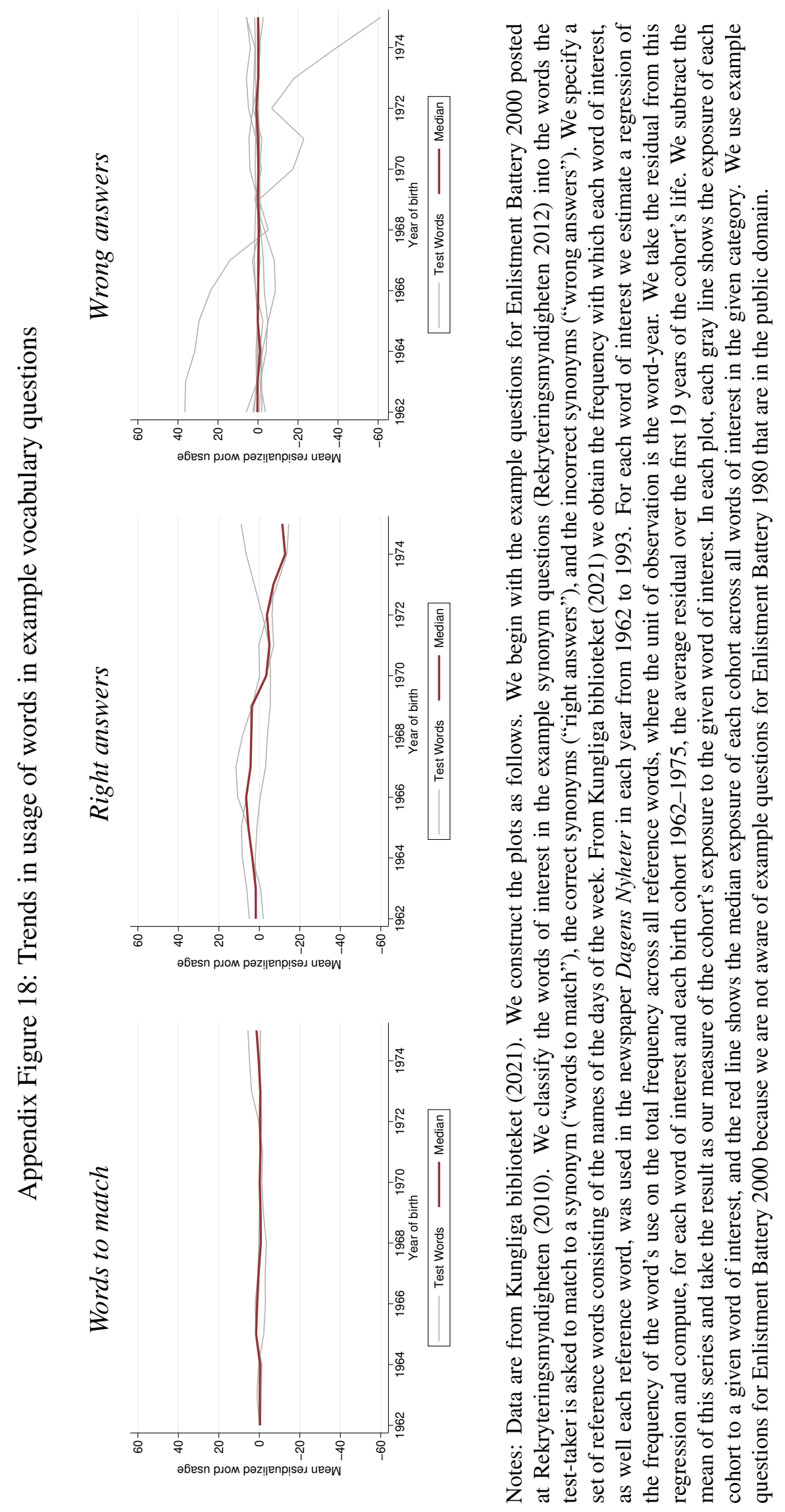




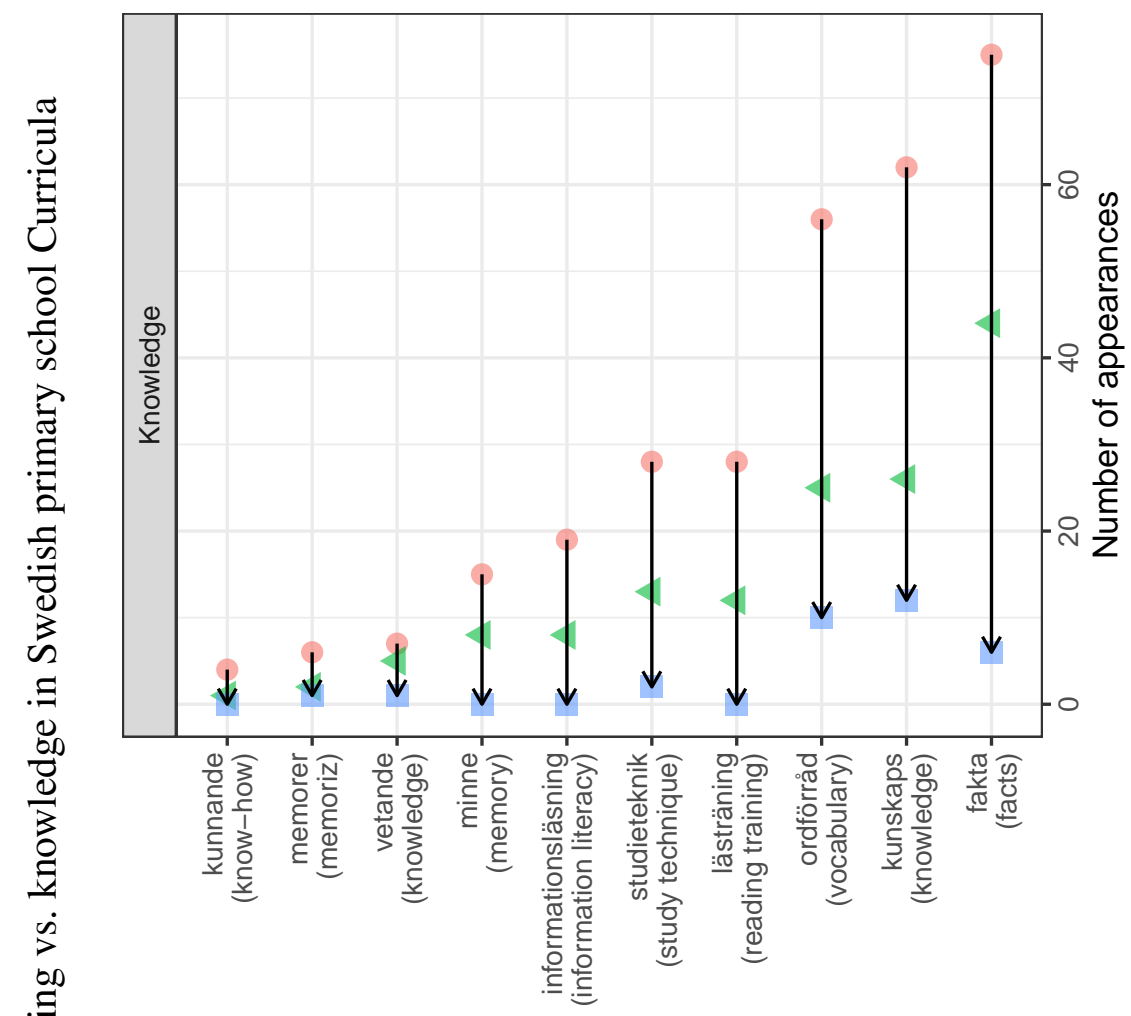

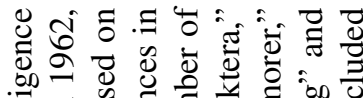

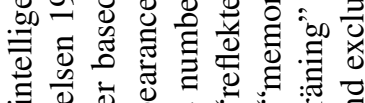

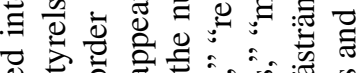
为 bot 홍 :

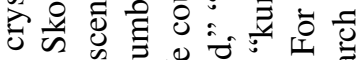

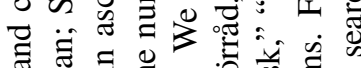

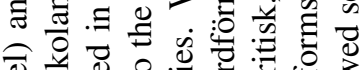
बे 항

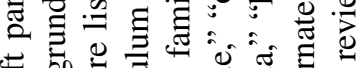

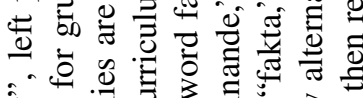
bi

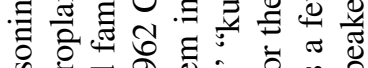

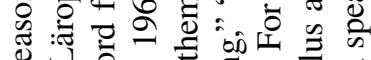

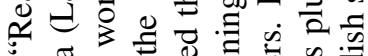

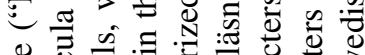
○ 区े

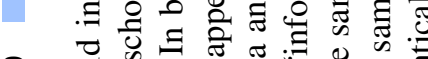
\&

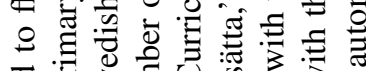

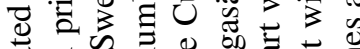

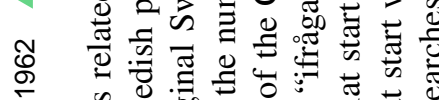

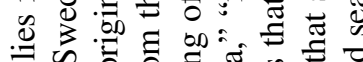

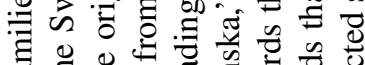
焉要 可 뭉

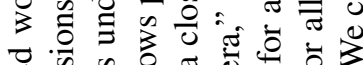

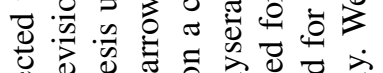

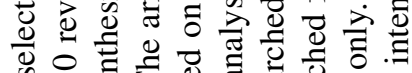

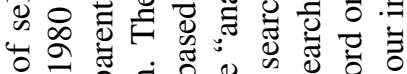

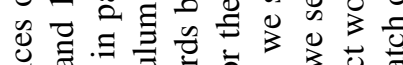

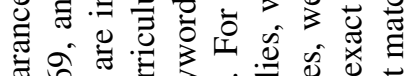
ซึ。

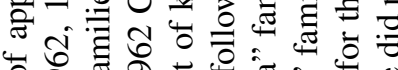

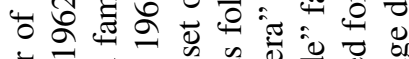

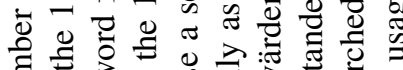

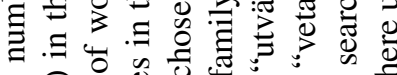
월 造造

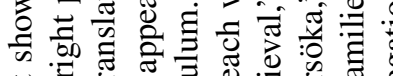
흔 2: 额

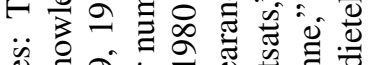

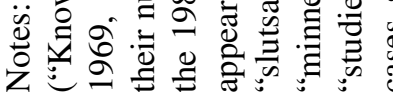




\section{E Additional References}

Eurostat. 2021. Employed person - LFS. Accessed at https: / / ec.europa.eu/eurostat/ statistics-explained/index.php/Glossary:Employed_person_-_LFSon February 27, 2021.

Kungliga biblioteket. 2021. Svenska dagstidningar. Accessed at https://tidningar.kb.s e/ on November 15, 2021.

Rekryteringsmyndigheten. 2010. Teoretiska prov. December 30, 2010. https: / / web.archive.org/ web/20120326205641/http://www.rekryteringsmyndigheten.se/malgrupps navigering/om-du-skall-testas/tester-och-undersokningar/teoretis ka-prov, Accessed on October 28, 2021.

Rekryteringsmyndigheten. 2012. Prova på inskrivningsprovet. October 5, 2012.https:// web.archive.org/web/20121005001305/http://rekryteringsmyndigheten.s e/trmPublic/IProvet/inskrivningsprovet.htm. Accessed on October 28, 2021.

Statistics Sweden. 2020b. Labour Force Surveys (LFS). http://www.scb.se/am0401-en Received on October 23, 2020. 